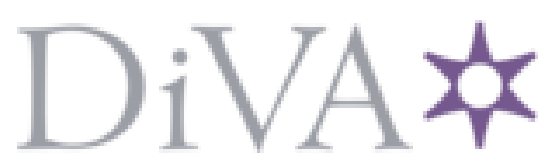

http://www.diva-portal.org

\title{
Postprint
}

This is the accepted version of a paper published in Chemical Reviews. This paper has been peerreviewed but does not include the final publisher proof-corrections or journal pagination.

Citation for the original published paper (version of record):

Verendel, J., Pamies, O., Dieguez, M., Andersson, P. (2014)

Asymmetric Hydrogenation of Olefins Using Chiral Crabtree-type Catalysts: Scope and Limitations.

Chemical Reviews, 114(4): 2130-2169

http://dx.doi.org/10.1021/cr400037u

Access to the published version may require subscription.

N.B. When citing this work, cite the original published paper.

Permanent link to this version:

http://urn.kb.se/resolve?urn=urn:nbn:se:su:diva- 102479 


\section{Asymmetric Hydrogenation of Olefins using Chiral Crabtree-type Catalysts - Scope and Limitations}

\section{J. Johan Verendel, Oscar Pàmies, Montserrat Diéguez* and}

Pher G. Andersson*

\begin{tabular}{|c|c|c|}
\hline \multicolumn{3}{|c|}{ Introduction } \\
\hline 1.1 & Motivation and Scope & 2 \\
\hline 1.2 & A Note on Conversion and Yield & 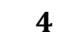 \\
\hline 1.3 & Early Developments, Reduction of Functionalized Alkenes & \\
\hline 1.4 & The Iridium-N,P Catalytic Hydrogenation System & 6 \\
\hline 1.5 & Mechanistic Aspects & 10 \\
\hline \multicolumn{3}{|c|}{2 Aryl and Alkyl Substituted Alkenes } \\
\hline 2.1 & Trisubstituted Alkenes & 15 \\
\hline & 1.1 Phosphorus/Carbene-Oxazoline Ligands & 19 \\
\hline & 1.2 Phosphorus-Pyridine Ligands & 28 \\
\hline & 1.3 Phosphorus/Carbene-Other-Nitrogen-Donor Ligands & 32 \\
\hline & 1.4 Other Ligands & 35 \\
\hline 2.2 & 1,1-Disubstituted Alkenes & 37 \\
\hline 2.3 & Tetrasubstituted Aryl/Alkyl Alkenes & 45 \\
\hline \multicolumn{3}{|c|}{3 Enols } \\
\hline 3.1 & Enol Esters and Enol Carbamates & 48 \\
\hline 3.2 & Enol Phosphinates and Enol Phosphonates & $\mathbf{5 1}$ \\
\hline 3.3 & Enol Ethers & 53 \\
\hline 3.4 & Silyl Enol Ethers & 57 \\
\hline \multicolumn{3}{|c|}{4 Enamides and Enamines } \\
\hline \multicolumn{2}{|c|}{5 Allylic and Homoallylic Alcohols and Ethers } & 60 \\
\hline \multicolumn{3}{|c|}{$6 \alpha, \beta$-Unsaturated Carbonyls } \\
\hline 6.1 & $\alpha, \beta$-Unsaturated Carboxylic Acids & 68 \\
\hline 6.2 & $\alpha, \beta$-Unsaturated Esters & 73 \\
\hline 6.3 & $\alpha, \beta$-Unsaturated Amides & 79 \\
\hline & $\alpha, \beta$-Unsaturated Ketones & 80 \\
\hline \multicolumn{3}{|c|}{7 Alkenes Bearing Other Heteroatoms } \\
\hline 7.1 & Phosphorus & 86 \\
\hline 7.2 & Boron & 90 \\
\hline 7.3 & Fluorine & 95 \\
\hline 7.4 & Silicon & 97 \\
\hline $8 \operatorname{Pr}$ & ediction of the Stereochemical Outcome & 99 \\
\hline 9 Co & nclusion and Perspective & \\
\hline
\end{tabular}




\section{Introduction}

\subsection{Motivation and Scope}

The asymmetric hydrogenation of alkenes using transition metal catalysts continues to be a growing field and a fundamental tool for organic synthetic chemists. In contrast to, for example, carbonyl reductions, the enantioselective addition of two hydrogen atoms to a carbon-carbon double bond relies almost exclusively on transition-metal-based catalysts. Moreover, the reaction frequently exhibits excellent chemo-, regio- and enantioselectivities. For the asymmetric hydrogenation of alkenes having coordinating functional groups such as amides and carboxylic acids in close proximity to the double bond, $\mathrm{Rh}(\mathrm{I})$ and $\mathrm{Ru}(\mathrm{II})$ species bearing diphosphine ligands ( $P, P$ ligands) are the catalysts of choice. ${ }^{1}$ As a complement, for nonfunctionalized olefins carrying no neighboring coordinating group, chiral mimics of Crabtree's catalyst, $\left[\operatorname{lr}(\mathrm{cod})(\mathrm{Py})\left(\mathrm{PC}_{3}\right)\right]\left[\mathrm{PF}_{6}\right]$, have been developed into versatile reagents that can reduce both di-, tri-, and tetrasubstituted alkenes with high enantioselectivity. ${ }^{2} \mathrm{~A}$ broad range of interesting alkene substrates have properties that lie in between these two extremes of functionalized and non-functionalized alkenes. Compounds such as $\alpha, \beta-$ unsaturated esters, enols and vinyl phosphonates, can be reduced selectively with several, fundamentally different, catalytic systems although chiral analogues of Crabtree's catalyst have proven superior to other catalyst types in many cases. Figure 1 summarizes the classification of alkene substrates in this review but is only a rough classification useful for the discussion and understanding. A specific alkene may chelate to metal centers in some cases but not in others. 


Chelating $\longrightarrow$ decreasing ability to chelate $\longrightarrow$ Non-functionalized<smiles>[R]OC(=O)C(NC=O)=C(C)C</smiles><smiles>[R]OC(=O)/C(C)=C\C</smiles><smiles>CC=C(c1ccccc1)c1ccccc1</smiles><smiles>C/C=C(/C)NC(=O)OC</smiles><smiles>C=C(CC)[Po+]O</smiles><smiles>C/C=C(/C)CC[SeH]OC(=O)OCC</smiles><smiles>C=C(Br)CC</smiles><smiles>CC=C(C)C(=O)O</smiles><smiles>CC/C(C)=C/CO</smiles>

Figure 1 Alkene substrates for the asymmetric hydrogenation can be categorized as chelating (containing adjacent coordinating functional groups), intermediate, or non-functionalized (containing no heteroatoms).

In this comprehensive review, we describe the development of chiral analogues of Crabtree's catalyst for the asymmetric hydrogenation of alkenes with particular emphasis on the developments made during the past five years. The field has seen substantial expansion, especially in the substrate scope for this type of catalysts and the applications of the reaction. Although several surveys of the field have been published, ${ }^{2 a, b, 2 d, e, 3}$ a recent comprehensive review is lacking. Many of the recent developments in this field concern the use of N,P-ligated iridium catalysts to hydrogenate weakly functionalized alkenes, giving chiral products with great potential in chemical synthesis. Our aim is to provide a clear overview of the catalysts suitable for a particular application with a given alkene, and to define the areas that need further studies. In addition to reviewing recent advances, we also want to clarify the scope and limitations of the N,P-ligated iridium system and, where relevant, compare it to other available catalytic systems.

The mechanistic understanding of asymmetric hydrogenation catalyzed by $\left[\operatorname{Ir}(\operatorname{cod})\left(\mathrm{N}, \mathrm{P}^{*}\right)\right]\left[\mathrm{BAr} \mathrm{F}_{\mathrm{F}}\right]\left(\mathrm{cod}=1,5\right.$-cyclooctadiene, $\mathrm{BAr}_{\mathrm{F}}=$ tetrakis $(3,5-$ bis(trifluoromethyl)phenyl)borate) complexes has been significantly expanded by several computational works and will also be considered, along with the possibility to predict the stereochemical outcome. 
We will focus exclusively on the enantioselective reduction of carboncarbon double bonds using hydrogen gas, thus excluding carbonyl and imine reductions as well as the asymmetric hydrogenation of heteroaromatic substrates, a topic that has been recently and comprehensively reviewed. ${ }^{4}$

\subsection{A Note on Conversion and Yield}

Metal-catalyzed asymmetric hydrogenation is a uniquely mild chemical transformation in that few, if any, byproducts are formed in the reaction. It has therefore become standard practice in screening experiments to only report the alkene conversion (conversion $=100 *$ product / (starting material + product)), except where the reactions do not proceed cleanly. Since the conversion attained in specific catalytic reactions depend on parameters such as pre-catalyst loading, reaction time and temperature, and given that most authors develop systems that generate complete or at least high conversion, we will not discuss alkene conversion except when it is of special relevance. Instead, focus will be on the reaction conditions required to produce an efficient catalytic system. The reader should assume that the reactions proceed cleanly and in high conversion unless otherwise stated. Yields will be stated when relevant; this will primarily be in cases where asymmetric hydrogenation is used in a longer synthesis or when the reaction does not proceed cleanly.

\subsection{Early Developments, Reduction of Functionalized Alkenes}

The birth of asymmetric hydrogenation is usually associated with the introduction of the first chiral bidentate ligand DIOP, (2,3-O-Isopropylidene2,3-dihydroxy-1,4-bis(diphenylphosphino)-butane), and its use in the rhodiumcatalyzed hydrogenation of dehydroamino acids. Using tartrate-derived (-)DIOP, Dang and Kagan reduced several dehydroamino acids in $>50 \%$ enantioselectivity at the beginning of the 1970s. ${ }^{5}$ In 1975, Knowles concluded that asymmetric hydrogenation finally approached Nature's capability in terms of stereospecificity. ${ }^{6}$ The hydrogenations of a range of $\alpha$-acetamidoacrylic acids such as $\mathbf{S 1}$ using Rh-DIPAMP (Scheme 1) occured with enantioselectivities above $90 \%$ ee. ${ }^{7}$ The catalytic asymmetric synthesis of the 
anti-Parkinson's drug L-DOPA using this methodology became a commercial process. $^{8}$
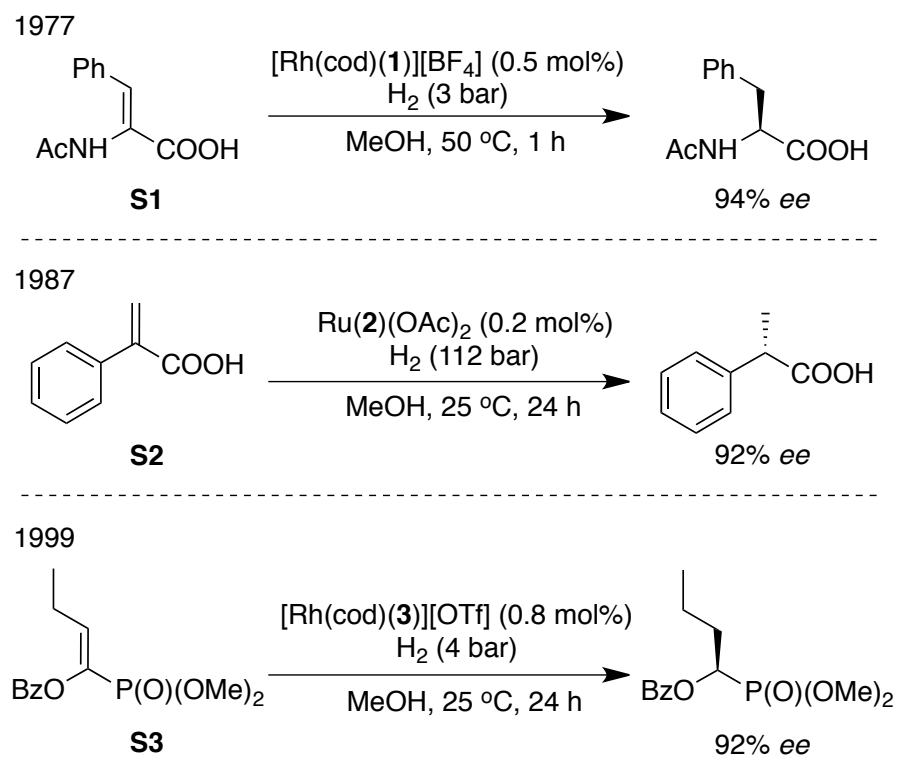<smiles>COc1ccccc1P=CCOc1ccccc1P(c1ccccc1)c1ccccc1</smiles>

$(S, S)$-DIPAMP

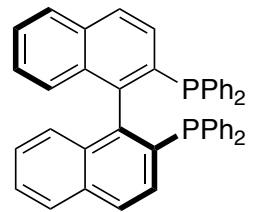

(S)-BINAP

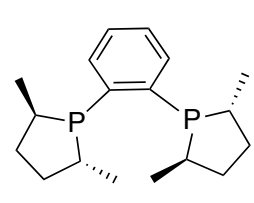

$(R, R)$-Me-DuPhos

Scheme 1 Asymmetric hydrogenation of functionalized alkenes using P,Pligated Rh- and Ru-catalysts.

More than ten years later, Noyori and co-workers published the asymmetric hydrogenation of allylic and homoallylic alcohols using $\operatorname{Ru}(\mathrm{BINAP})(\mathrm{OAc})_{2} .^{9}$ This catalyst, based on $\operatorname{BINAP}^{10} \mathbf{2}$, proved uniquely versatile, and was also used in the first asymmetric hydrogenation of $\alpha, \beta$-unsaturated carboxylic acids (Scheme 1), presented in the same year. ${ }^{11}$

The DuPhos ligand 3, developed by Burk and co-workers in $1990,{ }^{12}$ was unique in the sense that it could be easily modified and tuned to fit a specific substrate class. A new class of alkenes, enol esters, could be reduced in very high enantioselectivities using Rh catalysts ligated by DuPhos variants. ${ }^{13}$ 
Other novel substrate classes that could be reduced using DuPhos systems were $\alpha$-enol benzoate- and $\alpha$-acetamido phosphonates ${ }^{14}$ (Scheme 1 ) and $\beta$ acylamino acrylates. ${ }^{15}$

Asymmetric hydrogenation using $\mathrm{Rh}-$ and Ru-P,P systems has developed significantly over the last 40 years and allowed the enantioselective synthesis of a range of chiral synthetic intermediates with different functionalities. The asymmetric hydrogenation of alkenes by complexes of both types $[R h$ (diene) $(P, P)][X]$ and $R u(P, P)(O O C R)_{2}$ rely on coordination of additional functional groups to the metal to obtain high stereoselectivity. ${ }^{16}$ Typically, the coordination of the alkene is accompanied by that of an acetamide, acetate or alcohol to form a chelate, which locks the alkene in position and limits the set of available conformations. Additionally, these catalysts are usually applied in alcohol solvents that stabilize the metal complex against decomposition and allow proton transfer; thus, non-chelating alkenes compete less favorably with the solvent for metal coordination sites and are reduced at a lower rate. Attempts to use the P,P-ligated systems for the hydrogenation of weakly or non-functionalized alkenes have frequently proven unsuccessful. ${ }^{17}$

\subsection{The Iridium-N,P Catalytic Hydrogenation System}

During the 1970s, Crabtree and co-workers studied the properties of metal complexes of the type $\left[M(\operatorname{cod}) L_{2}\right][X](M=R h$ or Ir, $L=$ phosphine ligand, $X=$ $\mathrm{Cl}, \mathrm{BF}_{4}$ or $\mathrm{PF}_{6}$ ), which had previously been reported by Schrock and Osborn, ${ }^{18}$ to form active hydrogenation catalysts when exposed to $\mathrm{H}_{2}$. The Ircomplexes were less active than their rhodium counterparts in the alkene hydrogenation and, in coordinating solvents, the Ir complexes formed the stable solvate complexes $\left[\operatorname{Ir}(\mathrm{H})_{2}(\mathrm{~S})_{2} \mathrm{~L}_{2}\right][\mathrm{X}](\mathrm{S}=$ solvent $)$ upon exposure to $\mathrm{H}_{2} \cdot{ }^{19}$ When Crabtree and co-workers exchanged the coordinating solvents with polar, non-coordinating solvents such as $\mathrm{CH}_{2} \mathrm{Cl}_{2}$, more active catalytic systems were obtained, especially in the iridium case. ${ }^{20}$

Ligand-screening experiments that aimed to produce Ir catalysts with improved properties demonstrated that the mixed-ligand complex $\left[\operatorname{lr}(\operatorname{cod})(\mathrm{Py}) \mathrm{PCy}_{3}\right]\left[\mathrm{PF}_{6}\right] \mathbf{4}\left(\mathrm{Py}=\right.$ pyridine, $\mathrm{PCy}_{3}=$ tricyclohexylphosphine $)$ 
formed a catalyst which was both faster than the corresponding diphosphinecatalyst, and was able to reduce tri- and tetrasubstituted non-functionalized alkenes efficiently. ${ }^{20 a}$ The high activity of complex $\mathbf{4}$ was attributed partially to the small size of the pyridine ligand. However, a cis conformation of the pyridine and $\mathrm{PCy}_{3}$ ligands could be observed in some cases; ${ }^{21}$ it is thus possible that the activation of 4 with dihydrogen forms cations of the type $\left[\operatorname{Ir}(\mathrm{H})_{2}(\mathrm{Py}) \mathrm{PCy} \mathrm{y}_{3}\right]^{+}\left(\mathrm{Z}=\right.$ solvent, alkene or $\left.\mathrm{H}_{2}\right)$, which would exhibit unusually open alkene coordination sites (Scheme 2). This is in contrast to the corresponding diphosphine complexes in which, upon activation with dihydrogen, the two bulky phosphines are arranged trans to each other. ${ }^{22}$

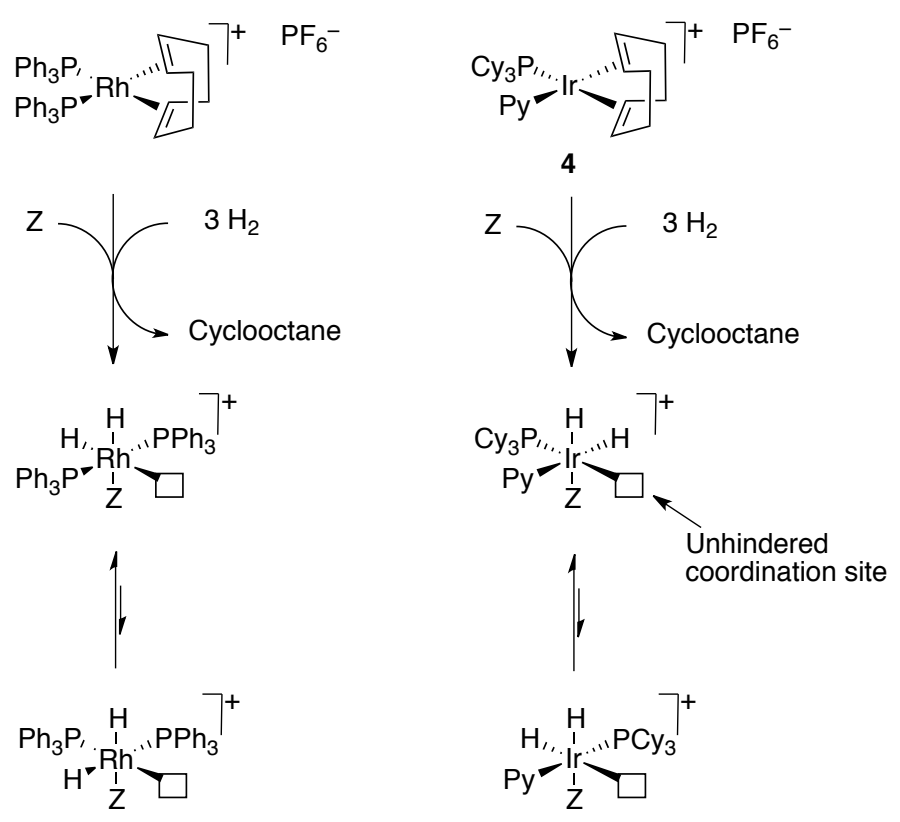

Scheme 2 Activation of 4 by $\mathrm{H}_{2}$ may generate an iridium complex with an unhindered coordination site.

Compound 4, commonly referred to as Crabtree's catalyst, also proved to be unusually air-stable, both as a solid and in solution. However cases where the coordination of the alkene to the metal was poor, the active catalyst decomposed into an inactive trinuclear iridium-hydride cluster (Scheme 3 ). ${ }^{23}$ Thus, high loadings of pre-catalyst were required for high product yields. 


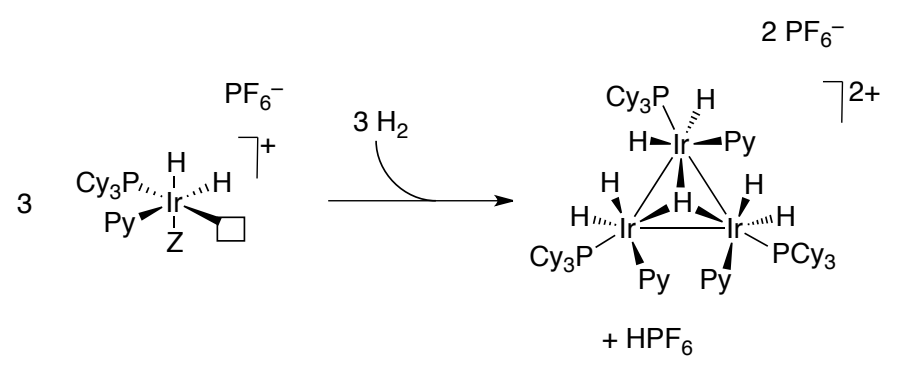

Scheme 3 Complex 4 decomposes under $\mathrm{H}_{2}$ when no alkene is coordinated to the metal. $\left(\mathrm{Z}=\right.$ solvent or $\left.\mathrm{H}_{2}\right)$

In 1997, Pfaltz and co-workers prepared the first chiral mimic of Crabtree's catalyst, $\left[\operatorname{Ir}(\mathrm{cod})\left(\mathrm{N}, \mathrm{P}^{*}\right)\right]\left[\mathrm{PF}_{6}\right]$, using a phosphinooxazoline $\mathbf{5}$ $(\mathrm{PHOX})^{24}$ as a chiral N,P-chelating species. ${ }^{25}$ The complex was exceptionally enantioselective in the asymmetric hydrogenation of non-functionalized triand tetrasubstituted alkenes such as $\mathbf{S 4}$ and $\mathbf{S 5}$ (Scheme 4). ${ }^{26}$ It did, as in the achiral version, decompose during the reaction, and full conversion could not be obtained with less than $3 \mathrm{~mol} \%$ catalyst. $^{27}$ Based on the conclusion by Crabtree et al. that the catalyst was deactivated due to poor alkene coordination, the extremely weakly coordinating counterion $\mathrm{BAr}_{\mathrm{F}}{ }^{-}$was tested as a replacement for $\mathrm{PF}_{6}{ }^{-}$, forming complexes of the type $[\operatorname{Ir}(\mathrm{cod})(\mathrm{PHOX})]\left[\mathrm{BAr}_{\mathrm{F}}\right]$ such as 6 (Scheme 4). Indeed, both $\mathrm{BAr}_{\mathrm{F}}{ }^{-}$and other, similar counterions gave catalysts that achieved higher turnover frequencies and stabilities, and consequently the catalyst loading could be decreased to below $1 \mathrm{~mol} \%$ while maintaining high enantioselectivity (Scheme 4). ${ }^{26,28}$ Additionally, the catalyst became more stable to humidity and more solubile in non-polar solvents. 


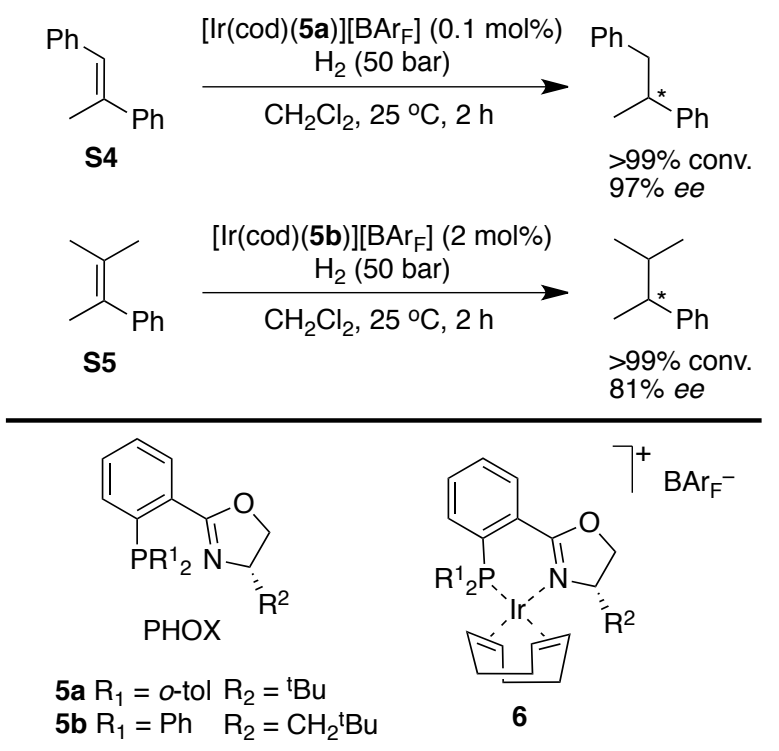

Scheme 4 The PHOX ligands 5 were the first chiral N,P-ligands to used in complexes of the type $[\operatorname{Ir}(\operatorname{cod})(\mathrm{N}, \mathrm{P})]\left[\mathrm{BAr}_{\mathrm{F}}\right]$ such as $\mathbf{6}$, as catalysts for the asymmetric hydrogenation of non-functionalized tri- and tetrasubstituted alkenes.

These benefits of using $\mathrm{BAr}_{\mathrm{F}}^{-}$, which is prepared by quadruple alkylation of $\mathrm{BF}_{3}$ with (3,5-bis(trifluoromethyl)phenyl)magnesium bromide ${ }^{29}$ (Scheme 5), have made it the standard counterion for these catalytic systems.

Following the groundbreaking initial discoveries by Pfaltz, hundreds of chiral nitrogen-phosphorus, nitrogen-carbene and other ligands have been incorporated in iridium complexes and tested as asymmetric hydrogenation catalysts. $^{2 e, 3 a, 3 d}$ As a result, highly selective catalysts have been prepared for a wide range of sterically and electronically different alkene substrates. ${ }^{3 c}$

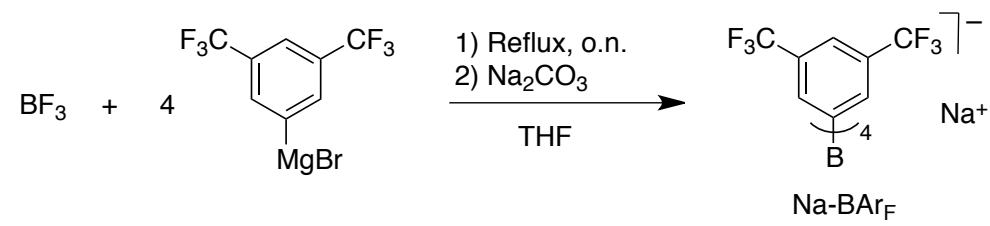

Scheme 5 Preparation of $\mathrm{NaBAr}_{\mathrm{F}}$. 


\subsection{Mechanistic Aspects}

This section aims to describe the fundamental mechanics of catalytic hydrogenation using $[\operatorname{lr}(\operatorname{cod})(\mathrm{N}, \mathrm{P})]\left[\mathrm{BAr}_{\mathrm{F}}\right]$ complexes. The implications of the mechanism on selectivity are discussed in Section 8.

As noted by Crabtree, oxidative addition of $\mathrm{H}_{2}$ and subsequent alkene coordination, for cations of the type $\left[\operatorname{lr}(\operatorname{cod})\left[L^{\prime}\right]^{+}\right.$, are feasible, ${ }^{30}$ and the reaction is especially rapid for Crabtree's catalyst. ${ }^{21}$ Crabtree and co-workers

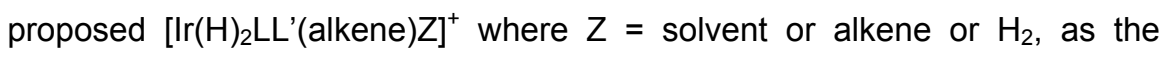
catalyst resting state. ${ }^{22 \mathrm{~b}}$ Additionally, they suggested that the migratory insertion was the rate-determining step in the catalytic cycle, and that the high $(+3)$ oxidation state of the complex contributed to the exceptional stability of these catalysts towards oxidation. ${ }^{22 b}$ Despite thorough studies of the $\left[\operatorname{lr}(\operatorname{cod}) L^{\prime}\right]\left[\mathrm{PF}_{6}\right]$ systems, mechanistic details proved hard to elucidate, due mainly to the high catalytic activity of the systems.

Meuwly, Pfaltz, and co-workers performed the first studies on the addition of dihydrogen to a chiral version of Crabtree's catalyst, $[\operatorname{lr}(\operatorname{cod})(\mathrm{N}, \mathrm{P})]\left[\mathrm{BAr}_{\mathrm{F}}\right]$, using a bidentate $\mathrm{PHOX}$ ligand. ${ }^{31}{ }^{1} \mathrm{H}$ NMR revealed that in THF, at $0{ }^{\circ} \mathrm{C}$ and under an atmosphere of $\mathrm{H}_{2}$, cyclooctadiene was quickly hydrogenated to form complexes of the type $\left[\operatorname{lr}(\mathrm{H})_{2}(\mathrm{~N}, \mathrm{P})(\mathrm{THF})_{2}\right]^{+}$. As shown in Scheme 6 , the hydrides arranged themselves trans to the oxazoline nitrogen and to one of the solvent molecules. In dichloromethane, a complex mixture of hydridic metal complexes was observed, but DFT calculation indicated that similar structures were favorable in the two solvents.

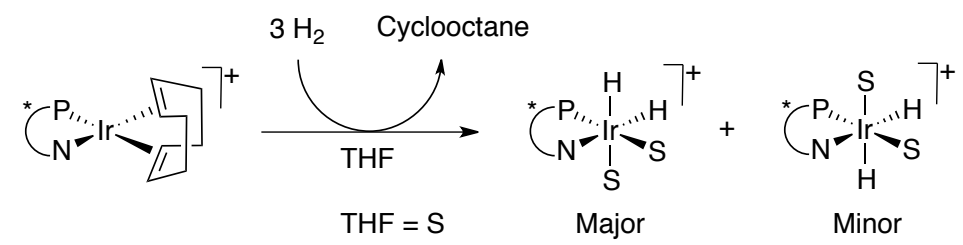

Scheme 6 Activation of $[\operatorname{Ir}(\operatorname{cod})(\mathrm{N}, \mathrm{P})]\left[\mathrm{BAr}_{\mathrm{F}}\right]$ by $\mathrm{H}_{2}$ in $\mathrm{THF}$ generates a pair of isomers of $\left[\operatorname{lr}(\mathrm{H})_{2}(\mathrm{~N}, \mathrm{P})(\mathrm{THF})_{2}\right]\left[\mathrm{BAr}_{\mathrm{F}}\right]$. The $\mathrm{BAr}_{\mathrm{F}}{ }^{-}$counterion has been omitted for clarity. 
The simplest catalytic hydrogenation cycle starting from $\left[\operatorname{lr}(\mathrm{H})_{2}(\mathrm{~N}, \mathrm{P}) \mathrm{S}_{2}\right]^{+}$ would be the substitution of the solvent by an alkene to form $\left[\operatorname{lr}(\mathrm{H})_{2}(\mathrm{~N}, \mathrm{P})(\text { alkene }) \mathrm{Z}\right]^{+}$, where $\mathrm{Z}=$ solvent or $\mathrm{H}_{2}$, followed by migratory insertion and reductive elimination to release the product alkane. Such a reaction pathway, analogous to alkene hydrogenation by $[\mathrm{Rh}(\text { diene })(\mathrm{P}, \mathrm{P})]^{+},{ }^{32}$ was indicated by Dieteker and Chen. ${ }^{33}$ They studied gas-phase reactions of $\left[\operatorname{lr}(\mathrm{cod})(\mathrm{PHOX}]\left[\mathrm{BAr}_{\mathrm{F}}\right], \mathrm{H}_{2}\right.$, and styrene using ESI-MS/MS and found that, when the hydrogenation product cation $[\mathrm{Ir}(\mathrm{PHOX})(\mathrm{PhEt})]^{+}$was isolated and collided with argon, $[\operatorname{Ir}(\mathrm{PHOX})(\text { styrene })]^{+}$was the major species, thus showing that the reaction was reversible in the gas phase.

The observation of cations with masses corresponding to $\left[\mathrm{IrH}_{2}(\mathrm{PHOX})(\text { styrene })\right]^{+}$and $\left[\mathrm{IrH}_{4}(\mathrm{PHOX})(\text { styrene })\right]^{+}$implied that both oxidation states +3 and +5 were possible for iridium. However, collisions of $[\operatorname{lr}(\mathrm{PHOX})(\text { styrene })]^{+}$with $\mathrm{D}_{2}$ only gave additional masses corresponding to $\mathrm{d}_{1-}$ $[\operatorname{Ir}(\mathrm{PHOX})(\text { styrene })]^{+}$and $\mathrm{d}_{2}-[\operatorname{Ir}(\mathrm{PHOX})(\text { styrene })]^{+}$. As only mono- and dideuterated complexes could be detected, a mechanism involving more than two hydrides (such as $\operatorname{Ir}(\mathrm{V})$ ) was deemed unlikely and an $\operatorname{Ir}(\mathrm{I}) / \operatorname{lr}(\mathrm{III})$ catalytic cycle was proposed.

A similar, dihydridic, catalytic cycle was proposed for complexes such as $\left[\operatorname{Ir}(\mathrm{cod})(\operatorname{IMes})\left(\mathrm{P}\left({ }^{n} \mathrm{Bu}\right)_{3}\right)\right]\left[\mathrm{BAr}_{\mathrm{F}}\right], \quad(\mathrm{IMes}=1,3-$ bis(2,4,6-trimethylphenyl)imidazol-2-ylidene) i.e. an achiral analogue of Crabtree's catalyst. ${ }^{34}$ Parahydrogen induced polarization (PHIP) ${ }^{1} \mathrm{H}$ NMR experiments indicated that a dihydride mechanism was operating, but other mechanisms could not be ruled out. ${ }^{35}$ Roseblade and Pfaltz also considered a related mechanism, ${ }^{36}$ starting from the oxidative addition product $\left[\operatorname{Ir}(\mathrm{H})_{2}(\mathrm{~N}, \mathrm{P}) \mathrm{S}_{2}\right]^{+}$(Complex A, Scheme 7). They proposed that complex $\mathbf{A}$ underwent substitution by an alkene trans to the phosphorus, resulting in complex B. Alkene coordination to form $\mathbf{B}$ is usually facile; the rate of hydrogenation of a trisubstituted alkene catalyzed by $\left[\operatorname{lr}(\operatorname{cod})(\mathrm{PHOX}]\left[\mathrm{BAr}_{\mathrm{F}}\right]\right.$ has proven to be close to zero-order in alkene. ${ }^{27}$ Hydride migration to the alkene then gives the $\sigma$-alkyl intermediate $\mathbf{C}$, which subsequently undergoes reductive elimination to form $\mathbf{D}$. Oxidation by a new molecule of $\mathrm{H}_{2}$ and solvent coordination regenerate $A$. 


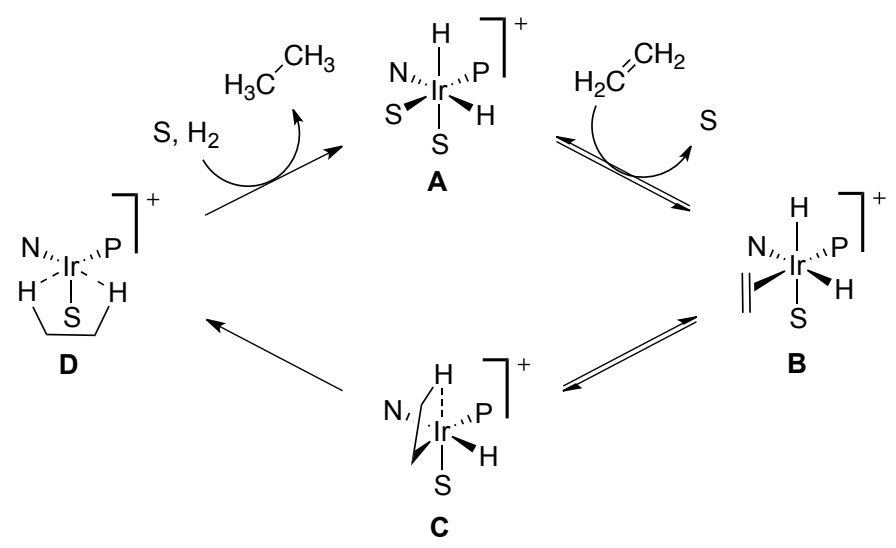

Scheme 7 Alkene hydrogenation via an $\operatorname{Ir}(\mathrm{I}) / \mathrm{Ir}(\mathrm{III})$ dihydride catalytic cycle. The $\mathrm{BAr}_{\mathrm{F}}^{-}$counterion has been omitted. $\mathrm{S}=$ solvent.

DFT studies starting from complexes of the type $\left[\mathrm{Ir}(\mathrm{H})_{2}(\mathrm{~N}, \mathrm{P})(\text { alkene }) \mathrm{S}\right]^{+}$ ( $S$ = solvent, alkene = ethane; Complex B, Scheme 7) with a truncated N,P ligand $\left(\mathrm{N}, \mathrm{P}=\mathrm{MeN}=\mathrm{CH}-\mathrm{CH}=\mathrm{CH}-\mathrm{PMe}_{2}\right.$ ) prompted Brandt and co-workers to suggest an alternative mechanism. ${ }^{37}$ Calculations indicated that both migratory insertion and reductive elimination, as shown in Scheme 7, had high energy barriers. However, when the coordinated $\mathrm{CH}_{2} \mathrm{Cl}_{2}$ was exchanged for an $\eta^{2}$-coordinated $\mathrm{H}_{2}$ molecule to give $\left[\operatorname{Ir}(\mathrm{H})_{2}\left(\mathrm{H}_{2}\right)(\mathrm{N}, \mathrm{P}) \text { (alkene) }\right]^{+}$(Complex $\mathbf{F}$, Scheme 8). Starting from $\mathbf{F}$, both migratory insertion and reductive elimination are more feasible. Additionally, the migratory insertion occured simultaneously with the oxidative addition of the coordinated dihydrogen molecule to form $\mathbf{G}$ (Scheme 8, Path A). The $\operatorname{Ir}(\mathrm{V})$ species $\mathbf{G}$ then undergoes reductive elimination to form $\mathbf{H}$ which, by coordination of another alkene and a solvent molecule, reforms $\mathbf{E}$ (the suggested catalyst resting state). The migratory insertion (step $\mathbf{F}$ $\rightarrow \mathbf{G}$ ) was calculated to have the only significant energy barrier and was proposed to be the rate-determining step. However, kinetic studies have shown that the reaction is first-order in hydrogen pressure. This result was later confirmed for pressures up to 50 bar. $^{28}$ In order to reconcile these results, the authors noted that the substitution of $\mathrm{CH}_{2} \mathrm{Cl}_{2}$ by $\mathrm{H}_{2}$ (Scheme $8, \mathbf{E}$ $\rightarrow$ F) could be the rate determining step if it were endergonic. Although DFT calculations indicated that it was thermodynamically neutral under standard conditions, the reaction could be endergonic under the reaction conditions, 
where the concentration of $\mathrm{CH}_{2} \mathrm{Cl}_{2}$ is higher than that of $\mathrm{H}_{2}$. It is also possible, however, that the reaction rate can be limited by $\mathrm{H}_{2}$ diffusion, at least in cases where the alkene hydrogenation is fast, as reported by Blackmond and coworkers. ${ }^{38}$ They demonstrated that it was more important to control the rate of mass-transfer (i.e. convection) than the gas pressure over the solution, since the former had greater impact on the concentration of $\mathrm{H}_{2}$ in solution.

The effect of hydrogen pressure on asymmetric hydrogenation using $[\operatorname{lr}(\operatorname{cod})(\mathrm{N}, \mathrm{C})]\left[\mathrm{BAr}_{\mathrm{F}}\right]$ pre-catalysts $(\mathrm{C}=\mathrm{N}$-heterocyclic carbene) has been studied. For some alkene substrates, no pressure-dependence was observed, whereas for others, pressure had significantly influenced both the reaction rate and enantioselectivity. ${ }^{39}$

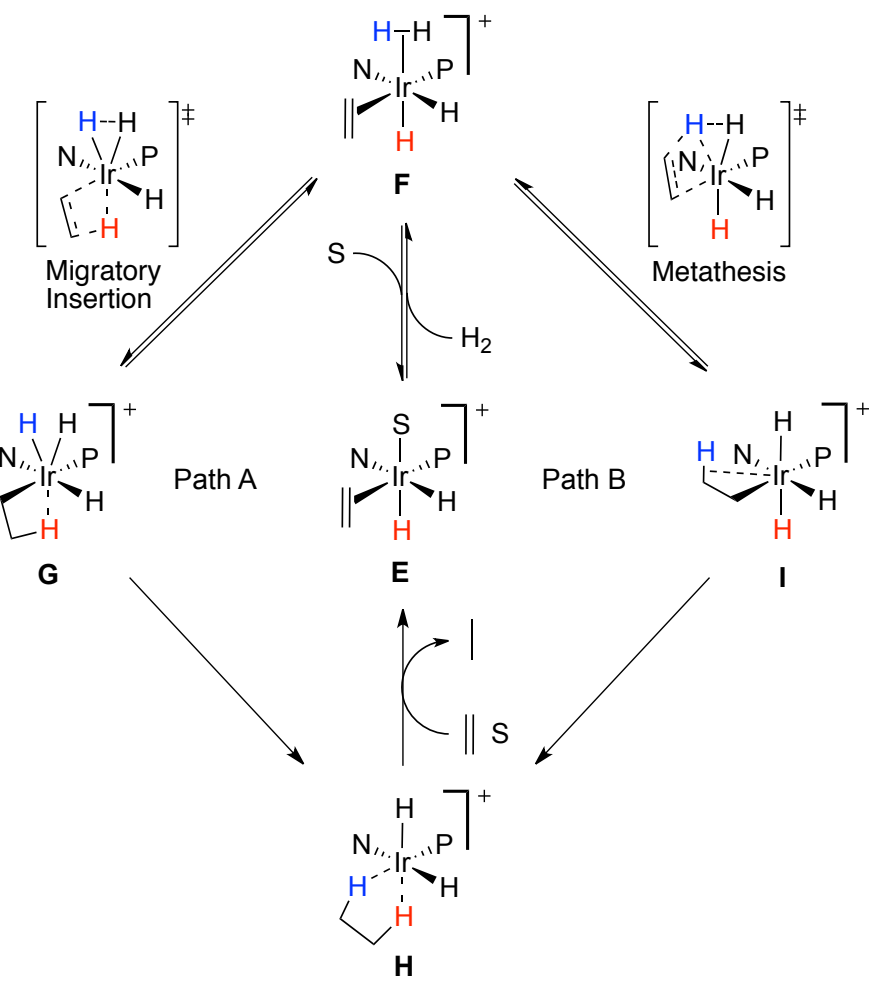

Scheme 8 Hydrogenation of an alkene starting from an $\eta^{2}-\mathrm{H}_{2}$ complex $(\mathbf{F})$ and going through an $\operatorname{Ir}(\mathrm{III}) / \mathrm{rr}(\mathrm{V})$ catalytic cycle. The reaction has been suggested to go through either a concerted migratory insertion-oxidative 
addition (Path A) or a hydrogen metathesis (Path B). The $\mathrm{BAr}_{\mathrm{F}}{ }^{-}$counterion has been omitted for clarity. $\mathrm{S}=$ solvent.

Burgess, Hall and co-workers performed DFT calculations on the mechanism of Ir-catalyzed asymmetric olefin hydrogenation using their N,Cligated system. ${ }^{40}$ Their lowest energy pathway (Scheme 8, Path B) was similar to the one proposed by Brandt et al. Starting from complex $\mathbf{F}$, they calculated that the first hydrogen was transferred to the alkene from the coordinated dihydrogen molecule via metathesis. The $\operatorname{Ir}(\mathrm{V}) \sigma$-alkyl complex I thus formed then underwent reductive elimination to yield $\mathbf{H}$.

Calculations performed for an experimentally reported $[\operatorname{lr}(\operatorname{cod})(\mathrm{N}, \mathrm{P})]^{+}$ catalyst system, beginning from complex cations of the type $\left[\operatorname{lr}(\mathrm{H})_{2}(\mathrm{~N}, \mathrm{P})(\text { alkene }) \mathrm{X}\right]^{+}$, revealed that the lowest energy barriers were available when $X=\mathrm{H}_{2}$ and the system followed an $\operatorname{Ir}(\mathrm{III}) /(\mathrm{V})$ pathway (Scheme 8). ${ }^{41}$ It also indicated that the migratory insertion (Path $A$ ) was lower in energy than the metathesis (Path B) for this type of catalyst. This was true for calculations of gas-phase species and for species in a solvent field. The $\operatorname{Ir}(\mathrm{I}) /(\mathrm{III})$ pathways, calculated for $\mathrm{X}=\mathrm{CH}_{2} \mathrm{Cl}_{2}$ or an empty coordination site, were more than $10 \mathrm{kcal} / \mathrm{mol}$ higher in energy. Analogous results have been obtained in studies on a $\left[\operatorname{lr}(\mathrm{H})_{2}(\mathrm{~N}, \mathrm{P})(\text { alkene }) \mathrm{X}\right]^{+}$system with a different ligand. ${ }^{42}$

To conclude the mechanistic discussions, although much relevant experimental data is lacking, several DFT studies have indicated that the hydrogenation of non-functionalized alkenes by chiral mimics of Crabtree's catalyst proceeds via an $\operatorname{Ir}(\mathrm{III}) / \mathrm{Ir}(\mathrm{V})$ tetrahydride mechanism. It is likely, as noted by several authors, that the mechanism can depend on the substrate and the hydrogen concentration. For instance, chelating substrates can easily be envisioned to disfavor the formation of the Ir-dihydride-dihydrogen complex (F, Scheme 8) and instead form a dihydride complex with a chelating alkene (i.e. complexes B and C, Scheme 7, with S replaced by a coordinating functional group from the alkene). 


\section{Aryl and Alkyl Substituted Alkenes}

\subsection{Trisubstituted Alkenes}

Aryl/alkyl trisubstituted alkenes (Figure 2) have become the benchmark substrates for assessing the efficiency of new catalytic systems in the hydrogenation of minimally functionalized olefins. In general, the asymmetric reduction of 1,2-diarylalkenes (such as trans a-methylstilbene S4), proceeds with higher enantioselectivities than monoarylated alkenes (i.e. E-2-(4methoxyphenyl)-2-butene S6), for which only a limited number of catalysts provides high levels of enantioselectivity. ${ }^{2 d, e, 3 a, 3 c, d, 36,43}$ On the other hand, the geometry of the double bond also affects the catalytic outcome, and hydrogenation of E-olefins affords higher enantioselectivities than that of Zolefins. The lower enantioselectivities achieved in the hydrogenation of Zisomers can sometimes be attributed to an ZIE isomerization process to form the more stable E-alkene, which frequently gives the opposite enantiomer of the hydrogenated product. ${ }^{2 \mathrm{~d}, e, 3 \mathrm{a}, 3 \mathrm{c}, \mathrm{d}, 36,43}$ The fact that the sense of enantioselectivity is controlled by the olefin geometry can be used to gain access to both enantiomers of the hydrogenated product with the same catalyst, provided that isomerization can be supressed. However, this also presents a limitation since mixtures of ZIE isomers have to be avoided to achieve high enantioselectivities. Z-2-(4-methoxyphenyl)-2-butene S7 and dihydronaphthalenes (i.e. 7-methoxy-4-methyl-1,2-dihydronaphthalene S8) are frequently used to study the ligand scope in the hydrogenation of Zalkenes. Dihydronaphthalenes have recently received much attention because the corresponding chiral tetraline motif is found in numerous natural products. $^{44}$

Trialkyl substituted alkenes (substrates with no aromatic groups attached to the alkene) haven't been studied in detail. The reasons for limited information is probably due to the difficulty in developing methods for eedetermination and the lack of an aryl group that could direct the reaction via $\pi$-stacking interaction between the substrate and the chiral catalyst. Nevertheless, this substrate class has been hydrogenated using Ir-N,P 
catalysts with high efficiency (ee's up to $95 \%$ in the hydrogenation of 1 methoxy-4-(3-methyl-pent-3-enyl)-benzene S9). ${ }^{45}$

Recently, the substrate scope has been extended to 1,1-diaryl or 1,1,2triaryl substituted substrates (i.e. 1-(1,2-diphenyl-vinyl)-3,5-dimethyl-benzene S10) and cyclic dienes (i.e. 1,5-dimethyl-cyclohexa-1,4-diene S11). The former substrate class provides an easy entry point to diarylmethine stereogenic centers, which are present in several important drugs and natural products. ${ }^{46}$<smiles>CC(=Cc1ccccc1)c1ccccc1</smiles>

S4<smiles>COc1ccc2c(C)cccc2c1</smiles>

S8<smiles>CC1=CCC=C(C)C1</smiles>

S11<smiles>C/C=C(\C)c1ccc(OC)cc1</smiles>

S6<smiles>CC=C(C)CCc1ccc(OC)cc1</smiles>

S9<smiles>C/C=C(/C)c1ccc(OC)cc1</smiles>

S7

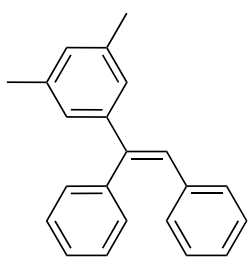

S10

Figure 2 Representative aryl-alkyl, alkyl-alkyl and aryl-aryl trisubstituted alkenes.

The first successful application in the asymmetric reduction of minimally functionalized olefins was reported by Buchwald and co-workers in 1993. ${ }^{47}$ A chiral titanocene catalyst precursor, 7, provided high enantioselectivities (ee's ranging from $83 \%$ - >99\%; Table 1, entry 1 ) in the hydrogenation of a limited range of $E$ - and Z-trisubstituted olefins (Scheme 9). However, high pressure (140 bar of $\left.\mathrm{H}_{2}\right)$, high temperature $\left(65^{\circ} \mathrm{C}\right)$ and long reactions times (several days) were required to achieve full alkene conversions. Moreover, the catalyst is highly unstable and the use of a drybox is required for its preparation. 


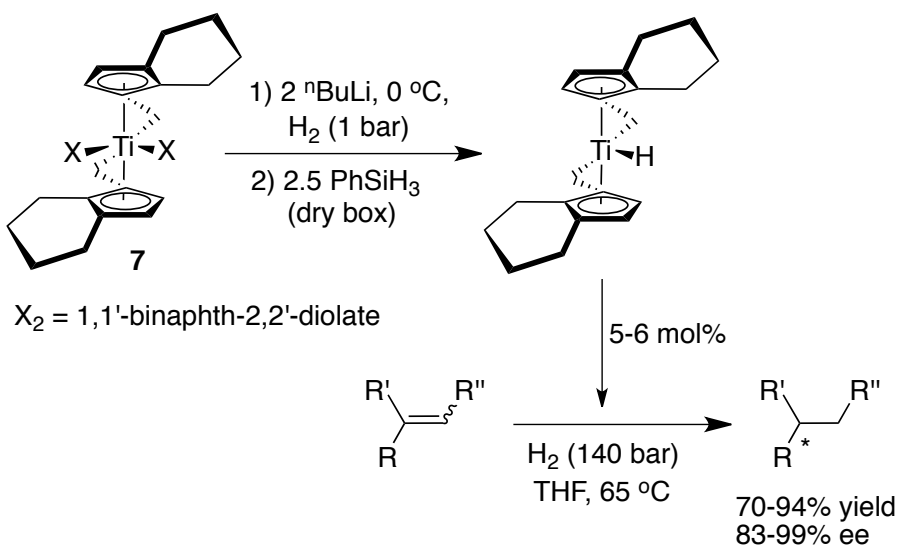

Scheme 9 Asymmetric hydrogenation of trisubstituted olefins using chiral titanocene complex 7 .

The application of Rh- and Ru-catalyst precursors with phosphorus ligands for the asymmetric reduction of minimally functionalized trisubstituted olefins has not been accomplished with good enantioselectivities. ${ }^{48}$ Nevertheless, $\left[\mathrm{Rh}(\operatorname{cod})\left(1 R, 1^{\prime} R, 2 S, 2^{\prime} S\right.\right.$-Duanphos)] $\mathrm{BF}_{4}$ has been successfully applied in the asymmetric hydrogenation of trisubstituted olefins in various E/Z-mixtures (Scheme 10). ${ }^{49}$ However, the presence of a directing hydroxyl group at the ortho position of a phenyl substituent in the substrate is required and the authors found that coordination of the phenol to Rh plays a crucial role in the enantiodiscrimination process. Thus, the hydrogenation of methyl ether analogues led to lower activities and enantioselectivities (ee's $<20 \%$ ).

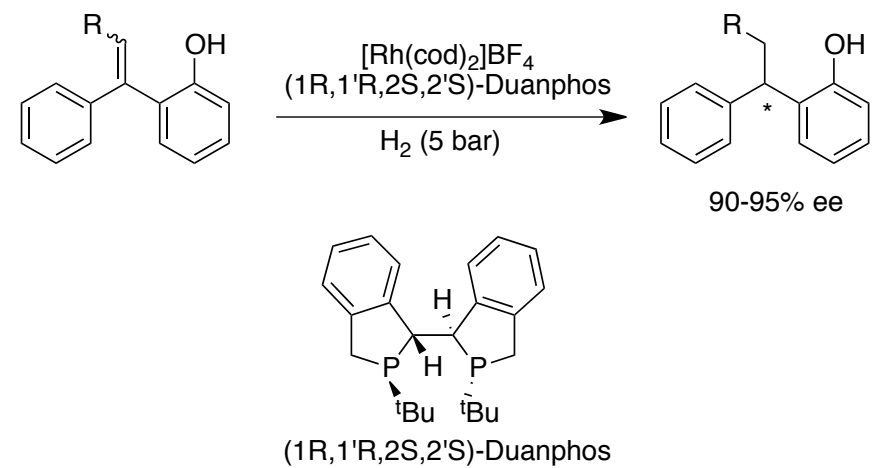


Scheme 10 Asymmetric hydrogenation of trisubstituted olefins containing a directing hydroxyl group using Rh-Duanphos catalysts.

As mentioned in Section 1.4, a breakthrough in the hydrogenation of minimally functionalized olefins came in 1997 when Pfaltz' and co-workers used phosphine-oxazoline ligands $\mathrm{PHOX} 5^{26-27,50}$ (Figure 3; $\mathrm{R}^{1}=\mathrm{Ph}, \mathrm{o}-\mathrm{Tol}$ and $\left.\mathrm{R}^{2}={ }^{\mathrm{i}} \mathrm{Pr},{ }^{\mathrm{t}} \mathrm{Bu}, \mathrm{CH}_{2}{ }^{\mathrm{t}} \mathrm{Bu}\right)$ to design [ $\left.\operatorname{lr}(\mathrm{cod})(\mathrm{PHOX})\right]\left[\mathrm{BAr}_{\mathrm{F}}\right]$, a chiral analogue of Crabtree's catalyst. ${ }^{30}$ These catalysts, in comparison to titanocene complex 7 , required lower pressures (50 bar of $\mathrm{H}_{2}$ ), temperatures ( $\mathrm{rt}$ ) and reaction times (full conversions in 2 hours). They have been successfully used for the asymmetric hydrogenation of a limited range of alkenes (mainly trisubstituted E-1,2-diaryl olefins including those bearing a furyl and a thiophenyl heterocyclic substituents with ee's up to $98 \%$; Table 1 , entry 2 ). ${ }^{26-27,43,45,51}$ These catalysts, afforded lower levels of enantioselectivity in the hydrogenation of more demanding Z-olefins $(42 \%$ ee in the hydrogenation of s7; Table 1, entry 2). The authors found that enantioselectivity is affected by the ligand parameters and the best enantioselectivities were obtained with the ligand that combines a tert-butyl on the oxazoline and a bis(o-tolyl)phosphanyl group (ligand $\mathbf{5 a}$, Table 1, entry 2).
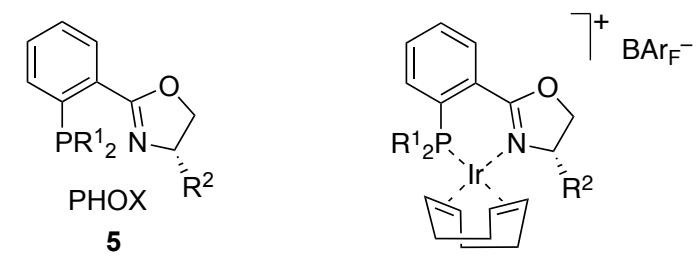

$$
\begin{array}{ll}
\text { a: } R^{1}=o-T o l & R^{2}={ }^{t} B u \\
\text { b: } R^{1}=P h & R^{2}=\mathrm{CH}_{2}{ }^{t} B u \\
\text { c: } R^{1}=\text { Mes } & R^{2}={ }^{t} B u \\
\text { d: } R^{1}=P h & R^{2}={ }^{t} B u
\end{array}
$$

Figure 3 Phosphine-oxazoline PHOX ligands $\mathbf{5}$ and the corresponding Irprecatalyst.

Since Pfaltz' discovery of the utility of $[\operatorname{Ir}(\operatorname{cod}) 5]\left[B \mathrm{Br}_{\mathrm{F}}\right]$ the composition of the ligands has been extended by replacing the phosphine moiety with other phosphorus-donor group analogues (i.e. phosphinite, carbene and phosphite) and the oxazoline moiety with different $\mathrm{N}$-donor groups (such as 
pyridine, thiazole and oxazole). The structure of the chiral ligand's backbone has also been modified. Recently, the use of iridium catalysts containing P,S and $\mathrm{P}, \mathrm{O}$ heterodonor ligands have been presented. All these modifications has led to the discovery of new ligands that have considerably broadened the scope of Ir-catalyzed asymmetric hydrogenation of minimally functionalized trisubstituted olefins. The enantioselective reduction of aryl/heteroayl-alkyl olefins, triarylsubstituted olefins and pure alkyl olefins can be efficiently achieved.

In the following sections, we compile the most representative catalytic data reported in the Ir-catalyzed asymmetric hydrogenation of minimally functionalized trisubstituted olefins arranged according to the type of ligands. We also discuss their application to the synthesis of complex molecules.

\subsubsection{Phosphorus/Carbene-Oxazoline Ligands}

Several successful phosphorus/carbene-oxazoline compounds have been developed for the Ir-catalyzed asymmetric hydrogenation (Figure 4). Most of them are phosphine-oxazoline, N-phosphine-oxazoline and phosphiniteoxazoline ligands and to a lesser extent phosphite/phosphoroamiditeoxazoline and carbene-based ligands.

\section{Phosphine-Oxazoline Ligands}

A modification in the oxazoline moiety of the PHOX ligands, with the development of phosphine-benzoxazine analogues 8 (Figure 4, $\mathrm{R}={ }^{\mathrm{t}} \mathrm{Bu}$, ${ }^{\mathrm{i}} \mathrm{Pr}$ ) was reported in 2001. ${ }^{52}$ As observed with the PHOX ligands, the presence of bulky tert-butyl groups at the oxazine ring led to the highest enantioselectivities. However, these ligands provided lower enantioselectivities (ee's up to $90 \%$ for substrate S4) than the PHOX ligands 5.

Ligands 9 have been applied in the Ir-catalyzed hydrogenation of several trisubstituted aryl-alkyl alkenes (Figure $4, \mathrm{R}^{1}=\mathrm{Ph}, \mathrm{o}-\mathrm{Tol}, \mathrm{R}^{2}=\mathrm{Me}$, ${ }^{t} \mathrm{Bu}, 1$-adamantyl, $\left.\mathrm{CPh}_{3}\right)^{53}$ and enantioselectivities shown to depend strongly on both the ligand parameters and the substrate type. Thus, while the best 
enantioselectivities for Z-isomer $\mathbf{S 7}$ were obtained with a tert-butyl group at the oxazoline and a diphenylphosphanyl group (ligand 9a; Table 1, entry 3), for stilbene derivatives the presence of a bis(o-tolyl)phosphanyl group is needed for ee's to be high (ligand $\mathbf{9 b}$; Table 1 , entry 3 ). These ligands proved to be superior to the PHOX ligands in the hydrogenation of Z-alkenes (i.e. $75 \%$ ee for substrate s7; Table 1, entries 2 vs 3 ), while ee's for the hydrogenation of E-alkenes were lower (ee's up to $94 \%$ for trans- $\alpha$ methylstilbene S4; Table 1, entries 2 vs 3). A further modification of ligands 9 by introduction of the ortho-phenylene tether backbone motif of the PHOX ligands gave rise to new ligands 10 (Figure $4, R^{1}=P h, C y$, and $R^{2}={ }^{t} B u, 1-A d$, $\mathrm{CHPh}_{2}, 3,5-{ }^{\mathrm{t}} \mathrm{Bu}_{2}-\mathrm{Ph}$ ) that proved to be excellent in the hydrogenation of transa-methylstilbene derivatives (ee's up to $99 \%$ ). ${ }^{54}$ Again the presence of bulky substituents at both oxazoline and phosphine moieties (ligand 10a) led to the highest enantioselectivities (Table 1, entry 4). 


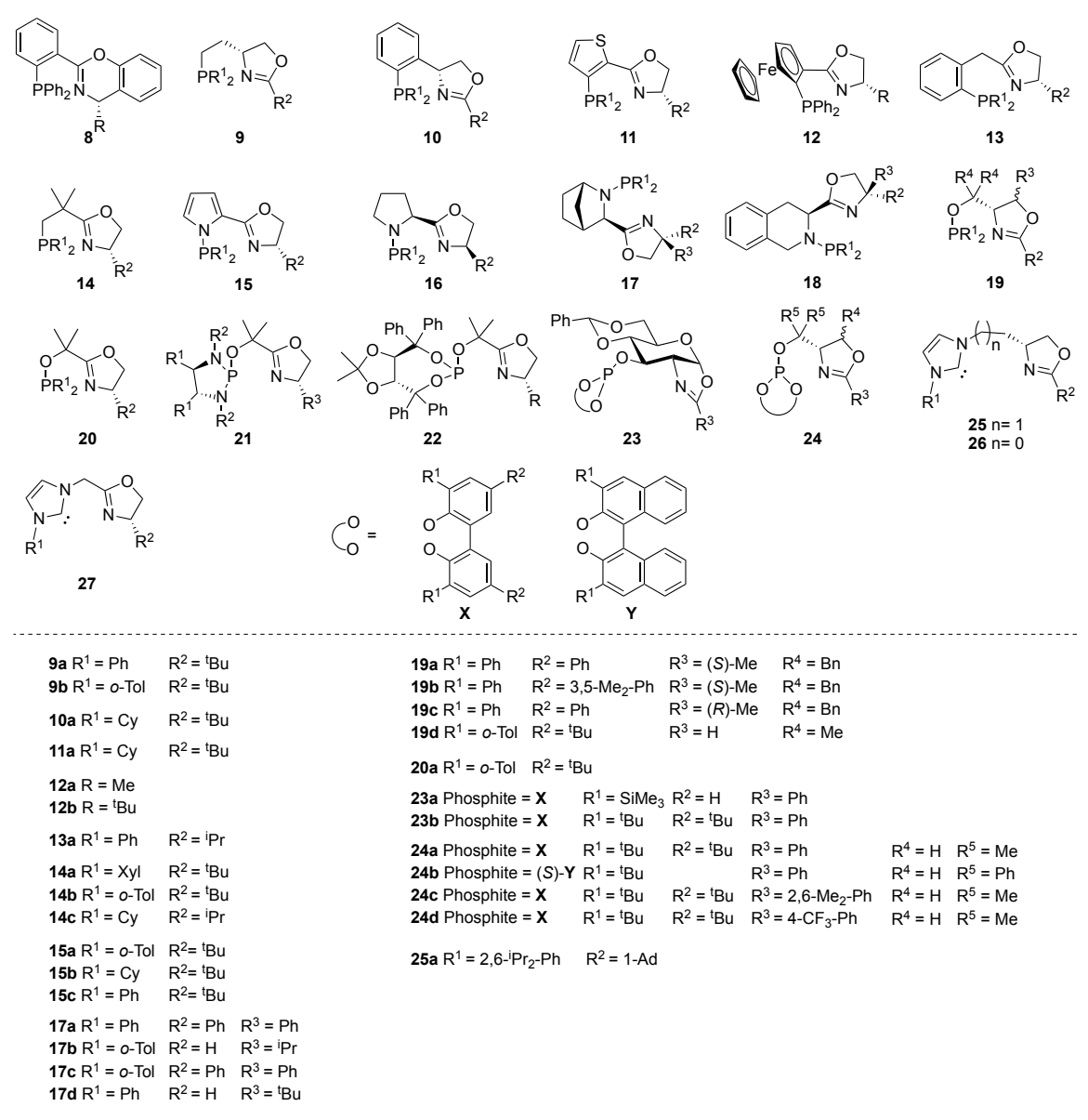

Figure 4 Phosphorus/carbene-oxazoline ligand families developed for the Ir-catalyzed asymmetric hydrogenation of aryl/alkyl trisubstituted olefins.

In 2003, the application of ligands 11 (Figure 4, $\mathrm{R}^{1}=\mathrm{Ph}, \mathrm{o}-\mathrm{Tol}, \mathrm{Cy}, \mathrm{R}^{2}={ }^{\mathrm{i}} \mathrm{Pr}$, ${ }^{\mathrm{t}} \mathrm{Bu}$ ) in which the phenyl ring of the PHOX has been replaced by thiophene, was reported for the Ir-catalyzed hydrogenation of trans-a-methylstilbene (ee's up to $99 \%$ ). ${ }^{55}$ For ligands 10 , the best enantioselectivity was obtained with the ligand bearing a tert-butyl group at the oxazoline and a biscyclohexylphosphanyl group (ligand 11a; Table 1, entry 5).

Another modification of the PHOX ligand in which a ferrocenyl group has been introduced instead of the phenyl ring (ligands 12; Figure 4, R= Me, $\left.{ }^{\mathrm{i}} \mathrm{Pr},{ }^{\mathrm{t}} \mathrm{Bu}, \mathrm{Ph}, \mathrm{Bn}\right)$ has been presented. ${ }^{56}$ Interestingly, the best enantioselectivities were obtained with the ligand that contains a small methyl 
substituent at the oxazoline moiety. These ligands proved to be superior to the PHOX ligands in the hydrogenation of the 4-methyl-1,2dihydronaphthalene $\mathbf{S 8}(89 \% \mathrm{ee})$ in which the alkene has Z-configuration, while ee's for the hydrogenation of $E$-alkenes were lower (ee's up to $89 \%$ for trans-a-methylstilbene S4).

In 2008, based on the PHOX ligands, new phosphine-oxazoline ligands 13 were developed. In these ligands, the flat ortho-phenylene tether is replaced by a benzylic group (Figure $4 ; \mathrm{R}^{1}=\mathrm{Ph}, o-\mathrm{Tol}, p$-Tol, $\mathrm{R}^{2}=\mathrm{Me}$, ${ }^{\mathrm{i}} \mathrm{Pr}$, $\left.{ }^{\mathrm{t}} \mathrm{Bu}\right){ }^{57}$ These ligands were successfully applied in the Ir-catalyzed asymmetric hydrogenation of a range of $E$ - and Z-stilbene derivatives (ee's up to $97 \%$ and $90 \%$, respectively; Table 1, entry 6 ). The best enantioselectivities were achieved with the ligand that contains an isopropyl oxazoline substituent and a diphenylphosphanyl group (ligand 13a; Table 1, entry 6).

Ligands 14, where the ortho-phenylene tether of the PHOX-ligand has been replaced by a branched alkyl chain, (Figure $4, \mathrm{R}^{1}=\mathrm{Ph}, \mathrm{o}-\mathrm{Tol}, \mathrm{Xyl}, \mathrm{R}^{2}=$ ' $\mathrm{Pr},{ }^{\mathrm{t}} \mathrm{Bu}, \mathrm{Bn}$ ) provided higher enantioselectivities in the hydrogenation of trisubstituted $E$ - and Z-aryl/alkyl alkenes than the PHOX ligands (ee's up to 98\% for $E$-isomers and $96 \%$ for $Z$-isomers). ${ }^{44}$ Enantioselectivities were again best with ligand $14 a$ bearing bulky substituents at both oxazoline and phosphine moieties (Table 1 , entry 7 ). The potential utility of these new ligands was demonstrated in the synthesis of (R)-7-demethyl-2methoxycalamenene, an antitumor natural product (Scheme 11). 
<smiles>COc1ccc2c(c1)CCCC2=O</smiles><smiles>COc1ccc2c(c1)CCC=C2C(C)C</smiles><smiles>COc1ccc2c(c1)CCC[C@H]2C(C)C</smiles>

(c)

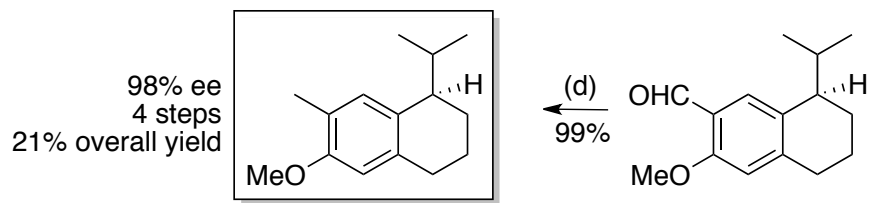

(a) ${ }^{\mathrm{PrMgCl}}(1.3 \mathrm{eq}), \mathrm{ZnCl}_{2}(0.1 \mathrm{eq}), \mathrm{THF}$, then $p$ - TsOH (cat.), $\mathrm{I}_{2}$ (cat), toluene, $110{ }^{\circ} \mathrm{C}, 16 \mathrm{~h}$; (b) catalyst Ir-14a $(0.5 \mathrm{~mol} \%) \mathrm{H}_{2}(5 \mathrm{bar}), \mathrm{CH}_{2} \mathrm{Cl}_{2}$, $4 \mathrm{~h}$; (c) N-methylformanilide, $\mathrm{POCl}_{3}, \mathrm{CH}_{2} \mathrm{Cl}_{2}, 40{ }^{\circ} \mathrm{C}, 48 \mathrm{~h}$ (d) $\mathrm{Pd} / \mathrm{C}$ $(10 \%), \mathrm{H}_{2}$ (100 bar), $24 \mathrm{~h}$.

Scheme 11 Total synthesis of $(R)$-7-demethyl-2-methoxycalamenene.

\section{N-Phosphine-Oxazoline Ligands}

In 2001, a modified version of the PHOX ligands featuring a pyrrole group as linker to the phosphorus was presented. ${ }^{58}$ These new ligands 15 proved to be highly efficient in the hydrogenation of trisubstituted alkenes (Figure $4, R^{1}=$ $\mathrm{Ph}, \mathrm{o}-\mathrm{Tol}, \mathrm{Cy} ; \mathrm{R}^{2}={ }^{\mathrm{i}} \mathrm{Pr},{ }^{\mathrm{t}} \mathrm{Bu}$ ). Enantiomeric excesses surpassed those previously obtained with the PHOX ligands (i.e. ee's up to $99 \%$ for $E$-stilbenes and up to $92 \%$ for 4 -methyl-1,2-dihydronaphthalenes; Table 1, entry 8 ). The best enantioselectivities were obtained with ligands bearing a tert-butyl group in the oxazoline moiety and either ortho-tolyl or cyclohexenyl P-substituents (ligands $15 a$ and $15 b$, respectively).

The proline-derived $\mathrm{N}$-phosphine-oxazoline ligands 16 (Figure 4, $\mathrm{R}^{1}=$ $\mathrm{Ph}, \mathrm{o}-\mathrm{Tol}, \mathrm{R}^{2}={ }^{\mathrm{i}} \mathrm{Pr},{ }^{\mathrm{t}} \mathrm{Bu}$ ) provided lower enantioselectivities than the previous pyrrole-based ligands 15 (ee's up to $94 \%$ for $E$-stilbenes and up to $64 \%$ for 4 methyl-1,2-dihydronaphthalenes). ${ }^{59}$ Again, the highest enantioselectivities were achieved with ligands bearing a bulky tert-butyl oxazoline moiety.

Andersson and co-workers developed ligands 17 and 18 for the Ircatalyzed hydrogenation of alkenes (Figure 4,$17 ; \mathrm{R}^{1}=\mathrm{Ph}, \mathrm{o}-\mathrm{Tol}, \mathrm{Cy}, \mathrm{R}^{2}=\mathrm{H}$, ${ }^{\mathrm{t}} \mathrm{Bu}, \mathrm{Ph}, \mathrm{R}^{3}=\mathrm{H}, \mathrm{Ph}$ and 18; $\left.\mathrm{R}^{1}=\mathrm{Ph}, \mathrm{R}^{2}=\mathrm{H},{ }^{\mathrm{i}} \mathrm{Pr}, \mathrm{Ph}, \mathrm{R}^{3}=\mathrm{H},{ }^{\mathrm{i}} \mathrm{Pr}, \mathrm{Ph}\right){ }^{60}$ 
Ligands 17, containing a chiral rigid bicyclic backbone, provided much higher enantioselectivities than ligands 18 , with a more flexible backbone. The authors found that ligand 17 a with phenyl substituents at $R^{1}, R^{2}$ and $R^{3}$ positions provided the best enantioselectivities (ee's up to $99 \%$ for $E$-isomers and $95 \%$ for 4-methyl-1,2-dihydronaphthalene S8; Table 1 , entry 9). ${ }^{60 a}$ It should be noted that Ir-17a catalyst also provided enantioselectivities up to $80 \%$ in the hydrogenation of triarylsubstituted olefins (Table 1 , entry 9). ${ }^{61}$ These catalysts also afforded, for the first time, high enantioselectivities in the hydrogenation of enol phosphinates, ${ }^{62}$ vinyl silanes, ${ }^{63}$ fluorinated olefins ${ }^{64}$ and vinyl boronates ${ }^{65}$ (vide infra).

Table 1 Enantioselectivities achieved using selected ligands in the asymmetric hydrogenation of the most representative, weakly functionalized, trisubstituted olefins.

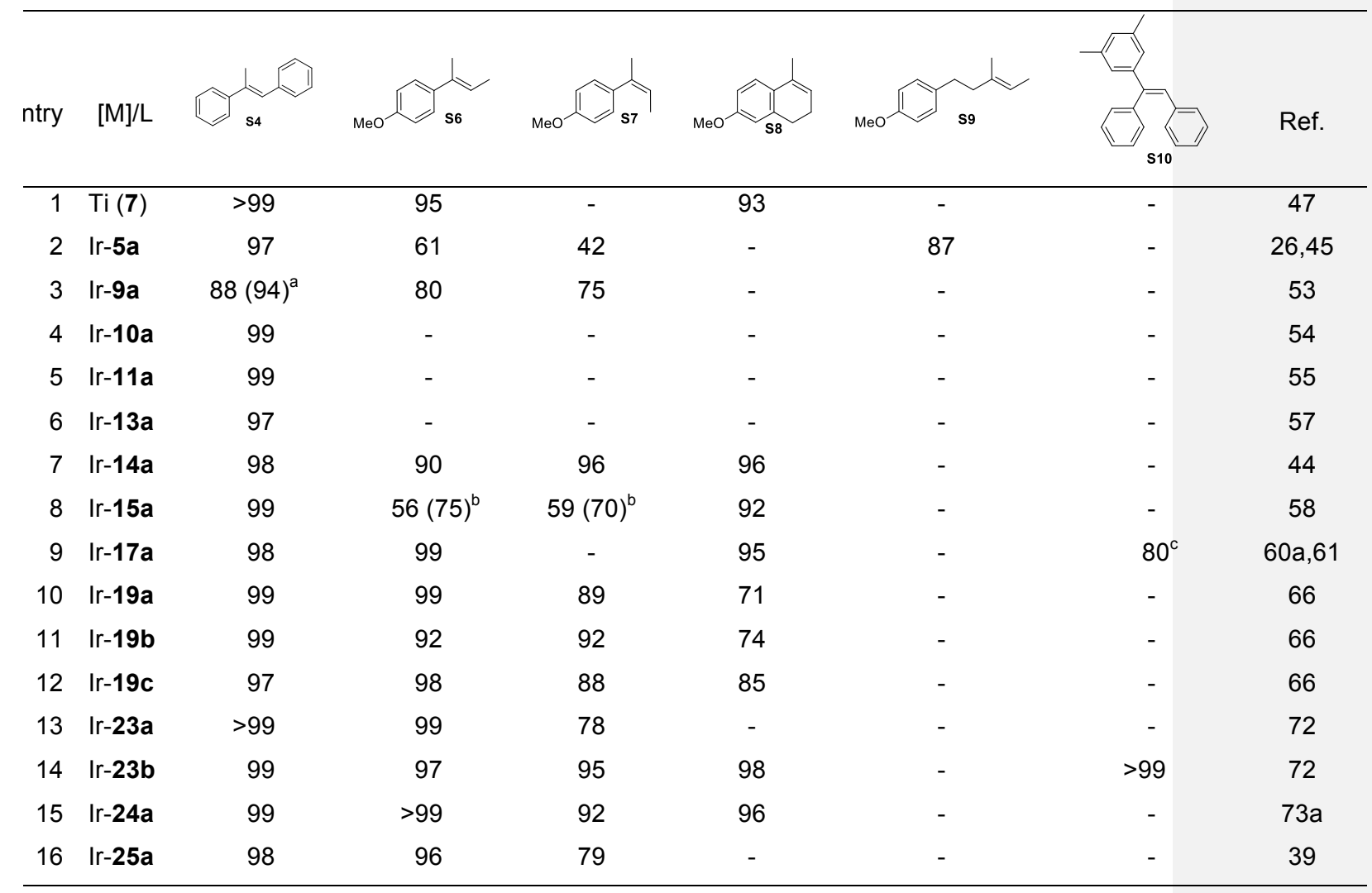




\begin{tabular}{|c|c|c|c|c|c|c|c|c|}
\hline 17 & Ir-28a & 96 & - & - & - & - & - & 75 \\
\hline 18 & $\mid r-31 a$ & 97 & 87 & 90 & - & - & - & 77 \\
\hline 19 & Ir-32a & $>99$ & $>99$ & 98 & $92(99)^{d}$ & 95 & - & $79 a-b, 45$ \\
\hline 20 & Ir-38 & 95 & - & - & 92 & - & - & 84 \\
\hline 21 & Ir-40a & 94 & $81(90)^{\mathrm{e}}$ & 88 & 91 & - & - & 86 \\
\hline 22 & Ir-41a & $93(98)^{f}$ & 94 & - & - & - & $>99^{c}$ & 61,87 \\
\hline 23 & Ir-42a & $>99$ & 96 & - & 94 & - & $94^{c}$ & 61,89 \\
\hline 24 & Ir-45a & 98 & 99 & 90 & 99 & - & - & 92 \\
\hline 25 & Ir-58a & 99 & 99 & 94 & 86 & - & 99 & 102 \\
\hline 26 & $\mid \mathrm{r}-61 \mathrm{a}$ & 98 & - & - & - & - & - & $103 a$ \\
\hline 27 & $\mid \mathrm{Ir}-61 \mathrm{~b}$ & 99 & - & - & - & - & - & $103 a$ \\
\hline
\end{tabular}

${ }^{a}$ Using ligand 9b. ${ }^{b}$ Using ligand $15 b .{ }^{c}$ With substrate 1-(1,2-diphenyl-vinyl)-4-methylbenzene. ${ }^{d}$ Using ligand bearing bulky $2,4,6$-tri-Me-Ph as $\mathrm{R}^{2}$-substituent. ${ }^{\mathrm{e}}$ Using ligand 40b. ${ }^{f}$ Using ligand $41 \mathrm{~b}$.

\section{Phosphinite-Oxazoline Ligands}

Two families of phosphinite-oxazoline ligands have been developed for Ircatalyzed asymmetric hydrogenation. Phosphinite-oxazolines 19 (Figure 4, $\mathrm{R}^{1}$ $=\mathrm{Ph}, \mathrm{o}-\mathrm{Tol}, \mathrm{Cy}, \mathrm{R}^{2}={ }^{\mathrm{t}} \mathrm{Bu}, \mathrm{Ph}$, ferrocenyl, 2-Naph; $\mathrm{R}^{3}=\mathrm{H}, \mathrm{Me}, 3,5-\mathrm{Me}_{2}-\mathrm{Ph}$ and $\mathrm{R}^{4}=\mathrm{Me},{ }^{\mathrm{i}} \mathrm{Pr},{ }^{\mathrm{i}} \mathrm{Bu}, \mathrm{Bn}$ ) constitute one of the most effective ligands for this transformation $^{66}$ and the presence of a second stereocenter in the oxazoline moiety $\left(R^{3}=\mathrm{Me}\right)$ affects enantioselectivity. ${ }^{66 \mathrm{~b}}$ Enantioselectivities up to $99 \%$ for a range of $E$-isomers and up to $92 \%$ for Z-isomers were achieved. In general, the best enantioselectivities were achieved with ligands containing a methyl substituent at $R^{3}$, a benzyl substituent at $R^{4}$ and a phenyl at $R^{1}$. However, the appropriate substituent at the oxazoline and the configuration of the $\mathrm{R}^{3}$ substituent depends on the substrate to be reduced. Thus, for $E-$ trisubstitued olefins ee's are best with ligands 19a (Figure 4; Table 1, entry 10) and 19b (Table 1, entry 11), while for Z-olefins $\mathbf{S 7}$ and $\mathbf{S 8}$ the highest enantioselectivities were achieved using ligands $19 b$ and 19c, respectively (Table 1, entries 11-12). These ligands not only provided excellent enantioselectivities in the hydrogenation of a broad range of both $E$ - and $Z$ trisubstituted olefins but also in the reduction of $\alpha, \beta$-unsaturated esters ${ }^{66}$ and a limited range of more challenging terminal olefins (vide infra). ${ }^{67}$ It should be 
noted that these catalysts work efficiently in propylene carbonate as an environmental friendly solvent and this allowed the Ir-catalysts to be reused while still maintaining the excellent enantioselectivities. ${ }^{68}$

The second family of phosphinite-oxazoline ligands 20 (Figure $4, R^{1}=$ $\mathrm{Ph}, \mathrm{o}-\mathrm{Tol}, \mathrm{R}^{2}={ }^{\mathrm{i}} \mathrm{Pr},{ }^{\mathrm{t}} \mathrm{Bu}$ ) is based on ligands 19 in which the alkyl chain is bonded to carbon 2 instead of carbon 4 of the oxazoline moiety, which shifts the chirality from the alkyl chain to the oxazoline substituent. ${ }^{69}$ The scope of these ligands is narrower in comparison with the phosphinite-oxazoline ligands 19 but they are complementary. Ligands 20 provided high enantioselectivities for allylic alcohols (ee's up to $97 \%$ ) and alkenes bearing heteroaromatic substituents (ee's up to $99 \%$ ), for which the privileged ligands 19 provided moderate enantioselectivities (vide infra).

\section{Phosphoroamidite/Phosphite-Oxazoline Ligands}

Despite the advantage of phosphite/phosphoroamidite ligands in asymmetric catalysis, ${ }^{70}$ only a few of these ligand-types have been applied in Ir-catalyzed asymmetric hydrogenation. The first reports were based on the use of chiral 1,2-bis-sulfonylamines and TADDOL to synthesize chiral phosphoroamiditeoxazolines 21 and phosphite-oxazolines 22, respectively (Figure 4, 21; $\mathrm{R}^{1}=$ $\mathrm{Ph}, \mathrm{p}$-Tol, $\mathrm{Cy}, 3,5-\mathrm{Xyl}-\left(\mathrm{CH}_{2}\right)_{4}, \mathrm{R}^{2}=\mathrm{SO}_{2}-\mathrm{R}$, 3-OMe-Ph, 4-OMe-Ph, 4- ${ }^{\mathrm{t}} \mathrm{Bu}-\mathrm{Ph}, 4-$ $\mathrm{Ph}-\mathrm{Ph}, 2-\mathrm{Naph}, \mathrm{R}^{3}={ }^{\mathrm{t}} \mathrm{Bu}, \mathrm{Ph}$ and 22; $\left.\mathrm{R}=\mathrm{Ph},{ }^{\mathrm{t}} \mathrm{Bu}\right) .{ }^{71}$ However, their substrate range limitation was higher and enantioselectivities and activities lower than their related phosphinite/phosphine-oxazoline ligands (i.e. 14, 19 and 20). They also required higher catalyst loadings $(4 \mathrm{~mol} \%)$ and higher pressures (100 bar) to achieve full conversions.

The first successful application of phosphite-oxazoline ligands for this process was reported in 2008. Pyranoside phosphite-oxazoline ligands 23 (Figure 4, $\mathrm{R}^{3}=\mathrm{Me},{ }^{\mathrm{t}} \mathrm{Bu},{ }^{\mathrm{i}} \mathrm{Pr}, \mathrm{Ph}$ and $\mathrm{Bn}$ ), derived from D-glucosamine, provided excellent enantioselectivities in the hydrogenation of a wide range of $E$ - and Z- trisubstituted olefins, including 4-methyl-1,2-dihydronaphthalenes and triarylsubstituted alkenes (Table 1 , entries 13 and 14 ). ${ }^{72}$ The best enantioselectivities were obtained with ligands that contain a phenyl oxazoline substituent and either an ortho disubstituted trimethylsilyl biphenyl phosphite 
moiety (for $E$-isomers, ee's up to $99 \%$; ligand $23 a$, entry 13 ) or a tetra tertbutyl biphenyl phosphite moiety (for Z-isomers and triarylsubstituted alkenes, ee's up to $98 \%$ and $>99 \%$, respectively; ligand $23 \mathbf{b}$, entry 14). The effectiveness of this ligand family extends to the use of more challenging 1,1disubstituted olefins and also to the use of olefins containing a neighboring polar group (vide infra). DFT calculations on this system agree with an $\operatorname{Ir}(I I / \mathrm{V})$ catalytic cycle with migratory insertion of a hydride as the selectivitydetermining step (vide supra).

Biaryl phosphite-oxazoline ligands 24 (Figure 4, $\mathrm{R}^{3}=\mathrm{Ph}, 4-\mathrm{Me}-\mathrm{Ph}, 4-$ $\mathrm{CF}_{3}-\mathrm{Ph} ; \mathrm{R}^{4}=\mathrm{H}, \mathrm{Me}$ and $\left.\mathrm{R}^{5}=\mathrm{H}, \mathrm{Me}\right)$, which are based on previous phosphinite-oxazoline ligands 19 , have been successfully applied in the hydrogenation of a range of $E$ - and Z-trisubstituted olefins. ${ }^{73}$ The results indicated that introducing a biaryl-phosphite moiety in the ligand design was highly advantageous in terms of catalytic activity and substrate versatility. Therefore, these ligands provided higher enantioselectivities and activities for a wider range of range of alkenes, including $E$ - and Z-trisubstitued olefins (ee's up to $>99 \%$ for $E$-isomers and up to $96 \%$ for Z-isomers; Table 1, entry 15), 1,1-disubstituted alkenes and alkenes containing a neighboring polar group (vide infra). The highest enantioselectivities for trisubstituted olefins were achieved with ligand 24a (Figure 4), which contains bulky tert-butyl groups at the $R^{1}$ and $R^{2}$ positions of the biaryl phosphite moiety, a phenyl group at the oxazoline $\left(R^{3}\right)$, a hydrogen at $R^{4}$ and methyl substituents at the $R^{5}$ positions (entry 15$)$.

\section{Carbene-Oxazoline Ligands}

Ligands 25 (Figure 4, $\mathrm{R}^{1}={ }^{\mathrm{t}} \mathrm{Bu}, \mathrm{CHPh}_{2}, \mathrm{Cy}, 1-\mathrm{Ad}, 2,4,6-\mathrm{Me}_{3}-\mathrm{Ph}, 2,6-\mathrm{Pr}_{2}-\mathrm{Ph}$ and $\mathrm{R}^{2}=1-\mathrm{Ad},{ }^{\mathrm{t}} \mathrm{Bu}, \mathrm{Bn}, \mathrm{Ph}$ ), in which the phosphine group of ligands 9 has been replaced by a carbene moiety, were evaluated as ligands for Ircatalyzed asymmetric hydrogenation in 2003. ${ }^{39}$ The ligands were successfully applied in the reduction of a range of $E$-trisubstituted (ee's up to $98 \%$; Table 1 , entry 16) and Z-trisubstituted olefins (ee's up to $79 \%$; Table 1, entry 16). This ligand library has also provided excellent enantioselectivities with substrates containing neighboring polar groups, which has been used in the synthesis of 
valuable chiral intermediates (vide infra). The results, which are comparable to those obtained with ligands 9 , indicated that the presence of a sterically hindered 1-adamanthyl group in the oxazoline and an ortho-disubstituted aryl group in the carbene moiety is necessary to achieve the highest levels of enantioselectivity (ligand 25a, entry 16). In certain cases the carbene group also allowed a decrease in hydrogen pressure to 1 bar (i.e. in the reduction of Z-2-(4-methoxyphenyl)-2-butene S7). These excellent results prompted the development of other carbene-based ligands (ligands 26 and 27) ${ }^{74}$ Ligands 26 (Figure 4; $R^{1}={ }^{i} \operatorname{Pr}$ and $R^{2}={ }^{t} \mathrm{Bu}$ ) and 27 (Figure 4; $\mathrm{R}^{1}=\mathrm{Me}$, ${ }^{\mathrm{i}} \mathrm{Pr},{ }^{\mathrm{t}} \mathrm{Bu}, 2,4,6$ $\mathrm{Me}_{3}-\mathrm{Ph}$, Neopentyl and $\mathrm{R}^{2}={ }^{\mathrm{t}} \mathrm{Bu}, \mathrm{Ph}, 1-\mathrm{Ad}, 2,6-\mathrm{Me}_{2}-\mathrm{Ph}$ ) were designed by replacing the P-moiety in $\mathbf{1 9}$ and $\mathbf{5}$ respectively but afforded lower levels of enantioselectivity.

\subsubsection{Phosphorus-Pyridine Ligands}

In order to mimic the coordination sphere of Crabtree's catalyst, Knochel's group prepared a new kind of chiral N,P-ligand that incorporates a pyridine moiety as a $\mathrm{N}$-donor. They developed phosphine-pyridine ligands 28 (Figure 5; $\mathrm{R}^{1}=\mathrm{Ph}, \mathrm{Cy} ; \mathrm{R}^{2}=\mathrm{H}, \mathrm{Ph} ; \mathrm{R}^{3}=\mathrm{H} ; \mathrm{R}^{2}-\mathrm{R}^{3}=\mathrm{CH}-\mathrm{CH}=\mathrm{CH}-\mathrm{CH}$ ), synthesized from readily available $\mathrm{D}-(+)$-camphor, for the hydrogenation of trisubstituted olefins and obtained moderate-to-high enantioselectivities in the reduction of $E$ stilbenes (ee's up to $96 \%$; Table 1, entry 17) ${ }^{75}$ The best enantioselectivities were achieved with the ligand that contains a diphenylphosphanyl group and a quinoline moiety (ligand $\mathbf{2 8 a}$, entry $\mathbf{1 7}$ ). 


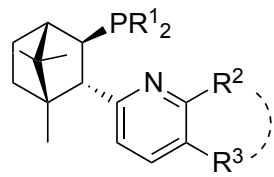

28<smiles>[R12]OC([R])c1ccccn1</smiles>

31<smiles></smiles>

35

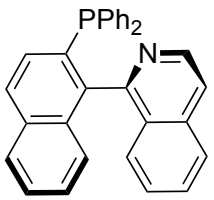

38<smiles>[R12]O[C@H]1CCCC[C@H]1c1cccc([R])n1</smiles>

29<smiles>[R12]OC1=[Y4]Cc2ccc([R])nc21</smiles>

32

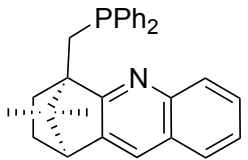

36<smiles>[R]OC(CPc1ccccc1)c1ccccn1</smiles>

30

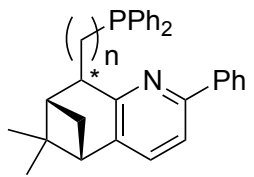

$33 \mathrm{n}=1$

$34 \mathrm{n}=0$<smiles>CC1c2ccc(-c3ccccc3Pc3ccccc3)nc2C2(C)CCC1C2</smiles>

37

$$
\begin{aligned}
& \text { 28a } \mathrm{R}^{1}=\mathrm{Ph} \quad \mathrm{R}^{2}-\mathrm{R}^{3}=\mathrm{CH}=\mathrm{CH}-\mathrm{CH}=\mathrm{CH} \\
& \text { 31a } R^{1}={ }^{t} B u \quad R^{2}={ }^{t} B u \\
& \text { 31b } R^{1}=0 \text {-Tol } R^{2}={ }^{t} B u \\
& \text { 32a } \mathrm{n}=1 \quad \mathrm{R}^{1}=0 \text {-Tol } \mathrm{R}^{2}=\mathrm{Ph} \\
& \text { 32b } n=1 \quad R^{1}={ }^{\mathrm{t}} \mathrm{Bu} \quad \mathrm{R}^{2}=\mathrm{Ph}
\end{aligned}
$$

Figure 5 Phosphorus-pyridine ligands developed for the Ir-catalyzed asymmetric hydrogenation of trisubstituted olefins.

Phosphinite-pyridine ligands 29 (Figure 5, $\mathrm{R}^{1}=\mathrm{Ph}, \mathrm{o}-\mathrm{Tol} ; \mathrm{R}^{2}=\mathrm{H}, \mathrm{Me}$, 'Pr) are related to $\mathbf{2 8}$ but the camphor moiety is replaced by a cyclohexanol group. ${ }^{76}$ This modification led to lower enantioselectivities in the reduction of E-stilbenes (ee's up to 93\%), indicating the importance of the bulky camphor component for high enantioselectivity. 
Phosphine-pyridine ligands 30 (Figure 5$)^{77}$ contain several silyl ether substituents $\left(\mathrm{R}=\mathrm{Si}\left({ }^{\mathrm{t}} \mathrm{Bu}\right) \mathrm{Me}_{2}, \mathrm{Si}\left({ }^{(} \mathrm{Pr}\right)_{3}, \mathrm{Si}\left({ }^{\mathrm{t}} \mathrm{Bu}\right) \mathrm{Ph}_{2}\right)$ at the alkyl chain bridge and were prepared with the aim to increase the rigidity and to provide a similar steric environment as the one in PHOX ligands 5. Despite this, the catalytic performance of $[\operatorname{Ir}(\operatorname{cod}) 30]\left[\mathrm{BAr}_{\mathrm{F}}\right]$ was inferior to that of the PHOX ligands. In the same report the phosphinite version of 30 (ligands 31; Figure $5, \mathrm{R}^{1}=\mathrm{Ph}$, o-Tol, $\mathrm{Cy},{ }^{\mathrm{t}} \mathrm{Bu}$ and $\mathrm{R}^{2}=\mathrm{Me},{ }^{\mathrm{t}} \mathrm{Bu}, \mathrm{Ph}, \mathrm{CPh}_{3}$ ) was also tested. ${ }^{77}$ The presence of a phosphinite moiety had a positive effect in terms of catalytic performance; i.e. the enantiomeric excess in the hydrogenation of trans-a-methylstilbene S4 increased from $88 \%$ to $97 \%$. The best enantioselectivities were obtained with ligand 31a that contains tert-butyl substituents at both the phosphinite $\left(R^{1}\right)$ and the alkyl backbone $\left(R^{2}\right)$ moieties (Table 1 , entry 18 ). Later, a series of phosphinite-pyridine ligands, related to 31 but with a (-)-menthol moiety at the $R^{2}$ position, were prepared. However these ligands were less enantioselective (ee's up to $80 \%$ in the reduction of trans-a-methylstilbene S4). ${ }^{78}$

A second generation of phosphinite-pyridine ligands 32 (Figure $5 ; R^{1}=$ $\mathrm{Ph}, \mathrm{o}-\mathrm{Tol}, \mathrm{Cy},{ }^{\mathrm{t}} \mathrm{Bu} ; \mathrm{R}^{2}=\mathrm{H}, \mathrm{Ph}, \mathrm{Me} ; \mathrm{R}^{3}=\mathrm{H}, \mathrm{Me}$ ), has also been developed with the aim of increasing the rigidity in the alkyl bridge moiety,. ${ }^{79}$ This ligand family gave excellent enantioselectivities for a wide range of olefins (ee's up to $>99 \%$; Table 1, entry 19) including purely alkyl trisubstituted ones. ${ }^{79 a-c}$ In general, the enantioselectivity was highest with a phenyl substituent at the $\mathrm{R}^{2}$ position and bulky substituents at the phosphinite moiety (ligand 32a and ligand 32b). To obtain excellent enantiocontrol in the reduction of 7-methoxy4-methyl-1,2-dihydronaphthalene $\mathbf{S 8}$, the introduction of a large aryl substituent (i.e. 2,4,6-tri-Me-Ph) at $R^{2}$ is necessary (Table 1 , entry 19). ${ }^{79 b}$ The utility of the catalytic system was demonstrated in the hydrogenation of $y$ tocotrienyl acetate to obtain $\mathrm{y}$-tocopherol, a principal component of vitamin $\mathrm{E}^{80}$ resulting in enantioselectivity $>98 \%$ for the $R R R$ enantiomer (Scheme 12a). ${ }^{45}$ Another synthetic application of Ir-32a can be found in the diastereoand enantioselective hydrogenation of farnesol stereoisomers (Scheme 12b). By changing the double bond's geometry these catalysts give access to the four stereoisomers of the product in high selectivity (diastereo- and enantioselectivity). ${ }^{2 d}$ See Chapter 5 for a detailed discussion on the asymmetric hydrogenation of allylic alcohols. 
(a)<smiles>CC(=O)Oc1cc2c(c(C)c1C)O[C@H](CC/C=C(\C)CC/C=C(\C)CCC=C(C)C)CC2</smiles><smiles>CC(=O)Oc1cc2c(c(C)c1C)O[C@@H](CCC[C@H](C)CCC[C@H](C)CCCC(C)C)CC2</smiles>

(b)<smiles>CC(C)=CCC/C(C)=C/CC/C(C)=C/CO</smiles>

Scheme 12 Hydrogenation of: (a) y-tocotrienyl acetate $\mathbf{S 1 2}$ and (b) farnesol isomers $\mathbf{S 1 3}$ using Ir-32 catalysts.

The phosphine- and phosphinite-pyridine ligands 33 and 35 (Figure 5) were prepared to increase the rigidity of ligands $\mathbf{3 0}$ and $\mathbf{3 1}$ by introducing an enantiomerically pure bicyclic moiety. ${ }^{81}$ These ligands, derived from readily available a-pinene, showed high enantioselectivities (ee's up to $97 \%$ ) but poor activities. A modification of ligand $\mathbf{3 3}$ in which the phosphine group is attached directly to the pinene moiety to form a five-membered chelate ring, yielded ligand 34 (Figure 5). ${ }^{82}$ Ligand $\mathbf{3 4}$ proved to be more effective in the reduction of enol phosphonates (ee's up to $90 \%$, vide infra) rather than aryl/alkyl trisubstituted olefins (ee' up to $37 \%$ ). Chelucci and coworkers increased the range of phosphine-pyridine ligands derived from a-pinene with the synthesis of compounds $\mathbf{3 6}$ and $\mathbf{3 7}$ (Figure 5). ${ }^{83}$ However, these ligands provided lower enantioselectivities than ligand $\mathbf{3 3}$ (ee's up to $94 \%$ in the reduction of trans- $\alpha$ methylstilbene S4). 
In 2007, the phosphine-quinoline ligand 38 (Figure 5), with axial chirality, was applied in the Ir-catalyzed hydrogenation of minimally functionalized trisubstituted olefins with promising results (ee's up to 95\% for both E- and Z-isomers; Table 1, entry 20). ${ }^{84}$ The concept of axial chirality was also used in the spiro phosphine-quinoline ligand 39 (Figure 5). ${ }^{85}$ This ligand showed low enantioselectivities in the Ir-hydrogenation of trans- $\alpha$ methylstilbene $\mathbf{S 4}$ (ee's up to $48 \%$ ee).

\subsubsection{Phosphorus/Carbene-Other-Nitrogen-Donor Ligands}

Although most of the ligands developed for the Ir-catalyzed asymmetric hydrogenation of minimally functionalized olefins contain either an oxazoline or a pyridine, other nitrogen donor groups have been successfully used in this process. The first application of other types of ligands in Ir-hydrogenation was reported with phosphine-imidazoline ligands $\mathbf{4 0}$ (Figure $6, \mathrm{R}^{1}=\mathrm{Ph}, \mathrm{o}-\mathrm{Tol} ; \mathrm{R}^{2}=$ 'Pr, ${ }^{\mathrm{t}} \mathrm{Bu} ; \mathrm{R}^{3}={ }^{\mathrm{i}} \mathrm{Pr},{ }^{\mathrm{t}} \mathrm{Bu}, \mathrm{Cy}, \mathrm{Ph}, \mathrm{Bn}, p$-Tol). ${ }^{86}$ One advantage of the imidazoline moiety over the oxazoline is the possibility to introduce a new substituent $R^{3}$ at the nitrogen that could serve as a linker to attach the ligand to a solid support. Enantioselectivities up to $94 \%$ were achieved for a range of standard $E$ - and Z-aryl/alkyl trisubstituted olefins using [Ir(cod)40a][BAr $\left.r_{F}\right]$ as precatalyst (Table 1, entry 21). In several cases, higher enantiomeric excesses were obtained than with analogous phosphine-oxazoline PHOX ligands (i.e. enantioselectivities for Z-2-(4-methoxyphenyl)-2-butene $\mathbf{S 7}$ increased from $42 \%$ to $88 \%$ ee). The best enantioselectivities were achieved with ligands containing bulky substituents at both $R^{1}$ and $R^{2}$ positions, while the substituent at $R^{3}$ had to be optimized for each substrate (i.e. ligands $40 a$ and 40b, Table 1, entry 21). Zwitterionic versions of these iridium complexes were prepared by introducing an anionic moiety at the $\mathrm{R}^{3}$ position of the imidazole group. ${ }^{51}$ However, the presence of the anionic derivatization has a negative influence on the asymmetric induction of the iridium complex. 


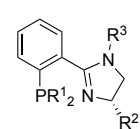

40

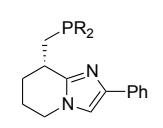

41

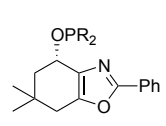

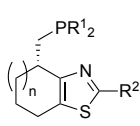

43
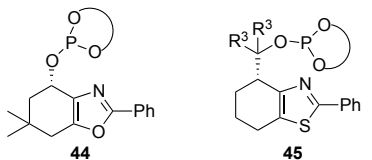

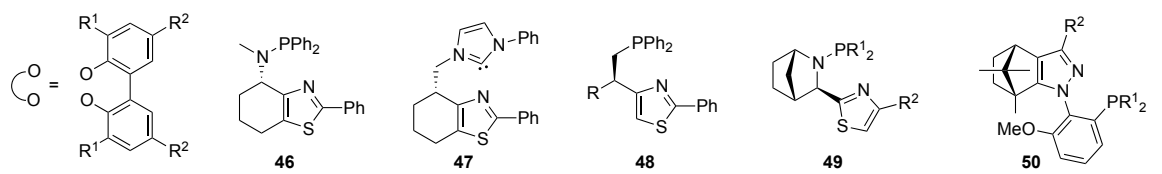

$$
\underbrace{\mathrm{PR}_{2}{ }_{2}}_{51}
$$

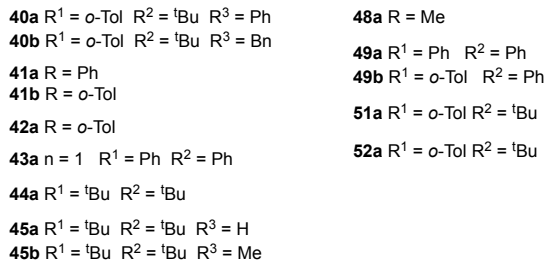

48a $R=M e$

49a $R^{1}=P h \quad R^{2}=P h$ $49 b R^{1}=o-$ Tol $R^{2}=P h$ $51 a R^{1}=0-$ Tol $R^{2}=$ tBu 52a $R^{1}=o-$ Tol $^{2}={ }^{\text {tBu }}$

Figure 6 Phosphorus/carbene-other nitrogen donor ligands applied in the Ir-catalyzed asymmetric hydrogenation of aryl/alkyl trisubstituted olefins.

Phosphine-imidazole ligands 41 (Figure 6; $\mathrm{R}=\mathrm{Ph}, \mathrm{o}-\mathrm{Tol}, 3,5$-diMe-Ph) have been used for the Ir-catalyzed hydrogenation of unfunctionalized olefins and gave high enantioselectivities for $E$-aryl/alkyl trisubstituted olefins (ee's up to $98 \%$; Table 1, entry 22$)^{61,87}$ and cyclic dienes (ee's up to $>99 \%$ for the trans isomer), ${ }^{88}$ but was only moderate in the reduction of Z-olefins (ee's up to $72 \%) .{ }^{87}$ In general, enantioselectivities were best for ligand $41 a$, containing a bisphenylphosphanyl group (Table 1, entry 22). However, the highest enantioselectivity in the reduction of trans-a-methylstilbene $\mathbf{S 4}$ was achieved with ligand $\mathbf{4 1 b}$ containing a bis(o-tolyl)phosphanyl group (Table 1, entry 22). Phosphinite-oxazoles 42 (Figure 6; $\mathrm{R}=\mathrm{Ph}, \mathrm{o}-\mathrm{Tol}, 3,5-\mathrm{diMe}-\mathrm{Ph})^{89}$ and phosphine-thiazoles 43 (Figure 6, $\mathrm{R}^{1}=\mathrm{Ph}, \mathrm{o}-\mathrm{Tol} ; \mathrm{R}^{2}=\mathrm{H}, \mathrm{Ph}$ ), related to ligands 41 , have also been evaluated. ${ }^{90}$ Both families of ligands have proven valuable in hydrogenation of minimally functionalized olefins, including those containing a neighboring polar group (vide infra). These ligands provided excellent enantioselectivities in the hydrogenation of both $E$ - and Z-aryl/alkyl 
trisubstituted olefins (ee's up to $>99 \%$ for $E$-substrates and up to $94 \%$ for $Z$ substrates; Table 1, entry 23) ${ }^{89-90}$ Ligands $\mathbf{4 3}$ have also proved to be optimal for the hydrogenation of cyclic alkenes, ${ }^{91}$ dienes (ee's up to $97 \%$ for the trans product in the hydrogenation of $\mathbf{S 1 1})^{88}$ and 1,1-diaryl trisubstitued olefins (ee's up to $>99 \%$ ). ${ }^{61}$ Interestingly, while oxazole ligands gave the highest enantioselectivities with bulky ortho-tolyl substituents at the phosphinite group (ligand 42a), thiazole ligands performed best with a diphenylphosphanyl group (ligand 43a). The authors found that the results could be explained by using a simple quadrant model (See section 8 for a detailed discussion).

Later, several modifications of these ligands were developed, including the replacement of the phosphine/phosphinite moieties by $\mathrm{N}$-phosphine, carbene and phosphite groups as well as modification in the ligand backbone. In this respect, biaryl phosphite containing ligands $\mathbf{4 4}$ and $\mathbf{4 5}$ (Figure 6, $\mathrm{R}^{3}=$ $\mathrm{Me}$ or $\mathrm{H}$ ), related to the successful ligands 42 and 43 , have also provided excellent enantioselectivities for both $E$ - and Z-trisubstituted olefins (Table 1, entry 24). ${ }^{92}$ The introduction of a biaryl phosphite moiety increases the substrate scope (i.e. ee's increased up to $99 \%$ in the reduction of 4-methyl1,2-dihydronaphthalene). In general phosphite-thiazole ligands 45 provided higher enantioselectivities than related phosphite-oxazole ligands 44 . For ligands 45 the best enantioselectivities were achieved using ligand $45 a$ (Figure 6), containing bulky tert-butyl groups at the ortho and para positions of the biphenyl phosphite moiety and hydrogens at the $\mathrm{R}^{3}$ positions. Related $\mathrm{N}$ phosphine-thiazole ligand 46 has been successfully applied in the hydrogenation of 1,1-diarylsubstitued olefins, providing comparably excellent enantioselectivities (ee's up to $>99 \%$ ) to that of phosphine-thiazole ligands 43. ${ }^{61}$ However, the replacement of the phosphine group in ligands $\mathbf{4 3}$ by a carbene moiety (Figure 6, ligand 47) led to lower enantioselectivities (ee's up to $90 \%$ ). ${ }^{93}$ Ligands $\mathbf{4 8}$, in which the rigid cyclic backbone in ligands $\mathbf{4 3}$ were eliminated, were less successful (Figure 6, R= Me, Bn, allyl). ${ }^{94}$ Recently, the $\mathrm{N}$-phosphine-thiazole ligands 49 (Figure 6, $\mathrm{R}^{1}=\mathrm{Ph}, \mathrm{o}-\mathrm{Tol} ; \mathrm{R}^{2}=\mathrm{Me},{ }^{\mathrm{t}} \mathrm{Bu}, \mathrm{Ph}$ ) with a more rigid bicyclic ligand backbone were prepared and evaluated. ${ }^{95}$ High enantioselectivities were achieved in the reduction of E-trisubstituted olefins (ee's up to $97 \%$ ) but enantioselectivities for Z-olefins decreased to $83 \%$. 
Other ligands in this class, $\mathbf{5 0},{ }^{96} \mathbf{5 1},{ }^{97}$ and $\mathbf{5 2}^{98}$ (Figure 6) have also been tested in the hydrogenation of trans- $\alpha$-methylstilbene and other alkenes, but did not produce very high ee's.

\subsubsection{Other Ligands}

The Ir-catalyzed asymmetric hydrogenation of minimally functionalized olefins has been dominated by the use of chiral bidentate N,P-ligands. In 2009, a new concept was reported for the development of chiral versions of Crabtree's catalyst in which the chirality is introduced by using only a chiral ferrocene monodentate ligand 53 (Figure 7). ${ }^{99}$ The use of $[\operatorname{lr}(\operatorname{cod})(53)(\mathrm{Py})]\left[B \mathrm{Br}_{\mathrm{F}}\right]$ catalyst precursor proved to be active in the hydrogenation of several trisubstituted olefins, but enantioselectivities were poor (ee's up to $12 \%$ ). 


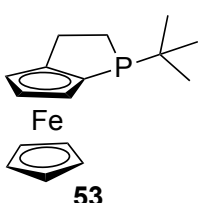

$\overbrace{\mathrm{N}}^{\mathrm{N}} \cdot \overbrace{\mathrm{PR}^{2}{ }_{2}}^{\cdot \mathrm{R}^{1}}$

56

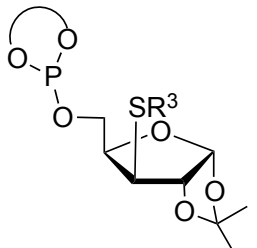

59<smiles>[R]N1CCN(C(CPc2ccccc2)C(C)C)C1</smiles>

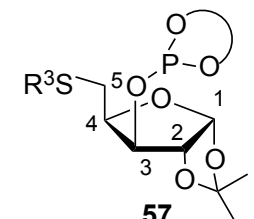

57<smiles>CC(C)N1[C]N(CC(Oc2ccccc2)c2ccccc2)C=C1</smiles>

55

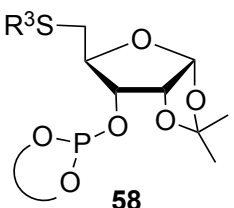<smiles>[R3]C1C(COP2OCCCO2)OC2OC(C)(C)OC21</smiles>

60<smiles>[R12]CC1CCCN1C([R])=O</smiles>

61<smiles>[R]c1cc([R])c(O)c(-c2cc([R])cc([R])c2O)c1</smiles>

58a Phosphite $=\mathbf{X} \quad \mathrm{R}^{1}={ }^{\mathrm{t}} \mathrm{Bu} \quad \mathrm{R}^{2}={ }^{\mathrm{t}} \mathrm{Bu} \quad \mathrm{R}^{3}=2,6-\mathrm{Me}_{2}-\mathrm{Ph}$

58b Phosphite $=(R)-Z \quad \mathrm{R}^{3}=2,6-\mathrm{Me}_{2}-\mathrm{Ph}$

61a $\mathrm{R}^{1}={ }^{\mathrm{t}} \mathrm{Bu} \quad \mathrm{R}^{2}=\mathrm{CPh}_{3}$

61b $R^{1}=$ Cy $R^{2}=1-A d N H$

Figure 7 Other ligands applied in the asymmetric Ir-catalyzed hydrogenation of trisubstituted olefins.

Since most of the research in the design of new chiral ligands for Ircatalyzed asymmetric hydrogenation has been focused on developing chiral mimics of Crabtree's catalyst, the possibility of changing the nature of the $\mathrm{N}$ donor atom in these heterodonor ligands hasn't been considered to a large extent. In 2006, the application of phosphine/phosphinite carbene ligands 54 and 55 (Figure 7; R= Me, 'Pr, Mes) in the Ir-catalyzed hydrogenation of both $E$ - and Z-aryl/alkyl trisubstituted olefins was reported to give low activities and 
enantioselectivities (ee's up to $63 \%$ ). ${ }^{100}$ Later phosphine-carbene ligands 56 (Figure 7; $\mathrm{R}^{1}=\mathrm{Me}$, Et, ' $\mathrm{Pr} ; \mathrm{R}^{2}=2,4,6-\mathrm{Me}_{3}-\mathrm{Ph}, 2,6-{ }^{\prime} \mathrm{Pr}_{2}-\mathrm{Ph}$ ) that formed a larger chelate ring-size upon coordination to Ir, provided higher activities, but enantioselectivities were still moderate. ${ }^{101}$

A breakthrough in the development of chiral non-N-containing ligands for this transformation came with the development of a highly modular phosphitethioether ligand library (ligands 57-60; Figure 7, ${ }^{3}=\mathrm{Me},{ }^{\mathrm{i}} \mathrm{Pr}$, ${ }^{\mathrm{t}} \mathrm{Bu}, \mathrm{Ph}, 2,6-\mathrm{Me}_{2}-$ $\mathrm{Ph}$ ), which provides excellent activities and enantioselectivities for a wide range of $E$ - and Z- trisubstituted olefins, including the more challenging 4methyl-1,2-dihydronaphthalenes and 1,1-diaryl trisubstituted olefins (ee's up to $99 \%$; Table 1, entry 25). These ligands consist of four main ligand backbones produced by systematically varying the position of the thioether group at either C-3 or C-5 of the furanoside backbone and the configuration of C-3. The introduction of a thioether moiety in the ligand design may be beneficial because: (i) the $S$ atoms become a stereogenic center when coordinated to the metal, which moves the chirality closer to the metal, and (ii) the thioether group is more stable than the oxazoline moiety. The best results were obtained with ribofuranoside ligands 58 containing a bulky 2,6-Me $2-\mathrm{Ph}$ thioether group in the C-5 position and either a tetra tert-butyl biphenyl phosphite moiety (ligand 58a, Figure 7 ) or an $R$-enantiopure 5,5',6,6'tetramethyl-3,3'-di-tert-butyl-1,1'-biphenyl-2,2'-diol (ligand 58b) in the C-3 position of the furanoside backbone. ${ }^{102}$

Proline-based chiral $\mathrm{P}, \mathrm{O}$ ligands 61 (Figure $7, \mathrm{R}^{1}=\mathrm{Ph},{ }^{\mathrm{t}} \mathrm{Bu}, \mathrm{Cy}, \mathrm{o}-\mathrm{Tol}$ and $\mathrm{R}^{2}={ }^{\mathrm{t}} \mathrm{Bu}, 1-\mathrm{Ad}, \mathrm{CPh}_{3}, 1 \mathrm{Ad}-\mathrm{NH}, \mathrm{MesNH}, \mathrm{CPh}_{3} \mathrm{NH}$ ) have also been used in Ir-catalyzed asymmetric hydrogenation. ${ }^{103}$ Phosphines bearing either a bulky amide (ligand 61a; Table 1, entry 26) or urea groups (ligand 61b; Table 1, entry 27) at the pyrrolidine $\mathrm{N}$-atom, formed efficient Ir-catalysts for the asymmetric hydrogenation of several minimally functionalized olefins (ee's up to $99 \%$ in the hydrogenation of trans a-methylstilbene S4).

\subsection{1,1-Disubstituted Alkenes}

Disubstituted terminal alkenes are a challenging substrate class when compared to the more widely investigated trisubstituted olefins. There are two 
reasons for this. The first is that in the absence of a third substituent on the double bond, the catalyst has to distinguish solely between the two alkyl/arylsubstituents $R^{1}$ and $R^{2}$ for enantiodiscrimination (Scheme 13a). This is a more demanding task compared to distinguishing between hydrogen and an alkylor aryl-group as in the case of the trisubstituted alkenes. The second is that the terminal double bond can isomerize to form the more stable internal alkene, which usually leads to the predominant formation of the other enantiomer of the hydrogenated product (Scheme 13b). Efficient catalytic systems for the asymmetric reduction of 1,1-disubstituted aryl-alkyl alkenes have been elusive until very recently. Next, we discuss the progress made in the asymmetric hydrogenation of minimally functionalized terminal olefins, beginning with the latest development in design, from the initial discovery of lanthanide catalytic precursors, through to the use of transition metaldiphosphine/iminophosphorane precursors, to the successful Ir-N,P catalytic systems.

(a)<smiles>[R]C(=C)[Y13]([H])=[V]</smiles>

One enantiomer Optical antipode (b)<smiles>[R]C=C(C)[R]C=CC</smiles>

One enantiomer Optical antipode

Scheme 13 Proposed reasons for the low enantioselectivities associated with the hydrogenation of terminal olefins.

The early approaches to tackle the asymmetric hydrogenation of disubstituted alkenes involved the use of chiral biscyclopentadienyl Smcomplexes $^{104}$ or Ru-diphosphine catalysts. ${ }^{105}$ In the first case, enantioselectivities up to $96 \%$ in the reduction of 2-phenyl-but-1-ene S14 (Table 2, entry 1) were achieved using $\left[\mathrm{Sm}(62)\left(\mathrm{CH}(\mathrm{TMS})_{2}\right)\right]$ catalyst precursor (Figure 8). However, due to the low temperatures $\left(-78{ }^{\circ} \mathrm{C}\right)$ required to achieve the highest levels of enantioselectivity and the low modularity of the catalytic system, ${ }^{104}$ the interest of using this type of complexes has 
diminished. In the second case, enantioselectivities up to $89 \%$ were reported in the hydrogenation of a range of 2-phenyl-2-but-1-enes (Table 2, entries 2, 8,10 and 22) using $\left[\mathrm{RuCl}_{2}(3)\right]_{\mathrm{n}} \cdot \mathrm{DMF}$ (Figure 8 ). ${ }^{17 \mathrm{c}}$ It should be noted that the use of other diphosphine ligands (i.e. Et-DuPhos or BINAP) were not effective. ${ }^{17 c}$

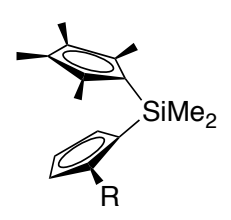

$62 \mathrm{R}=(-)-$ menthyl

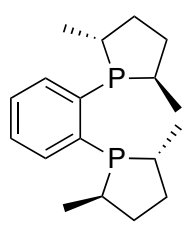

3

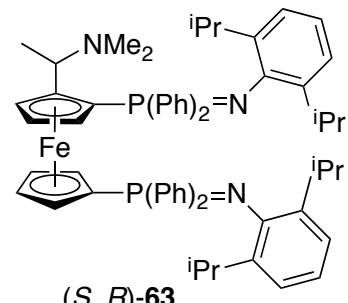

$(S, R)-63$

Figure 8 Ligands 62, 3 and 63 applied in the asymmetric hydrogenation of 1,1-disubstituted aryl/alkyl olefins.

An important discovery in this area was made by Pfaltz and co-workers when they successfully applied Ir-N,P catalytic systems for the hydrogenation of minimally functionalized trisubstituted olefins to terminal olefins. ${ }^{2 b, 2 d, e, 3 c, d} A$ complete screening of Ir-complexes containing highly modular phosphineoxazoline ligands 5 (Figure 3) and phosphinite-oxazoline ligands 19 (Figure 4) in the reduction of a range of 2-phenyl-2-but-1-enes indicated that the ligand parameters have an important effect on enantioselectivity. ${ }^{66-67}$ The enantioselectivities (ee's up to 94\%, Table 2, entries 9, 11, 15, 23, 41 and 42) were best with the Ir-catalytic system containing the basic cyclohexyl phosphinite-oxazoline derived from threonine 19a (Figure 4). These results surpass the enantioselectivities obtained using Ru-3 catalytic system (i.e. Table 2, entries 9 and 11 vs 8 and 10, respectively). Interestingly, the selectivity is highly pressure dependent in the Ir-catalyzed reduction of these terminal alkenes. Hydrogenation at atmospheric pressure of $\mathrm{H}_{2}$ gave significantly higher ee's than at higher pressures (ee increases from $58 \%$ to $94 \%$ when pressure is decreased from 50 bar to 1 bar). ${ }^{66}$ 
Table 2 Enantioselectivities achieved using selected ligands in the asymmetric hydrogenation of 1,1'-disubstituted aryl-alkyl alkenes

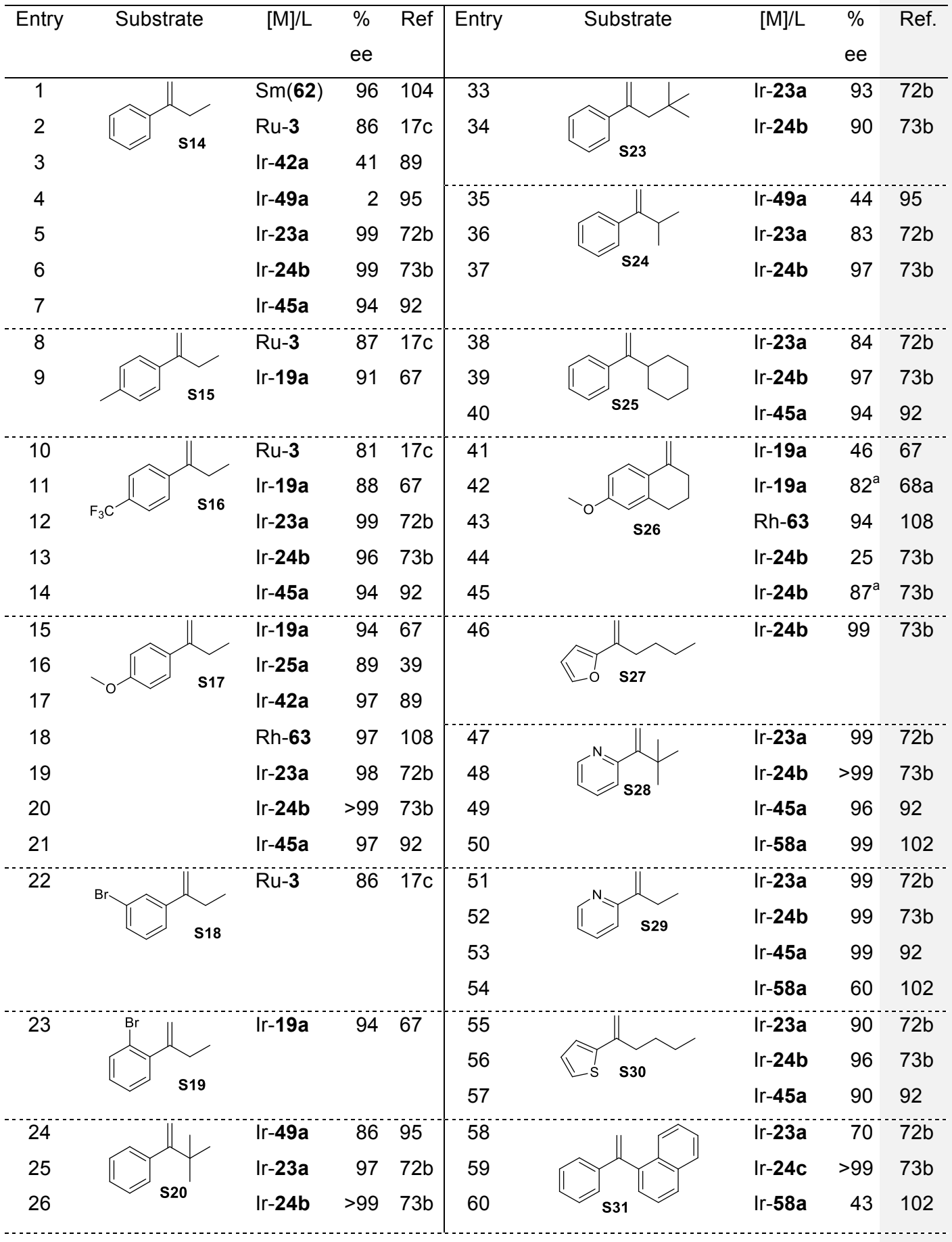




\begin{tabular}{|c|c|c|c|c|c|c|c|}
\hline 27 & $\mid r-58 a$ & 98 & 102 & & & & \\
\hline 28 & $\mid r-23 a$ & 90 & $72 \mathrm{~b}$ & 61 & $\mid r-23 a$ & 68 & $72 \mathrm{~b}$ \\
\hline 29 & $\mid r-24 b$ & 94 & $73 b$ & 62 & Ir-24c & 99 & $73 b$ \\
\hline 30 & Ir-58a & 62 & 102 & & & & \\
\hline 31 & $\mid r-23 a$ & 93 & $72 b$ & 63 & Ir-23a & 65 & $72 b$ \\
\hline 32 & Ir-24b & 93 & $73 b$ & 64 & $\mid r-24 d$ & 65 & $73 b$ \\
\hline
\end{tabular}

${ }^{a}$ Using PC as solvent

Later, Börner's group disclosed that Ir-19a catalyst is efficient when using propylene carbonate (PC) as an environmentally friendly alternative solvent to dichloromethane. ${ }^{68 a}$ Although reaction rates are lower in PC than in dichloromethane, the isomerization of the terminal double bond to the more stable internal alkene is also slower in PC than in dichloromethane. For example, the isomerization of 4-methylene-1,2,3,4-tetrahydronaphthalene S26 to 4-methyl-1,2-dihydronaphthalene is approximately three times slower in PC than in dichloromethane. Due to the suppressed isomerization, enantioselectivities increased from $46 \%$ to $82 \%$ in the reduction of $\mathbf{S 2 6}$ when using PC (Table 2, entries 41 vs 42). Another advantage of using PC as the solvent is that it allows catalysts to be repeatedly recycled by a simple twophase extraction with an apolar solvent (typically hexane). Catalyst Ir-19a could be reused up to five times with no significant losses in enantioselectivity, although the reaction time increased. ${ }^{68 a}$ This is probably due to the iridium catalyst partially passing into the hexane phase and/or the formation of inactive triiridium hydride clusters. ${ }^{23 b, 30}$

The catalyst precursors $[\operatorname{Ir}(\operatorname{cod}) 25]\left[\mathrm{BAr}_{\mathrm{F}}\right]$, containing $\mathrm{N}$-heterocyclic carbene-oxazoline ligands 25 (Figure 4) have been applied in the reduction of 2-(4-methoxyphenyl)-1-butene $\mathbf{S 1 7}$ (Table 2, entry 16). ${ }^{39}$ Enantioselectivities up to $89 \%$, comparable to those obtained using the Ru-3 catalytic system, were obtained using Ir-precursor containing ligand 25a (Figure 4). Interestingly, the Ir-25a catalytic system was also successfully applied in the asymmetric reduction of unfunctionalized 1,1-disubstituted dienes with enantioselectivities up to $87 \%$ and good diastereoselectivities (Figure 9). ${ }^{106}$ 


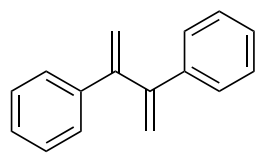

ent: meso \% ee $1.0: 2.9 \quad 87$

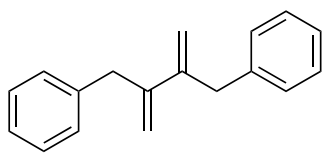

ent : meso \% ee

$1.0: 2.9 \quad 24$

Figure 9 Asymmetric hydrogenation of 1,1-disubstituted dienes using Ir25a catalyst.

The Ir-catalytic system containing phosphinite-oxazole 42a (Figure 6) has been used to hydrogenate 2-(4-methoxyphenyl)-1-butene $\mathbf{S 1 7}$ with enantioselectivities up to $97 \%$ (Table 2, entry 17). ${ }^{89}$ However, enantioselectivities were only moderate for other terminal 2-arylbut-1-enes (i.e. Table 2, entry 3). ${ }^{107}$ The application of a series of $\mathrm{N}$-phosphine-thiazole ligands 49 (Figure 6) in the hydrogenation of some terminal aryl-alkyl olefins with moderate success was also reported (Table 2, entries 4, 24 and 35). ${ }^{95}$ The best enantioselectivity (up to $86 \%$ ) was obtained in the reduction of $\mathbf{S 2 0}$ (Table 2, entry 24) using a ligand bearing phenyl substituents at both thiazole and N-phosphine moieties (ligand 49a; Figure 6).

(Iminophosphoranyl)ferrocene ligands 64 (Figure 8) have been successfully applied in the Rh-catalyzed hydrogenation of S13 (ee's up to 97\%, Table 2, entry 18) and S26 (ee's up to 94\%, Table 1, entry 43). ${ }^{108}$ Despite this success, no new substrates have been applied and the potential of this catalyst system needs to be further investigated.

Despite all these important contributions, the asymmetric hydrogenation of terminal alkenes using Ir-N,P catalyst systems still experienced a limited substrate scope. In 2008 it was shown that the presence of biaryl-phosphite moieties in the ligand design is highly advantageous for the Ir-catalyzed reduction of minimally functionalized olefins. $^{72-73}$ Three families of phosphite-nitrogen ligands were successfully applied in the reduction of a broad range of 1,1-disubstituted alkenes (ligands 23, 24 in Figure 4 and ligands 45 in Figure 6). The use of biaryl phosphite moieties in the ligand design is a common feature of these ligand libraries where the availability of biaryl alcohols and the robustness of the phosphite towards oxidation are the key factors for the high modularity and stability of 
the ligands. The first family was the previously mentioned phosphite-oxazoline ligands 23 derived from D-glucosamine (Figure 4) ${ }^{72 a}$ By carefully selecting the ligand parameters (substituents at the oxazoline moiety and substituents/configuration at the biaryl phosphite moiety) enantioselectivities ranging from 83 to $99 \%$ were obtained using ligand 23a (Figure 4). ${ }^{72 b}$ The results obtained when reducing several 1,1-disubstituted aryl/heteroaryl-alkyl substrates indicated that enantioselectivity is affected by the nature of the substrate alkyl chain (ee's ranging from $83 \%$ to $99 \%$, Table 2, entries 5,12 , $19,25,28,31,33,36,38,47,51$ and 55$)$. One possible explanation for this is the competition between direct hydrogenation versus isomerization for the different substrates. This is supported by the fact that the hydrogenation of substrate S20 bearing a tert-butyl group, for which isomerization cannot occur, provides high levels of enantioselectivity (ee's up to $97 \%$; Table 2, entry 25), while the lowest enantioselectivity of the series (ee's up to $84 \%$; Table 2, entries 36 and 38) is found for substrates $\mathbf{S 2 4}$ and $\mathbf{S 2 5}$, which form the most stable isomerized tetrasubstituted olefins.

The second family, related to ligands $\mathbf{1 9}$, proved to be superior to the glucosamine-based phosphite-oxazoline ligands $23 .^{73}[\operatorname{lr}(\operatorname{cod})(24)]\left[B A r_{F}\right]$ (Figure 4) appeared as a privileged catalytic system for the hydrogenation of several types of aryl-alkyl, heteroaryl-alkyl and aryl-aryl 1,1-disubstituted olefins, including those bearing a neighboring polar group (vide infra). ${ }^{73 b}$ However, all these examples required the presence of an aromatic substituent conjugated to the alkene and there are no reported examples of purely alkylsubstituted terminal olefins. In contrast to trisubstituted olefins, enantioselectivities were best with the ligand containing an S-binaphthyl phosphite moiety and phenyl substituents at the alkyl backbone chain (ligand 24b; Figure 4). Several para-substituted 2-phenylbut-2-enes and several $a$ alkylstyrenes bearing increasing sterically demanding alkyl substituents were hydrogenated with excellent enantioselectivities (90-99\% ee) (Table 2, entries $6,13,20,26,29,32,34,37$ and 39). Ir-24b catalytic system was also used in combination with PC as the solvent. As observed by Börner and co-workers using Ir-19a, enantioselectivity in the reduction of $\mathbf{S 2 6}$ was improved (Table 2, entries 44 vs 45) and catalysts were recycled up to five times with no significant losses in enantioselectivity. A range of heteroaryl-alkyl substrates 
containing a furyl, pyridyl and thiophenyl groups could be hydrogenated efficiently at 1 bar of hydrogen using the Ir-24b catalytic system (ee's ranging 96->99\%, Table 2, entries 46, 48, 52 and 56 ). By suitable tuning of the ligand components, the Ir-24c (Figure 4) and Ir-24d (Figure 4) catalysts were also efficient in the hydrogenation of 1,1-diaryl substrates, which provides a facile alternative for the preparation of diarylalkanes that are present in several drugs and research materials (Table 2, entries 59, 62 and 64).

The third family was designed to study how effective the biaryl phosphite moiety will be when combined with other $N$-donor groups than oxazolines. Two types of $\mathrm{N}$-donor group were studied, oxazole (Figure 6 , ligands 44) and thiazole (Figure 6, ligands 45). ${ }^{92}$ Phosphite-thiazole ligand 45a (Figure 6) provided similar levels of enantioselectivity as those obtained with glucosamine-based Ir-23a catalytic system (Table 2, entries 7, 14, 21, 40, 49, 53 and 57).

The previously mentioned phosphite-thioether ligands 57-60 (Figure 7) were screened in the hydrogenation of several aryl/alkyl disubstituted substrates, including those containing a heteroaryl group. Again, furanoside ligand 58a provided the highest enantioselectivities (ee's up to 99\%; Table 2, entries $27,30,50$, and 60 ). ${ }^{102 a, b}$ For this substrate class the enantioselectivity is dependent on the alkyl substituent and this can, possibly, be attributed to the presence of an isomerization process under hydrogenation conditions. Enantioselectivities were best in the asymmetric reduction of aryl and heteroaryl/tert-butyl substrates $\mathbf{S} 20$ and $\mathbf{S 2 8}$. Conveniently, both enantiomers of the hydrogenation product can be obtained in high enantioselectivity, by simply changing the configuration of the biaryl phosphite moiety.

While chiral versions of Crabtree's catalyst have proved very useful for the asymmetric hydrogenation of unfunctionalized 1,1-disubstituted alkenes, a complementary reactivity can be found in the previously described RhDuanphos catalytic system (Scheme 10). Here the hydrogenation of 1,1-diaryl substrates bearing a directing hydroxyl group at the ortho position of one of the aryl groups gives ee's up to $>99 \%$ while the corresponding alkenes devoid of the hydroxyl moiety gives essentially racemic mixtures. ${ }^{49}$ 


\subsection{Tetrasubstituted Aryl/Alkyl Alkenes}

Despite the advances during the last five years in the hydrogenation of minimally functionalized olefins and with the development of new ligand libraries that allowed a considerably increased range of substrates to be hydrogenated, the enantioselective reduction of tetrasubstituted olefins remain a challenge. The range of such substrates that can be efficiently hydrogenated is still narrow.

Buchwald and co-workers reported the first successful example on the asymmetric hydrogenation of tetrasubstituted alkenes. In this study, a chiral zirconocene complex 64 (Figure 10), which is the $\mathrm{Zr}$ analogue of the previously mentioned titanocene complex 7 , was used. ${ }^{109}$ The hydridezirconocene catalyst afforded high enantioselectivities (ee's over $90 \%$ ) for a range of tetrasubstituted acyclic olefins and dihydronaphthalenes (Table 3, entries 1, 12, 15, 19 and 21). However, as observed for the titanium analogue 7 , the potential utility is hampered by the high catalyst loadings, long reaction times and high pressures required.
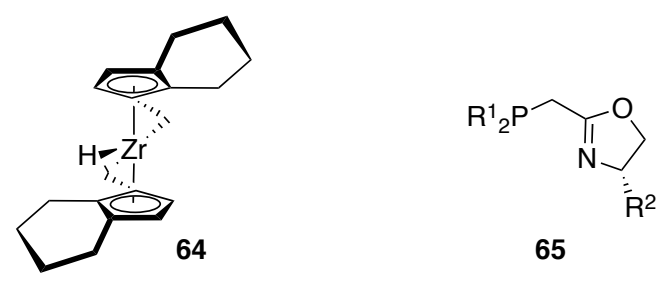

Figure 10 Zirconocene complex 64 and phosphine-oxazoline ligands 65 applied in the asymmetric hydrogenation of tetrasubstituted olefins.

Ir-PHOX catalytic systems (Figure 3) have also been applied in the hydrogenation of the tetrasubstituted olefin 1-(1,2-dimethyl-propenyl)-4methoxy-benzene S5, providing promising results (ee's up to $81 \%$ and full conversion after 2 hours, Scheme 4 ) at a lower catalyst loading and pressure than what was required when using Zr-64 (Table 3, entry 2). ${ }^{26-27,50}$ The requirements of the ligand to achieve high enantioselectivities for tetrasubstituted olefins are different from those needed for the reduction of trisubstituted ones. For tetrasubstituted alkenes, enantioselectivities are best with the less bulky ligand $\mathbf{5 b}$ that contains a $\mathrm{CH}_{2}{ }^{\mathrm{t}} \mathrm{Bu}$ group on the oxazoline 
and a bisphenylphosphanyl group (Figure 3). The Ir-PHOX ligands have been successfully applied in the hydrogenation of tricyclic ring olefins S34 (Table 3, entry 10). ${ }^{110}$ These results opened up the asymmetric reduction of this substrate class to the use of other Ir-N,P catalysts and some of the ligands used in the reduction of trisubstituted olefins have also been tested. In this context, the previously mentioned phosphine-benzoxazine ligands 8 (Figure 4) provided low conversions (up to $63 \%$ ) and enantioselectivities (up to $31 \%$ ) in the hydrogenation of 1-(1,2-dimethyl-propenyl)-4-methoxy-benzene S5 (Table 3, entry 3) and 1-isopropylidene-6-methoxy-1,2,3,4-tetrahydronaphthalene. ${ }^{52}$

The proline based N-phosphine-oxazoline ligands 16 (Figure 4), which provided higher enantioselectivities in the hydrogenation of trisubstituted olefins than PHOX ligands, have been tested in the hydrogenation of tetrasubstituted substrate $\mathbf{S 5}{ }^{59}$ However for this substrate low activities and enantioselectivities were obtained (ee's up to $16 \%$; Table 3, entry 4).

The use of phosphinite-ligands 19 (Figure 4) provided similarly high levels of enantioselectivity as the PHOX-based catalytic system did in the hydrogenation of tetrasubstituted olefins (ee's up to $82 \%$; Table 3 , entry 5). ${ }^{110}$ As observed in the hydrogenation of disubstituted olefins and, in contrast to the hydrogenation of trisubstituted olefins, the ligand that provided the highest enantioselectivity with tetrasubstituted olefin S5 contains cyclohexyl substitutents at the phosphinite moiety (ligand 19a; Figure 4).

Phosphinite-oxazoline ligands 20 (Figure 4) have also been evaluated and provided low levels of enantioselectivity in the reduction of standard tetrasubstituted substrate S5 (ee's up to $14 \%$; Table 3, entry 6). ${ }^{110}$ However, 20a provided excellent enantioselectivities (ee's up to 95\%) for a limited range of tetrasubstituted dihydronaphthalenes (Table 3 , entries 13 and 17).

The phosphinite-pyridine ligands 31 and 32 (Figure 5) have been screened for the Ir-catalyzed asymmetric hydrogenation of tetrasubstituted alkenes and Ir-31 afforded higher enantioselecivities than Ir-32 (Table 3, entries 7 vs 8). ${ }^{77,79 a}$ Enantioselectivities up to $81 \%$, comparable to that obtained for the PHOX ligands, were achieved using the phosphinite-pyridine ligand 31a (Figure 5) in the reduction of substrate $\mathbf{S 5}$. 
Phosphinite-oxazole ligands 42 (Figure 6) were evaluated in the hydrogenation of standard substrate $\mathbf{S 5}$ but enantioselectivities and activities were low (ee's up to $15 \%$ ). ${ }^{89}$

An important discovery was the use of simple and readily available phosphine-oxazoline ligands 65 (Figure 10; $\mathrm{R}^{1}=\mathrm{Ph}, \mathrm{Cy},{ }^{\mathrm{t}} \mathrm{Bu}, \mathrm{o}-\mathrm{Tol}$ and $\mathrm{R}^{2}=$ $\left.\mathrm{Ph},{ }^{\mathrm{i}} \mathrm{Pr},{ }^{\mathrm{t}} \mathrm{Bu}, \mathrm{CH}_{2}{ }^{\mathrm{t}} \mathrm{Bu}, \mathrm{Bn}\right)$, which form five membered chelate rings. ${ }^{110}$ This ligand family provided excellent enantioselectivities for the hydrogenation of the standard tetrasubstituted substrate S5, but also provided high enantioselectivities for a broad range of tetrasubstituted dihydronaphthalenes, including tricyclic ring olefins (Table 3, entries 9, 11, 14, 16, 18, 20, 22 and 23). Although, small changes at both the substituents of the ligands and that of the substrate affected the catalytic performance, it was found that ligand 65a (Figure 10, $\mathrm{R}^{1}=\mathrm{Ph}$ and $\mathrm{R}^{2}={ }^{\mathrm{i}} \mathrm{Pr}$ ), containing an isopropyl oxazoline substituent and a bisphenylphosphanyl group, provided the highest enantioselectivities for a broad range of tetrasubstituted dihydronaphthalenes.

Table 3 Enantioselectivities achieved using selected ligands in the asymmetric hydrogenation of tetrasubstituted alkenes.

\begin{tabular}{|c|c|c|c|c|c|c|c|c|c|}
\hline Entry & Substrate & {$[\mathrm{M}] / \mathrm{L}$} & $\%$ ee & Ref & Entry & Substrate & {$[\mathrm{M}] / \mathrm{L}$} & $\begin{array}{l}\% \\
\text { ee }\end{array}$ & Ref. \\
\hline 1 & & $\mathrm{Zr}$ & $96^{a}$ & 109 & 15 & & $\operatorname{Zr}(64)$ & 93 & 109 \\
\hline 2 & & (64) & 81 & 26 & 16 & & $\mid r-65 a$ & 94 & 110 \\
\hline \multirow[t]{2}{*}{3} & & $\mid r-5 b$ & 31 & 52 & & & & & \\
\hline & & Ir-8 & & & & & & & \\
\hline 4 & & $\mid r-16$ & 16 & 59 & 17 & & $\mathrm{Ir}-20 \mathrm{a}$ & 95 & 110 \\
\hline 5 & & $\mid r-19 a$ & 82 & 110 & 18 & & $\mid r-65 a$ & 94 & 110 \\
\hline 6 & & Ir-20a & 14 & 110 & & & & & \\
\hline 7 & & $\mid r-31 a$ & 81 & 77 & 19 & & $\operatorname{Zr}(64)$ & 78 & 109 \\
\hline 8 & & $\mid r-32 a$ & 64 & $79 a$ & 20 & & $\mid r-65 a$ & 96 & 110 \\
\hline 9 & & $\mid r-65 a$ & 97 & 110 & & & & & \\
\hline 10 & & $\mid \mathrm{r}-5 \mathrm{~b}$ & 94 & 110 & 21 & & $\operatorname{Zr}(64)$ & 92 & 109 \\
\hline 11 & & Ir-65a & 96 & 110 & 22 & & Ir-65a & 73 & 110 \\
\hline
\end{tabular}




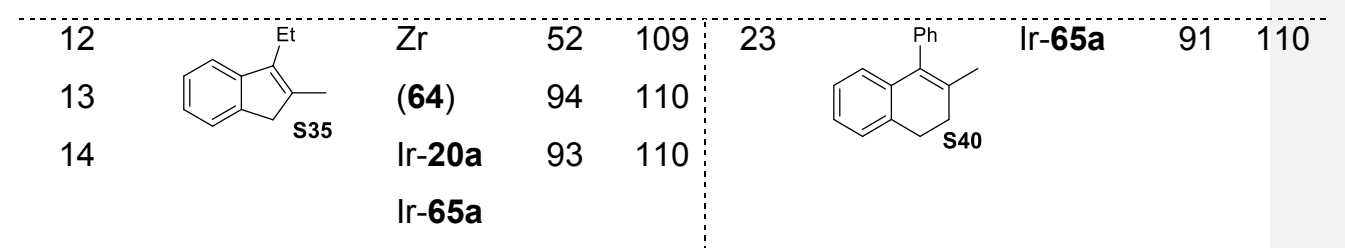

${ }^{a}$ Using $p$-fluoro derivative instead of OMe in S5.

\section{Enols}

Traditionally, the asymmetric hydrogenation of enols has been the subject of interest as an alternative method to the asymmetric hydrogenation of ketones in the preparation of chiral alcohols. However, the hydrogenation of enol derivatives can give chiral products besides alcohols that are difficult to access from ketone reduction such as chiral cyclic ethers and phosphines. Moreover the great diversity of protecting groups that can be introduced in the enol substrate can be used after hydrogenation as an alcohol protective group that can be deprotected at a later step in the synthesis of a more complex molecule.

\subsection{Enol Esters and Enol Carbamates}

Enol esters are the most widely used enol type substrate in asymmetric hydrogenation. ${ }^{111}$ The asymmetric hydrogenation of this substrate class readily gives access to chiral alcohols after hydrolysis of the ester group. The hydrogenation of this substrate class is dominated by Rh- and Ru-catalysts modified with chiral phosphorus ligands due to the coordinative ability of the ester group to the metal center (enol esters are structurally and electronically similar to enamides) (Table 4). ${ }^{111-112}$ There are very few examples of chiral analogues to Crabtree's catalyst that have been applied to this substrate class. For example, the hydrogenation of 1-phenylvinyl acetate $\mathbf{S 4 1}$ using phosphine-thiazoline ligands 43 (Figure 6) was ineffective (no conversion; Table 4, entry 5) but the use of Ir-17 catalysts (Figure 4) afforded exclusively the desired acetate but in the racemic form (Table 4, entry 3) ${ }^{62 b}$ Phosphiniteoxazole ligands 42 (Figure 6) however led to the formation of the decomposition product ethyl benzene (Table 4, entry 4). 
Table 4 Selected results for the asymmetric hydrogenation of model enol ester 1-phenylvinyl acetate S41

\begin{tabular}{|c|c|c|c|c|}
\hline Entry & {$[\mathrm{M}] / \mathrm{L}$} & $\%$ Conv & $\%$ ee & Ref. \\
\hline 1 & Rh-ZhangPhos & 100 & 97 & $112 b$ \\
\hline 2 & Rh-Cy-SMS-Phos & 100 & 97 & $112 a$ \\
\hline 3 & $\mid r-17$ & 100 & 0 & $62 b$ \\
\hline 4 & Ir-42 & $100^{\mathrm{a}}$ & - & $62 b$ \\
\hline 5 & Ir-43 & 0 & - & $62 b$ \\
\hline
\end{tabular}

Recently, Schneider and co-workers have successfully applied Irphosphine/phosphinite-oxazoline catalysts in the diastereoselective hydrogenation of enol benzoate $\mathbf{S 4 2}$ (Scheme 14 , step (a)). ${ }^{113}$ It should be noted that various chiral Rh-catalysts have failed to hydrogenate this substrate. After screening several Ir-N,P systems the best results were obtained with the Ir-PHOX catalytic systems (Figure 3) affording significant diastereoselectivities. They also found that the steric bulk within the P-aryl group exerted a decisive effect on both the activity and selectivity. The best activities and selectivities were achieved using ligand 5c containing bulky mesityl groups at the phosphine moiety (Figure 3). ${ }^{113}$ Enol benzoate $\mathbf{S 4 2}$ was hydrogenated to the anti product in 99\% yield and 96:4 dr, whereas the epimeric syn product was achieved in 98\% yield and 97:3 dr using the enantiometic 5c ligand (Scheme 14, step (a)). The hydrogenated products were used to prepare biologically relevant trideoxypropionate building blocks in the optically pure form by a simple auxiliary-controlled enolate methylation (Scheme 14, step (b)). Trideoxypropionate has further been applied in the total synthesis of the pheromones (+)-vittatalactone and (+)-norvittatalactone of the striped cucumber beetle Acalymma vittatum. ${ }^{113-114}$ 
<smiles>[R]C(=O)OC[C@@H](C)C[C@@H](C)CCC(=O)N1C(=O)OC[C@H]1Cc1ccccc1</smiles>

$\mathrm{R}=\mathrm{Ph}: \quad 99 \%, 96: 4$ anti:syn
$\mathrm{R}=\mathrm{NH}^{\mathrm{t} B u}: 95 \%, 98: 2$ anti:syn

(a) $\uparrow \operatorname{Ir}-5 \mathrm{c}(2 \mathrm{~mol} \%)$<smiles>[R]C(=O)O/C=C(/C)C[C@H](C)CCC(=O)N1C(=O)OCC1Cc1ccccc1</smiles>

$\mathrm{S} 42 \mathrm{R}=\mathrm{Ph}$

$\mathrm{S} 43 \mathrm{R}=\mathrm{NH}^{\mathrm{t}} \mathrm{Bu}$

(a) Ir-ent-5c (2 mol\%)<smiles>[R]C(=O)OCC(C)C[C@H](C)CCC(=O)N1C(=O)OC[C@H]1Cc1ccccc1</smiles>

$\mathrm{R}=\mathrm{Ph}:$

$\mathrm{R}=\mathrm{NH}^{\mathrm{t}} \mathrm{Bu}: 96 \%, 3: 97$ anti:syn<smiles></smiles><smiles>CC(COC(=O)c1ccccc1)C[C@@H](C)CC(C)C(=O)N1C(=O)OCC1Cc1ccccc1</smiles>

$93 \%$<smiles>[R]C(C)C[C@H](C)C[C@H](C)[C@H]1OC(=O)[C@H]1C</smiles>

$\mathrm{R}^{1}={ }^{\mathrm{i}} \mathrm{Bu}$; (+)-vittatalactone

$\mathrm{R}^{1}=\operatorname{Pr} ;(+)$-norvittatalactone

(a) $\mathrm{CH}_{2} \mathrm{Cl}_{2}, 85$ bar $\mathrm{H}_{2}$, r.t. $48 \mathrm{~h}$ (b) NaHMDS, Mel, THF, $-78^{\circ} \mathrm{C}$

Scheme 14 Hydrogenation of $\mathbf{S 4 2}$ and $\mathbf{S 4 3}$ using Ir-PHOX catalysts, followed by $\alpha$-methylation to form trideoxypropionates and their application in the total synthesis of pheromones.

The coordinating ability of the carbamate acyl group to the metal closely resembles the enamide instead of the acyl group of an enol ester, which has slightly weaker coordinating ability. ${ }^{115}$ Thus enol carbamates have appeared 
as an alternative to enol esters and for this substrate class Rhphosphoroamidite catalysts have afforded excellent enantioselectivities (ee's up to $98 \%$ ). ${ }^{115-116}$ However, Ir-PHOX catalysts (Figure 3) were efficient in the diastereoselective hydrogenation of the enol carbamate S43, analogue to enol ester S42, for which several Rh/P catalysts failed. ${ }^{113}$ As with enol ester $\mathbf{S 4 2}$, the use of the bulky PHOX ligand 5c (Figure 3) and its enantiomer (ent-5c) afforded both diastereoisomers in high yields and diastereomeric ratios (Scheme 14). ${ }^{113}$

\subsection{Enol Phosphinates and Enol Phosphonates}

Although the phosphinate and the phosphonate group are coordinative groups, there is only one report on the use of Rh-catalysts for the hydrogenation of enol phosphinates/phosphonates. Moderate enantioselectivities were achieved in the hydrogenation of enol phosphinates using a cationic Rh-catalyst modified with $(R)-1-[(S)-1$ ',2bis(diphenylphosphino)ferrocenyl]ethanol ligand ((R)-(S)-BPPFOH) (ee's up to $78 \%$; Table 5 , entry 1). ${ }^{117}$ The presence of triethylamine was necessary for high activities, which underlines the acid-sensitive nature of these substrates. Enol phosphinates and in some cases enol phosphonates can be reduced effectively using chiral analogues of Crabtree's catalysts. A screening of several ligands developed in the Andersson group disclosed that $\mathrm{N}$ phosphine-oxazoline ligand $\mathbf{1 7 b}$ (Figure 4) is effective for the hydrogenation of terminal enol phosphinates (Table 5 , entries 2 vs 3 and 4 ) ${ }^{62 b}$ Excellent enantioselectivities were achieved for a wide range of aryl and alkyl enol phosphinates (Figure 11). The authors took advantage of Berens work ${ }^{118}$ to demonstrate that this methodology can be used to prepare chiral phosphines by replacing the phosphityl group with diphenylphosphine. In the same study they found that the Ir-17b catalyst can also be used in the hydrogenation of enol phosphonates albeit with lower enantioselectivities (i.e. ee's dropped from $95 \%$ to $65 \%$ by replacing the phosphinate group with a phosphonate moiety). It should be noted that for the more acid-sensitive substrates (i.e. substrate S47, Figure 11) the use of small amounts of poly(4-vinylpyridine) resin was necessary to avoid substrate hydrogenolysis. ${ }^{62 b}$ 
Table 5 Selected results for the asymmetric

hydrogenation of model enol phosphinate 1-phenylvinyl

diphenylphosphinate $\mathbf{S 4 4}$

\begin{tabular}{|c|c|c|c|c|}
\hline Entry & {$[\mathrm{M}] / \mathrm{L}$} & $\%$ Conv & $\%$ ee & Ref. \\
\hline 1 & Rh-(R)-(S)-BPPFOH & 100 & 78 & 117 \\
\hline 2 & $\mid r-17 b$ & 100 & 95 & $62 b$ \\
\hline 3 & Ir-43 & 0 & - & $62 b$ \\
\hline 4 & Ir-42 & 47 & $63 \%$ & $62 b$ \\
\hline 5 & Ir-44a & 100 & $82 \%$ & 92 \\
\hline
\end{tabular}

It was also found that $\mid r-17 b$ catalyst was able to efficiently reduce trisubstituted aryl-alkyl and ester-functionalized enol phosphinates. ${ }^{62 a}$ Excellent enantioselectivities (up to $>99 \%$ ) and full conversion was observed for a range of substrates, including purely alkyl trisubstituted enol phosphinates (Figure 11). This latter finding is particularly valuable because the hydrogenation products, after deprotection, gives access to chiral alkyl alcohols that are usually difficult to obtain in high enantioselectivity from ketone hydrogenations.

Replacing the phosphinite moiety in ligands 42 by a biaryl phosphite group (ligand 44a; Figure 6) has a positive effect on enantioselectivity (Table 5 , entry 4 vs 5). ${ }^{92}$ High enantioselectivities (up to $92 \%$ ) were obtained in the hydrogenation of several di- and trisubstituted enol phosphinates using this catalytic system however the enantioselectivities achieved do not surpass the values achieved with Ir-17b catalytic system. 


\begin{tabular}{|c|c|c|c|c|c|c|c|c|c|}
\hline & $\mathrm{R}$ & \%ee & & $\mathrm{R}$ & $\%$ ee & & $\mathrm{R}^{1}$ & $\mathrm{R}^{2}$ & $\%$ ee \\
\hline S45 & $\mathrm{Me}$ & 96 & $\mathrm{~S} 50$ & Cy & 92 & S53 & $\mathrm{Ph}$ & $\mathrm{Me}$ & 96 \\
\hline S46 & ${ }^{t} \mathrm{Bu}$ & 94 & S51 & ${ }^{\mathrm{t}} \mathrm{Bu}$ & $>99$ & S54 & $\mathrm{Ph}$ & $\mathrm{Et}$ & 92 \\
\hline S47 & $\mathrm{OMe}$ & 98 & S52 & ${ }^{i} \operatorname{Pr}$ & 92 & S55 & $\mathrm{Ph}$ & ${ }^{\mathrm{i}} \mathrm{Pr}$ & 90 \\
\hline S48 & $\mathrm{CF}_{3}$ & 99 & & & & S56 & ${ }^{t} \mathrm{Bu}$ & Et & 90 \\
\hline S49 & $\mathrm{Br}$ & $>99$ & & & & S57 & ${ }^{\mathrm{i}} \mathrm{Pr}$ & $\mathrm{Me}$ & 91 \\
\hline
\end{tabular}

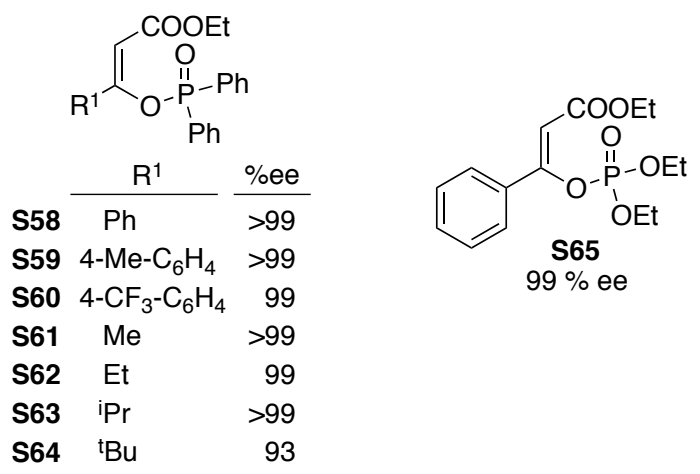

Figure 11 Representative enol phosphinates (S45-S64) and enol phosphonate (S65) efficiently reduced using Ir-17b catalytic system

\subsection{Enol Ethers}

In this section, simple enols, $\alpha$-alkyloxy and $\alpha$-alkyloxy $\alpha, \beta$-unsaturated carbonyls will be discussed along with a few examples of enol ethers that are also allylic alcohols.

Asymmetric hydrogenation of enol ethers directly provides chiral ethers, which is advantageous to access building blocks used to prepare bioactive compounds such as Eriprotabid, Tesaglitazar and Aleglitazar ${ }^{119}$ that are of interest to the agrochemical and pharmaceutical industries. ${ }^{120}$ However, enol ethers are sensitive to acid and since homogeneous hydrogenations tend to form protons, the addition of base is required.

Among the variety of enol ethers, $\alpha$-aryloxy and $\alpha$-alkoxy $\alpha, \beta$ unsaturated carboxylic acids have been the most popular for asymmetric hydrogenation since the resulting optically active a-oxy-functionalized 
carboxylic acids are important building blocks. ${ }^{120-121} \mathrm{~A}$ feature of this $\alpha$-aryloxy and $\alpha$-alkoxy $\alpha, \beta$-unsaturated carboxylic acids is that the carboxylate coordinates to the metal center, thus favoring the potential use of classical $\mathrm{Rh}$ - and Ru-diphosphine catalysts. In this context, a range of 3-methyl-2aryloxyacrylic acids and 3-aryl-2-ethoxyacrylic acids have been successfully hydrogenated in excellent enantioselectivities using both Rh- and Ru-catalysts in the presence of base (Figure 12). ${ }^{122}$ However, none of the Rh- and Rucatalysts have been reported to give high enantioselectivity in the asymmetric hydrogenation of both $\alpha$-aryloxy and $\alpha$-alkoxy $\alpha, \beta$-unsaturated carboxylic acids.
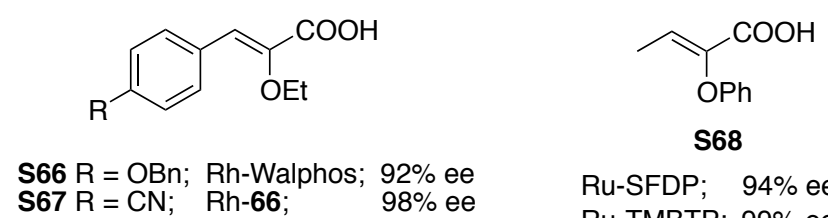

Ru-SFDP; $94 \%$ ee Ru-TMBTP; 99\% ee

Figure 12 Representative enantioselectivities in the hydrogenation of 3methyl-2-aryloxyacrylic acids and 3-aryl-2-ethoxyacrylic acids achieved using Rh- and Ru-catalytic systems. $66=\left[\left(R_{\mathrm{C}}, R_{\mathrm{C}}\right),\left(S_{\mathrm{Fc}}, S_{\mathrm{FC}}\right),\left(S_{\mathrm{P}}, S_{\mathrm{P}}\right)\right]-1,1^{\prime}-\operatorname{Bis}[2-(1-$ $\mathrm{N}, \mathrm{N}$-Dimethylaminoethyl)-1-ferrocenyl]phenyl phosphino ferrocene.

Zhou and coworkers have recently shown that chiral Crabtree's analogues are extremely effective in the hydrogenation of both $\alpha$-aryloxy and $\alpha$-alkoxy $\alpha, \beta$-unsaturated carboxylic acids. ${ }^{123}$ The authors found that by using chiral spiro phosphino-oxazoline ligands 67 (Figure 13, $\mathrm{R}^{1}=\mathrm{Ph}, 3,5-\mathrm{Me}_{2}-\mathrm{Ph}$, $3,5-{ }^{\mathrm{t}} \mathrm{Bu}_{2}-\mathrm{Ph}$ and $\mathrm{R}^{2}=\mathrm{Bn}, \mathrm{Ph}, \mathrm{Me}$ and $\mathrm{H}$ ), the hydrogenation proceeded smoothly to produce various $\alpha$-aryloxy and $\alpha$-alkoxy-substituted carboxylic acids with excellent enantioselectivities (ee's up to $>99 \%$ ) and reactivities (TON up to 10000 ) under mild conditions (Figure 13). The results indicated that for aryloxy enol ethers S69-S76 enantioselectivitites were best using ligand $67 \mathrm{a}$, containing bulky aryl phosphine substituents and a benzyl moiety in the oxazoline (Figure $13, R^{1}=3,5-{ }^{\mathrm{t}} \mathrm{Bu}_{2}-\mathrm{Ph}$ and $\mathrm{R}^{2}=\mathrm{Bn}$ ), while for alkoxy enol ethers S77-S84 enantioselectivities were best with ligand $67 \mathrm{~b}$ with a methyl oxazoline substituent (Figure $13, R^{1}=3,5{ }^{-}{ }^{\mathrm{B}} \mathrm{u}_{2}-\mathrm{Ph}$ and $\mathrm{R}^{2}=\mathrm{Me}$ ). It should be 
noted that the hydrogenation of $\alpha$-benzyloxy-substituted $\alpha, \beta$-unsaturated acids provided an efficient alternative for the synthesis of chiral $\alpha$-hydroxy acids after an easy deprotection. A mechanism involving a catalytic cycle between $\operatorname{Ir}^{\prime}$ and Ir III $^{\prime \prime}$ was proposed on the basis of the coordination model of the unsaturated acids with the iridium metal center. The rationale for the catalytic cycle, with an olefin dihydride complex as the key intermediate, was supported by deuterium-labeling studies.

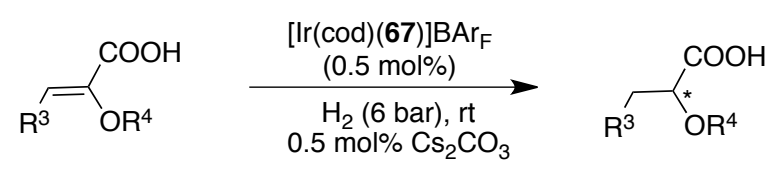

\begin{tabular}{|c|c|c|c|c|c|c|c|}
\hline & $\mathrm{R}^{3}$ & $\mathrm{R}^{4}$ & $\%$ ee & & $\mathrm{R}^{3}$ & $\mathrm{R}^{4}$ & $\%$ ee \\
\hline S69 & $\mathrm{Me}$ & $\mathrm{Ph}$ & 99 & S77 & $\mathrm{Ph}$ & $\mathrm{Me}$ & 99 \\
\hline S70 & $\mathrm{Me}$ & 4-Me- $\mathrm{C}_{6} \mathrm{H}_{4}$ & 99 & S78 & 4- $\mathrm{MeO}-\mathrm{C}_{6} \mathrm{H}_{4}$ & $\mathrm{Me}$ & 99 \\
\hline S71 & $\mathrm{Me}$ & 4-MeO- $\mathrm{C}_{6} \mathrm{H}_{4}$ & 99 & S79 & $4-\mathrm{CF}_{3}-\mathrm{C}_{6} \mathrm{H}_{4}$ & $\mathrm{Me}$ & 99 \\
\hline S72 & $\mathrm{Ph}$ & $\mathrm{Ph}$ & 99 & $\mathrm{~S} 80$ & $\mathrm{Me}$ & Me & 99 \\
\hline S73 & $\mathrm{Ph}$ & 4- $\mathrm{MeO}-\mathrm{C}_{6} \mathrm{H}_{4}$ & 99 & S81 & $\mathrm{Et}$ & $\mathrm{Me}$ & 95 \\
\hline S74 & 4-OMe-Ph & $\mathrm{Ph}$ & 99 & S82 & $\mathrm{Ph}$ & $\mathrm{Bn}$ & 99 \\
\hline S75 & $4-\mathrm{CF}_{3}-\mathrm{Ph}$ & $\mathrm{Ph}$ & 99 & S83 & $4-\mathrm{MeO}-\mathrm{C}_{6} \mathrm{H}_{4}$ & $\mathrm{Bn}$ & 99 \\
\hline S76 & Furan-2-yl & $\mathrm{Ph}$ & 99 & S84 & $4-\mathrm{CF}_{3}-\mathrm{C}_{6} \mathrm{H}_{4}$ & $\mathrm{Bn}$ & 99 \\
\hline
\end{tabular}

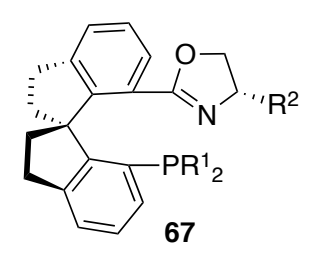

Figure 13 Representative enantioselectivities achieved in the hydrogenation of $\alpha$-aryloxy substituted carboxylic acids (S69-S76) and $\alpha$ alkoxy substituted carboxylic acids (S77-S84) using Ir-67 catalytic system.

Another important class of enol ethers is the non-coordinating alkylated ones (those without the carboxylic group). For this substrate class, very few Rh- and Ru-catalysts have been applied and moderate enantioselectivities were observed. The Ru-BINAP catalytic system afforded enantioselectivities ranging from $64 \%$ to $91 \%$ for a small range of cyclic alkyl enol ethers (Figure 14). ${ }^{124}$ Due to the lack of a coordinating group, Crabtree's analogues should be appropriate for this substrate class. The first report on the use of Ir/N,P 
catalysts for this purpose was done by Pflatz and coworkers. ${ }^{2 \mathrm{~d}}$ They disclosed that Ir-19a catalyst (Figure 4) was able to hydrogenate 2-phenyl-1,4benzopyran $\mathbf{S} 88$ with complete conversion and $98 \%$ ee (Figure 14).

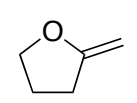

S85

Ru-BINAP

$91 \%$ ee

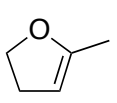

S86

Ru-BINAP

$87 \%$ ee<smiles>[R]C1=CCc2ccccc2O1</smiles>

$S 87 R=M e$

Ru-BINAP

$64 \%$ ee

S88 $R=P h$

Ir-19d

98\% ee

Figure 14 Representative enantioselectivities for the hydrogenation of cyclic alkyl enol ethers using Ru-BINAP and Ir-19 catalysts.

Complexes of the type $\left[\operatorname{Ir}(\operatorname{cod})\left(\mathrm{N}, \mathrm{P}^{*}\right)\right]\left[\mathrm{BAr}_{\mathrm{F}}\right]$ have been shown to generate protons under hydrogenation conditions and sometimes decompose substrates such as alkyl enol ethers before they can be hydrogenated. ${ }^{125}$ Iridium precursor with carbene-oxazoline ligand 25 a (Figure 4) is less prone to generate protons (i.e. less acidic) than similar N,P-ligated complexes and gave the chiral product without significant acid-mediated decomposition (Figure 15 , ee's up to $98 \%$ ). ${ }^{126}$ 


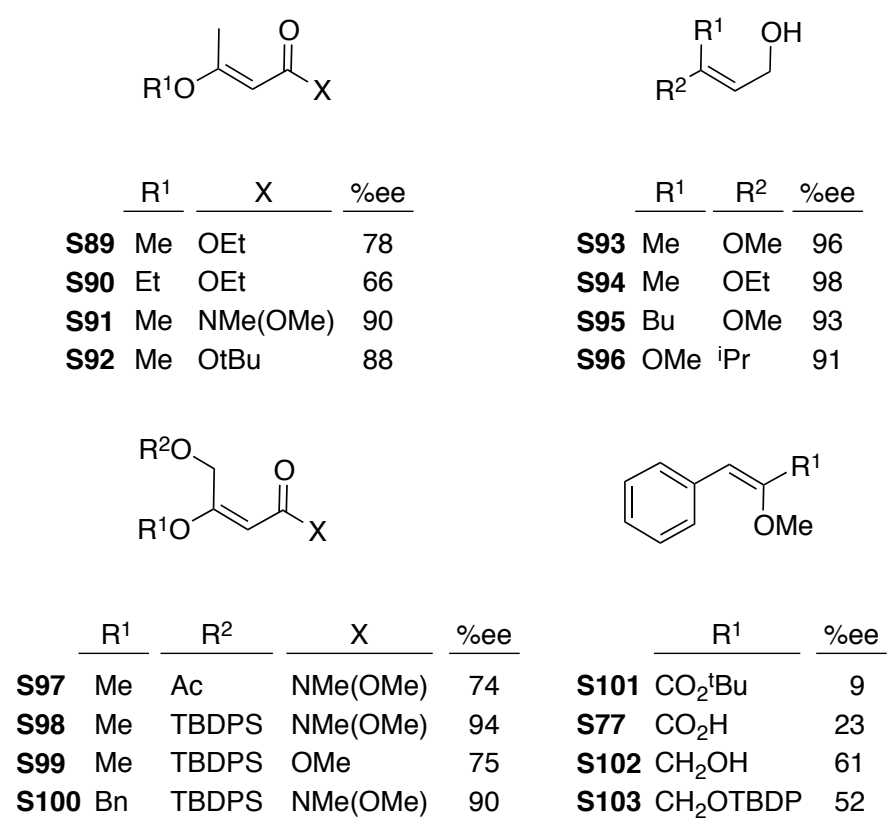

Figure 15 Representative enantioselectivities for the hydrogenation of alkyl enol ethers using Ir-25a catalyst.

\subsection{Silyl Enol Ethers}

Silyl enol ethers are non-coordinative substrates of varying sensitivity towards acid-degradation. Silyl enol ethers have been hydrogenated using Rhcatalysts, though in the absence of an additional coordinating functionality the enantioselectivities were extremely low (ee's up to $10 \%$ ). ${ }^{127}$ Attempts to hydrogenate silyl enol ethers using analogues of Crabtree's catalyst containing ligands 17 (Figure 4), $\mathbf{4 2}$ and $\mathbf{4 3}$ (Figure 6) have been made, but for alkyl enol ethers, complex mixtures were obtained. ${ }^{62 b}$ Thus, although no data has yet been reported, the use of Ir-catalysts modified with carbeneoxazoline ligands would be more appropriate in the asymmetric hydrogenation of silyl enol ethers.

\section{Enamides and Enamines}

Traditionally, the asymmetric hydrogenation of enamines and enamides has been the subject of interest as an alternative method to the asymmetric 
hydrogenation of imines for the preparation of chiral amines that can be used as resolving reagents, chiral auxiliaries, and intermediates for the synthesis of a variety of biologically active molecules. ${ }^{128}$

The hydrogenation of enamides is dominated by Rh- and Ru-catalysts modified with chiral phosphorus ligands primarily because of the coordinative ability of the amide group to the metal center. ${ }^{128 a}$ However, Knochel's group has demonstrated that chiral Crabtree's catalyst analogues can be used successfully in the asymmetric hydrogenation of enamides ${ }^{75}$ They found that $[\operatorname{lr}(\operatorname{cod})(\mathbf{2 8 a})]\left[\mathrm{BAr}_{\mathrm{F}}\right]$ catalytic precursor (Figure 5) can hydrogenate (Z)-methyl 2-acetylamino-3-phenylacrylate $\mathbf{S 1 0 4}$ in high enantiomeric excess (up to $96.5 \%$; Scheme 15) under mild reaction conditions (1 bar $\mathrm{H}_{2}$ ). Despite this early success in the synthesis of chiral amino acids, the use of other Ircomplexes has not yet been reported.

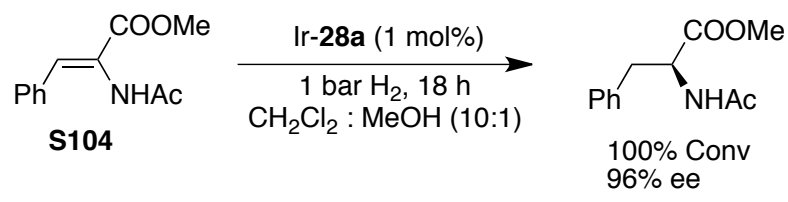

Scheme 15 Asymmetric hydrogenation of enamide S104 using Ir-28 catalysts

In contrast with the hydrogenation of enamides, there are very few examples of successful enantioselective hydrogenation of $\mathrm{N}, \mathrm{N}$-dialkyl enamines, which provides a direct approach to chiral tertiary amines. Enamines are electronrich and moisture sensitive, thus they make poor substrates, ${ }^{128 a}$ but the low coordinative ability of the enamines still makes them an attractive class of alkenes for the enantioselective hydrogenation using Crabtree's analogues. Despite this, to the best of our knowledge, only two reports have been published. ${ }^{129}$

In 2008, N-phosphine-oxazoline ligand 17b (Figure 4) was identified as a suitable ligand for the hydrogenation of enamines (Table 6, entries 2-3 and 5-7). ${ }^{129 a}$ Moderate-to-high enantioselectivities (ee's up to $84 \%$ ) were achieved in the asymmetric reduction of terminal 1-amino-1-aryl alkenes with no $\beta$ substituents (Table 6 , entries 2-3, 5-9, 10, 12, 14, 16). Interestingly, complete 
conversion to the tertiary amine product was observed at room temperature using 50 bar $\mathrm{H}_{2}$, but enantioselectivities were highly substrate dependent. The results indicate that enantioselectivities decreased considerably when the amino group was cyclic (i.e. ee's reduced from $84 \%$ to $33 \%$ by replacing the diethylamine group by a pyrrolidino group; Table 6 , entries 2 vs 12) and for exo-cyclic enamines (i.e. Table 6, entry 14 ).

In 2009, phosphine-oxazolines 5 and 14 (Figures 3 and 4), phosphinite-oxazoline 19 (Figure 4) and phosphinite-pyridine 32 (Figure 5) were reported to be useful ligands in the asymmetric hydrogenation of several terminal 1-aryl-enamines as well as several endo-cyclic and E-acyclic enamines. ${ }^{129 b}$ The best results were achieved with 1-amino-1-aryl alkenes bearing an aryl (ee's up to $91 \%$; Table 6 , entries 15,18 and 20) or a benzyl (ee's up to $92.5 \%$; Table 6, entries 23 and 25) substituent on the nitrogen atom, which were hydrogenated with good enantiomeric excesses using phosphine-oxazoline ligand $\mathbf{5 d}$ (Figure 3 ) and the phosphinite-oxazoline ligand 19a (Figure 4), respectively. Enantioselectivities in the hydrogenation of endo-cyclic and E-acyclic enamines were lower (ee's ranging 67-87\%; Table 6, entries 26-29). 


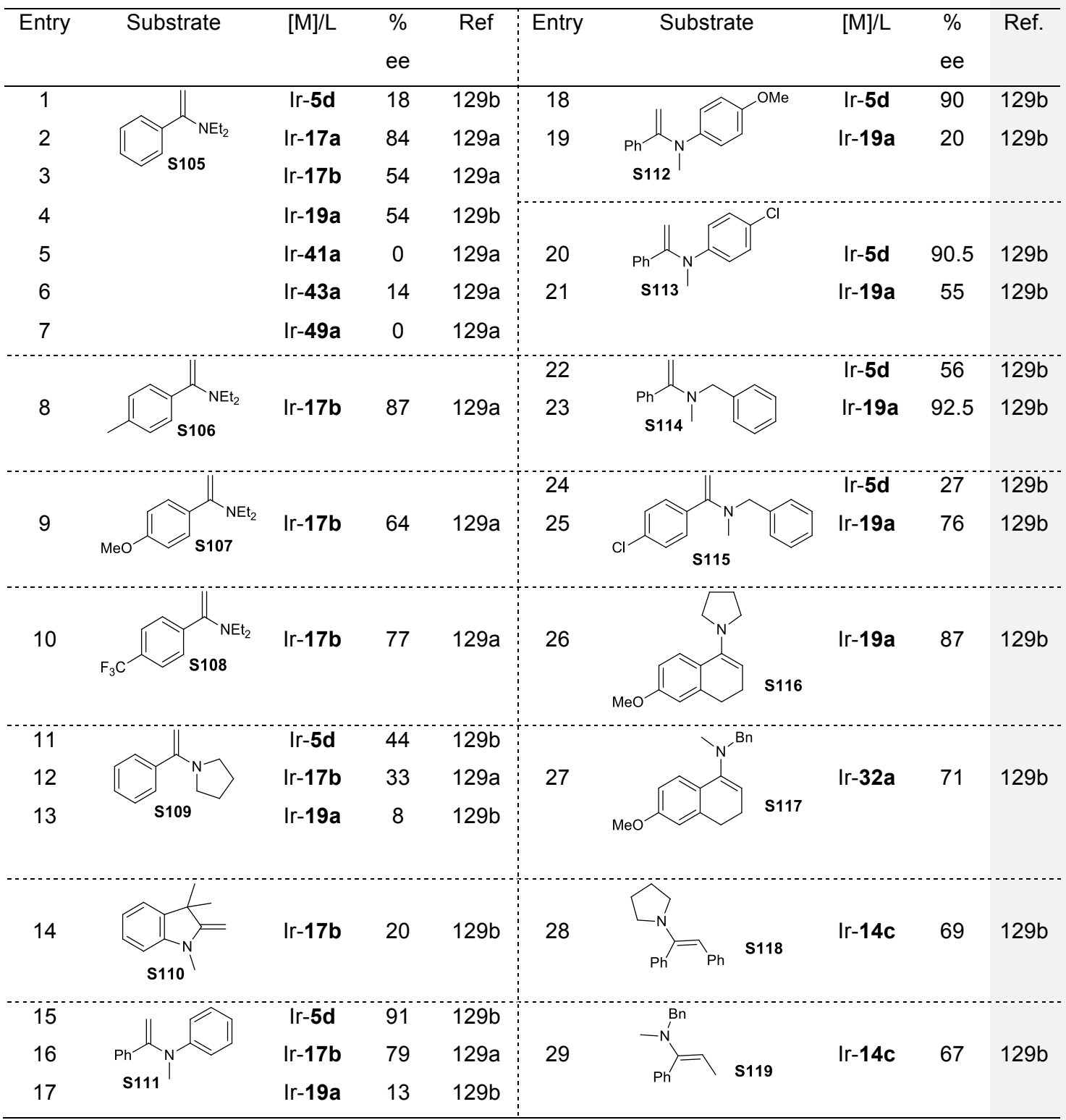

Table 6 Selected results for the asymmetric hydrogenation of enamines.

\section{Allylic and Homoallylic Alcohols and Ethers}

The asymmetric hydrogenation of allylic alcohols is of interest due to their abundance in natural sources such as essential oils, and their wide use as starting materials and/or major components in the food, fragrance and 
pharmaceutical industries. ${ }^{130}$ The hydrogenation of allylic alcohols has been traditionally dominated by Ru-complexes modified with chiral diphosphines. ${ }^{131}$ However, early reports on the use of chiral N,P-ligated Ir-catalysts with PHOX ligands 5 (Figure 3 ) indicated that this substrate class can be hydrogenated with high enantioselectivity. ${ }^{26}$ Trans-2-methyl-3-phenyl-2-propen-1-ol $\mathbf{S 1 2 0}$ was hydrogenated in excellent enantioselectivities (ee's up to $96 \%$; Table 7 , entry 1). Thus, the commercially available substrate $\mathbf{S 1 2 0}$ has since been used as a benchmark to test new Ir-catalysts (Table 7). The best enantioselectivities have been achieved using ligands $12 a^{56}$ (Figure 4 ) and $43 \mathrm{a}^{90}$ (Figure 6) ligands (ee's up to 99\%; Table 7, entries 3 and 16).

Table 7 Selected results for the asymmetric hydrogenation of allylic alcohols

\begin{tabular}{|c|c|c|c|c|c|c|c|c|c|}
\hline Entry & Substrate & {$[\mathrm{M}] / \mathrm{L}$} & $\begin{array}{l}\% \\
\text { ee }\end{array}$ & Ref & Entry & Substrate & {$[\mathrm{M}] / \mathrm{L}$} & $\begin{array}{l}\% \\
\text { ee }\end{array}$ & Ref. \\
\hline 1 & $\widehat{\widehat{\gamma}}$ & Ir-5a & 96 & 26 & & & & & \\
\hline 2 & $s 120$ & $\mid r-9 b$ & 67 & 53 & 25 & & Ir-48a & 97 & 61 \\
\hline 3 & & $\mid r-12 a$ & 98 & 56 & 26 & S121 & Ir-35 & 90 & 94 \\
\hline 4 & & Ir-13a & 90 & 57 & & & & & \\
\hline 5 & & $\mid r-14 b$ & 96 & 44 & & & & & \\
\hline 6 & & $\mid r-15 c$ & 95 & 58 & 27 & & Ir-41b & 92 & 61 \\
\hline 7 & & $\mid r-19 d$ & 97 & $66 a$ & & & & & \\
\hline 8 & & $\mid r-23 a$ & 92 & $72 a$ & & & & & \\
\hline 9 & & Ir-24a & 93 & $73 a$ & & & & & \\
\hline 10 & & Ir-28a & 69 & 75 & & & & & \\
\hline 11 & & $\mid r-31 b$ & 96 & 77 & 28 & & $\mid r-41 b$ & 92 & 61 \\
\hline 12 & & $\mid r-32 a$ & 97 & $79 a$ & & & & & \\
\hline 13 & & Ir-34 & 42 & 82 & & & & & \\
\hline 14 & & Ir-38 & 95 & 84 & & & & & \\
\hline 15 & & $\mid r-42 a$ & 98 & 89 & 29 & & Ir-41b & 90 & 61 \\
\hline 16 & & $\mid r-43 a$ & 99 & 90 & & $\mathrm{~S} 12$ & & & \\
\hline 17 & & $\mid r-45 b$ & 96 & 92 & & & & & \\
\hline 18 & & $\mid r-48 a$ & 91 & 61 & 30 & $\mathrm{OH}$ & $\mid r-19 d$ & 91 & $79 c$ \\
\hline 19 & & $\mid r-49 a$ & 93 & 94 & 31 & S125 & Ir-32a & 91 & $79 c$ \\
\hline
\end{tabular}




\begin{tabular}{|c|c|c|c|c|c|c|c|}
\hline 20 & Ir-51a & 70 & 97 & \multirow{3}{*}{32} & \multirow{3}{*}{$\mid r-19 a$} & \multirow{3}{*}{88} & \multirow{3}{*}{67} \\
\hline 21 & $\mid r-52 a$ & 49 & 98 & & & & \\
\hline 22 & Ir-53 & 20 & 99 & & & & \\
\hline 23 & Ir-58b & 90 & $102 c$ & 33 & Ir-24b & 95 & $73 b$ \\
\hline \multirow[t]{2}{*}{24} & $\mid r-61 c^{g}$ & 81 & 103 & 34 & Ir-45b & 90 & 92 \\
\hline & & & & 35 & Ir-58b & 83 & $102 c$ \\
\hline
\end{tabular}

${ }^{\mathrm{g}} \mathrm{R}^{1}={ }^{\mathrm{t}} \mathrm{Bu} ; \mathrm{R}^{2}=\mathrm{NCy}_{2}$

The substrate scope has recently been extended to include 1,1-aryl/alkyl-, 1,1-diaryl- and 1,3-dialkyl trisubstituted allylic alcohols and the challenging terminal allylic alcohols. For 1,1-aryl/alkyl and 1,1-diaryl trisubstituted olefins S121-S124 the best enantioselectivities have been achieved using phosphine-thiazole 48a (Figure 6) and phosphine-imidazole 41b (Figure 6) ligands, respectively (Table 7, entries 25 and 27-29). ${ }^{61,94}$ For the alkyl allylic alcohol S125 the use of phosphinite-oxazoline 19d (Figure 4) and phosphinite-pyridine 32a (Figure 5) ligands lead to high enantiomeric excess (ee's up to $91 \%$; Table 7 , entries $30-31$ ). ${ }^{79 c}$ This later finding was further exploited to hydrogenate all four stereoisomers of farnesol (Section 2.1.2, Scheme 12b). ${ }^{132}$ For terminal allylic alcohols, the Ir-catalyzed asymmetric hydrogenation has achieved ee's up to $88 \%$ in the hydrogenation of $\mathbf{S 1 2 6}$ using phosphinite-oxazoline 19a (Figure 4) ligand (Table 7, entry 32). ${ }^{67}$ Introducing a phosphite moiety in the ligand design is advantageous, achieving enantioselectivities up to $95 \%$ in the reduction of S127 (Table 7, entry 33$){ }^{73 b}$

Diastereoselective hydrogenation of allylic alcohols can be efficiently used to construct $\alpha, \omega$-functionalized 1,3-dimethyl and 1,3,5-trimethyl fragments (Scheme 16a). ${ }^{133}$ This finding constitutes an alternative to the diastereoselective hydrogenations of chiral homoallylic alcohols achieved largely using Rh- and Ir-diphosphine catalysts, which takes advantage of the chelating ability of the homoallylic substrate to achieve high diastereoselectivities. ${ }^{134}$ They showed that the chiral Crabtree analogue containing carbene-oxazoline ligand 25a (Figure 4) efficiently hydrogenated substrates S128-S131 to achieve the $\alpha, \omega$-difunctionalized 2,4dimethylpentane and 2,4,6-trimethylheptane in high diastereoselectivity. 
Interestingly, catalyst Ir-ent-25a gave appreciable selectivity for the opposite diastereoisomer, which illustrates that catalyst control is operative in these reactions. However, the geometry of the allylic alcohol is significant for optimizing the selectivity of the process. Thus, while for the reduction of $E$ allylic alcohol S128, the Ir-25a catalyst favored the anti product (syn/anti= 1:8.9), the use of Z-allylic alcohol $\mathbf{S 1 2 9}$ favors the syn product (syn/anti= 34:1) using Ir-25a (Scheme 16a). ${ }^{133 a, 135}$ The potential application of this methodology has been demonstrated with the preparation of $(S, R, R, S, R, S)$ $4,6,8,10,16,18$-hexamethyldocosane, a putative sex pheromone from an Australian beetle, for which the diastereoselective hydrogenation of $\mathbf{S 1 2 9}$ is the key step. ${ }^{133 b}$ Additionally, the same authors proved that $\alpha$ monofunctionalized 1,3-dimethyl chiral fragments can be achieved albeit with lower stereocontrol compared with the $\alpha, \omega$-difunctionalized (Scheme 16b). ${ }^{136}$ 
(a)

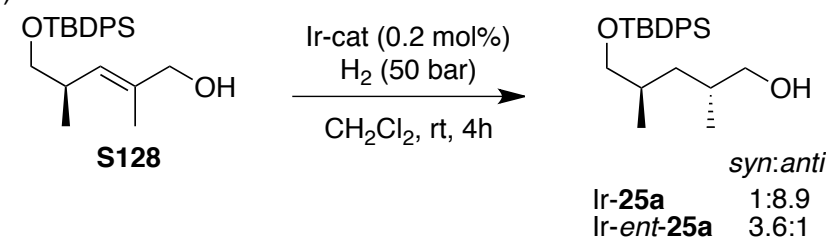

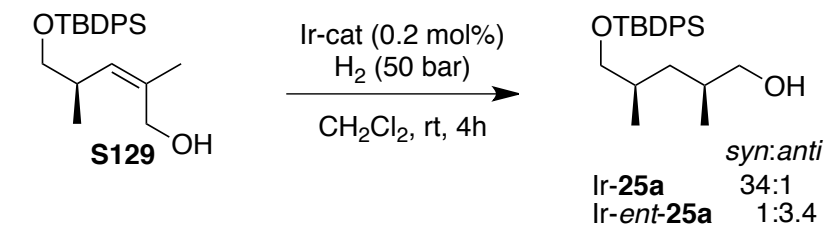

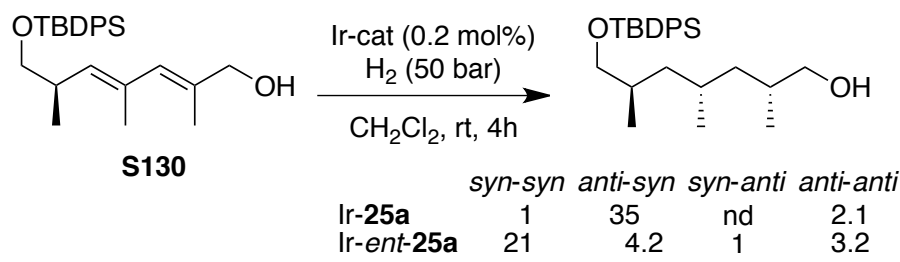<smiles>C/C(=C\[C@H](C)CC(C)C[18OH])CO</smiles>

(b)

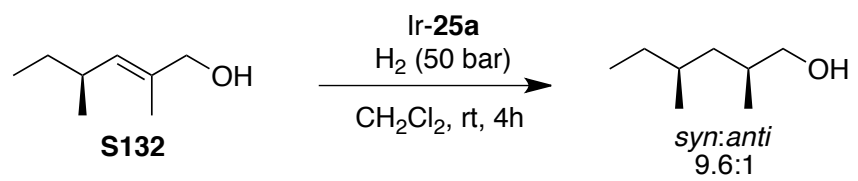

Scheme 16 Hydrogenation of allylic alcohols S128-S132.

Recently this methodology has been used for the preparation of $\alpha$-methyl- $\gamma-$ aminoacid derivatives from $\mathrm{N}$-acetyl protected allylic alcohols (syn/anti up to >19:1; Scheme 17). ${ }^{137}$ The stereoselectivity can be improved further by 
protecting the alcohol using a tert-butyldiphenylsilyl protecting group (syn/anti up to $49: 1$ ).<smiles>CC(=CC(Br)NC(=O)OCc1ccccc1)CO</smiles>

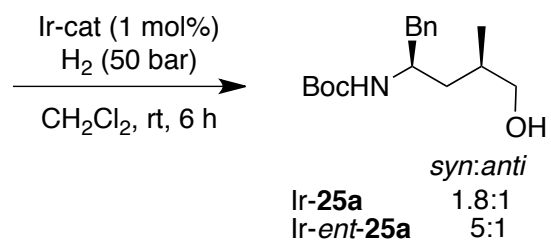

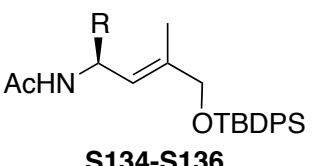

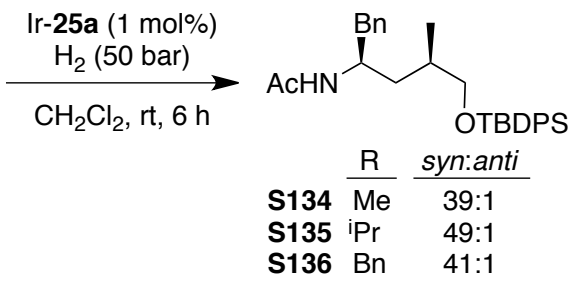<smiles>CC(=O)NC(P)/C=C(/C)CO[Pb]</smiles>

S137-S139
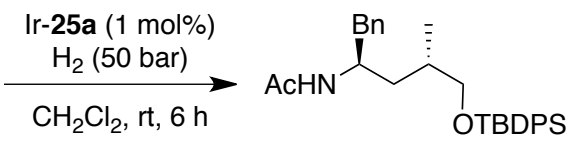

$$
\begin{array}{llc}
\mathrm{S} 137 & \mathrm{R} & \text { syn:anti } \\
{ } } & & 1: 40 \\
\mathrm{i} & \mathrm{Pr} & 1: 43
\end{array}
$$

Scheme 17 Hydrogenation of $\mathrm{N}$ - or O-protected amino alcohol derivatives S133-S139.

Diastereoselective reduction of allylic alcohols can also be used as an efficient alternative for the preparation of 1,3-hydroxymethyl fragments. ${ }^{138}$ The hydrogenation of the allylic alcohol $\mathbf{S 1 4 0}$ is catalyst controlled, which allows the preparation of both syn and anti stereoisomers with high stereocontrol (Scheme 18). This behavior is in contrast to the one observed for the hydrogenation of the related homoallylic alcohol $\mathbf{S 1 4 1}$, which proceeds via substrate control and therefore only one isomer is preferentially formed (Scheme 18). Alkenes derived from lactic acid (substrates $\mathbf{S} 142$ and $\mathbf{S 1 4 3}$, Scheme 18) were also explored and it was discovered that while the hydrogenation of $\mathbf{S 1 4 2}$ proceeds via catalyst control, the reduction of $\mathbf{S 1 4 3}$, in which the protecting group was changed from a secondary alcohol to a primary one, proceeds via substrate control. ${ }^{138}$ The latter has been attributed 
to the coordination of the allylic alcohol to iridium, which can occur via direct oxygen coordination to iridium or via hydrogen bonding from an Ir-hydride to the allylic alcohol oxygen. The authors illustrated the potential utility of this methodolgy in the total syntheses of (-)-dihydromyoporone ${ }^{138}$ and (-)spongidepsin. ${ }^{139}$<smiles>CC(CO)COCCO</smiles>

S140

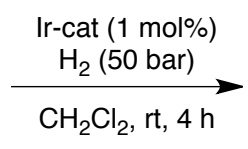

1) ri-cat $(1 \mathrm{~mol} \%)$

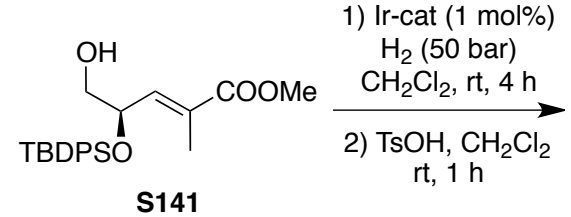

S141<smiles>CCOC(C)C=C(C)CO</smiles>

S142

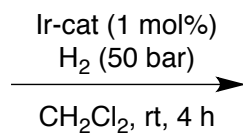

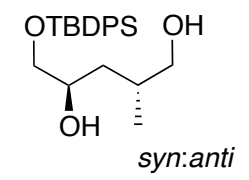

Ir-25a 1:24

Ir-ent-25a 14: 1<smiles>CC1CC(O[18OH])COC1=O</smiles>

syn:anti

$\begin{array}{ll}\text { Ir-25a } & 19: 1 \\ \text { Ir-ent-25a } & 17: 1\end{array}$

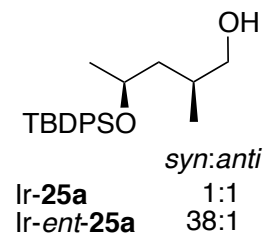

Ir-ent-25a $\quad 38: 1$<smiles>CC(=CC(C)O)COCCO</smiles>

S143

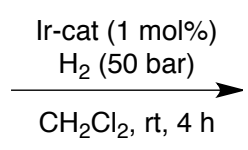

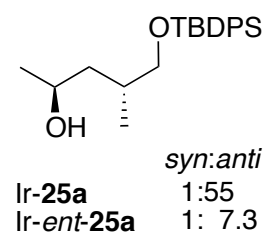

Scheme 18 Hydrogenation of allylic and homoallylic alcohols S140-S143.

Chiral Crabtree-type catalysts have recently been used to prepare 1,2dimethyl fragments very efficiently from chiral allylic and homoallylic alcohols (Scheme 19). In all the cases studied the hydrogenation proceeds via catalyst control rather than substrate control, which allows the formation of both 
diastereoisomers. ${ }^{140}$ The substrate however, also has an important effect on the stereoselectivities. Thus, while coordination effects are significant for homoallylic alcohols (i.e. substrate S144) the steric factors are important for the homoallylic silyl ethers (i.e. substrate S145). This methodology was used in the total synthesis of the neurotoxin (+)-kalkitoxin as well as in the total synthesis of (-)-lasitol, a substance isolated from Lasius meridionalis ants. ${ }^{140}$
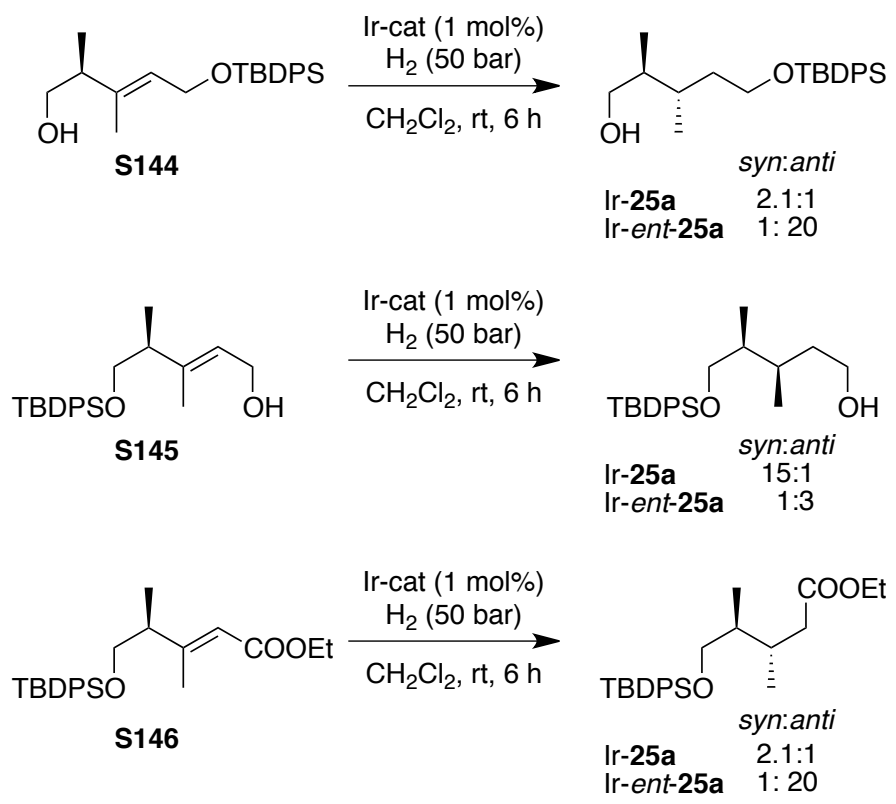

Scheme 19 Hydrogenation of allylic and homoallylic alcohols S144-S146

Similarly, chiral aldol-type 1,2-hydroxymethyl fragments were efficiently synthesized from trisubstituted allylic alcohols using chiral analogues of Crabtree's catalyst giving both the syn- and anti-isomers (Scheme 20). ${ }^{141}$ This methodology is in contrast to those developed using terminal allylic alcohols with metal-diphosphine catalysts that proceeds under substrate control. ${ }^{142}$ It is interesting to note that the best syn-selectivity was achieved using allylic alcohol S147 (Scheme 20). Glucitol derivatives S148-S149, which gives access to $\alpha, \omega$-difunctional fragments, could also be selectively reduced (Scheme 20). 


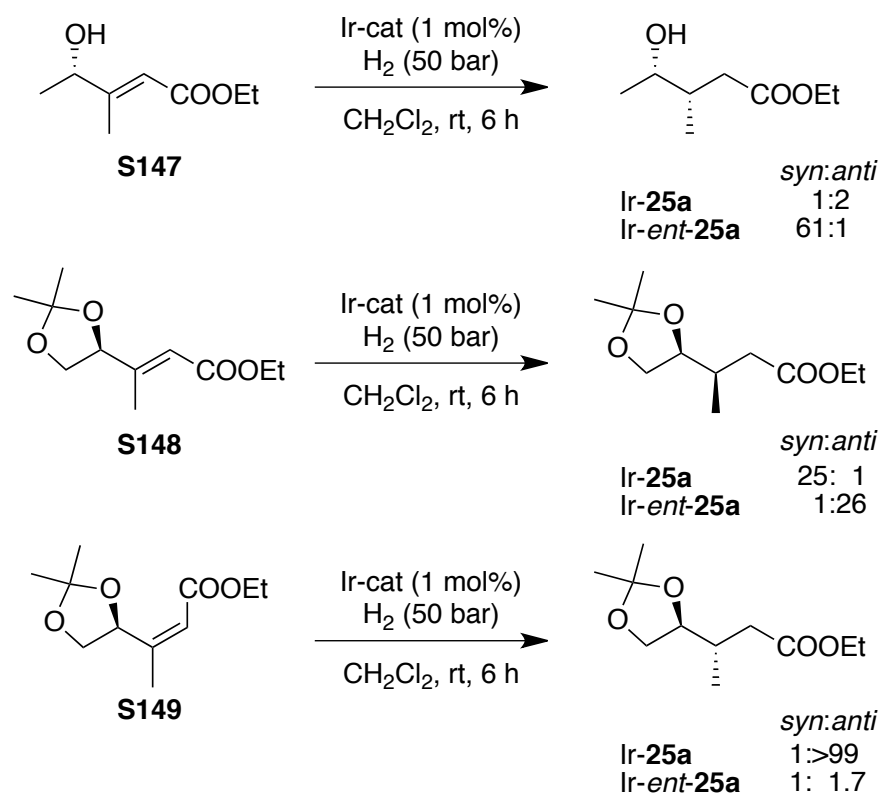

Scheme 20 Hydrogenation of allylic alcohol derivatives S147-S149.

\section{$6 \alpha, \beta$-Unsaturated Carbonyls}

\section{$6.1 \alpha, \beta-$ Unsaturated Carboxylic Acids}

Asymmetric hydrogenation of $\alpha, \beta$-unsaturated carboxylic acids using [Ru(BINAP)(OAc) $)_{2}$ (Scheme 1) was described by Noyori in $1987^{11}$ and has been developed to include a variety of di- and trisubstituted examples (Figure 16). ${ }^{122 a, b, 143}$ The reaction has also proven to give high enantioselectivities using rhodium-diphosphine or phosphoramidite catalysts although with a somewhat limited substrate scope. ${ }^{122 c, d, 144}$

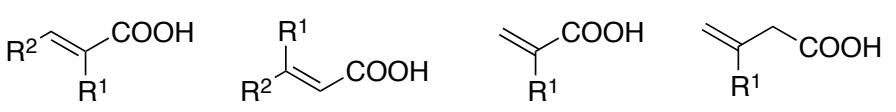

Figure 16 Typical substrates for the Rh and Ru catalyzed hydrogenation.

During the past few years, chiral analogues of Crabtree's catalyst have also been used to enantioselectively reduce $\alpha, \beta$-unsaturated carboxylic acids. 
a-Substituted cinnamic acids, which have served as the benchmark substrates for the ruthenium-catalyzed reaction have also been extensively studied with $[\operatorname{Ir}(\mathrm{cod})(\mathrm{N}, \mathrm{P})]\left[\mathrm{BAr}_{\mathrm{F}}\right]$ complexes. Unlike hydrogenation of weaklyfunctionalized olefins, the asymmetric hydrogenation of $\alpha, \beta$-unsaturated carboxylic acids is usually performed in methanol and is hence similar to the traditional P,P-ligated rhodium catalytic systems. Analogous to the ruthenium and rhodium case, coordination of the carboxylate ion to form a chelate with iridium has been suggested.

Using their spirocyclic ligand 67 a (Figure $13, R^{1}=3,5-{ }^{t} \mathrm{Bu}_{2}-\mathrm{Ph}$ and $\mathrm{R}^{2}=$ $\mathrm{Bn})$, Zhou and co-workers could reduce several $\alpha$-alkyl substituted cinnamic acids (S150 and S151) in excellent enantioselectivity (Table 8, entries 1 and $2) .{ }^{145}$ The reaction featured high catalytic activity under mild conditions but addition of base was crucial for high catalytic activity. A slightly modified ligand $67 \mathrm{c}$ (Figure 13, $\mathrm{R}^{1}=3,5-{ }^{\mathrm{t}} \mathrm{Bu} \mathrm{u}_{2}-\mathrm{Ph}$ and $\mathrm{R}^{2}={ }^{i} \mathrm{Pr}$ ) was used when targeting alkyl-alkyl substituted alkenes (i.e. substrates S152-S153; Table 8, entries 3 and 4). 
Table 8 Representative results from the asymmetric hydrogenation of $\alpha, \beta$ disubstituted $\alpha, \beta$-unsaturated carboxylic acids using spirocyclic ligands 67 and 68 .

\begin{tabular}{|c|c|c|c|c|c|c|c|c|}
\hline & & & & $\operatorname{Ir}(\operatorname{cod})(\mathbf{L})]$ & & & & \\
\hline & & & & $\begin{array}{c}\mathrm{H}_{2}(6-30 \\
\text { Base } \\
\mathrm{rt}, \mathrm{MeO}\end{array}$ & & I & & \\
\hline ntry & & $\mathrm{R}^{1}$ & $\mathrm{R}^{2}$ & $\begin{array}{l}\text { Ir-cat. } \\
(\mathrm{mol} \%)\end{array}$ & L & Base & $\begin{array}{l}e e \\
(\%)\end{array}$ & Ref. \\
\hline 1 & S150 & $\mathrm{Me}$ & $\mathrm{Ph}$ & 0.25 & $67 a$ & $0.5 \mathrm{NEt}_{3}$ & $>99$ & 145 \\
\hline 2 & S151 & $\mathrm{iPr}$ & $\mathrm{Ph}$ & 0.25 & $67 a$ & $0.5 \mathrm{NEt}_{3}$ & 99 & 145 \\
\hline 3 & S152 & $\mathrm{Me}$ & $\mathrm{Et}$ & 0.25 & $67 c$ & $0.5 \mathrm{Cs}_{2} \mathrm{CO}_{3}$ & 98 & 145 \\
\hline 4 & S153 & ${ }^{n P r}$ & $\mathrm{Me}$ & 0.25 & $67 c$ & $0.5 \mathrm{Cs}_{2} \mathrm{CO}_{3}$ & 98 & 145 \\
\hline 5 & S154 & $\mathrm{Ph}$ & $\mathrm{Me}$ & 1.0 & $68 a$ & $1.0 \mathrm{NEt}_{3}$ & 94 & 146 \\
\hline $6^{a}$ & S155 & $\mathrm{Ph}$ & $\mathrm{Ph}$ & 1.0 & $68 a$ & $1.0 \mathrm{NEt}_{3}$ & 94 & 146 \\
\hline $7^{b}$ & S155 & $\mathrm{Ph}$ & $\mathrm{Ph}$ & 0.25 & $67 d$ & $0.5 \mathrm{Cs}_{2} \mathrm{CO}_{3}$ & 95 & 146 \\
\hline
\end{tabular}

a Reaction performed at $50^{\circ} \mathrm{C} .{ }^{b}$ Reaction performed at $45^{\circ} \mathrm{C}$.<smiles>[R]C1COC(C2=CCC[C@H]2C(P)=CCCCP)=N1</smiles>

68

Another spirocyclic phosphine-oxazoline ligand, 68a (Table 8, $\mathrm{R}^{1}=0-$ tol, $R^{2}=P h$ ), was utilized in the asymmetric hydrogenation of $\alpha$-aryl substituted unsaturated carboxylates S154 and S155. ${ }^{146}$ Under somewhat forceful conditions, enantioselectivities $>90 \%$ ee were obtained for a series of substrates (Table 8, entries 5 and 6). Ligand $\mathbf{6 7 d}$ (Figure 13, $\mathrm{R}^{1}=3,5-{ }^{\mathrm{t}} \mathrm{Bu}_{2}-\mathrm{Ph}$ and $R^{2}=H$ ), which contains an unsubstituted oxazoline ring, was the best ligand from this family in the reduction of these bulky alkene substrates (Table 8, entry 7). ${ }^{147}$ The reaction could be performed under one atmosphere of $\mathrm{H}_{2}$ and enantioselectivities over $90 \%$ were consistently obtained. Synthesis of the isoflavane derivative (S)-equol using this methodology as the enantiodetermining step resulted in conversion of $\mathbf{S} 156$ in $97 \%$ yield and $98 \%$ 
ee (Scheme 21). By increasing the reaction time and temperature a substrate to catalyst ratio of $5000: 1$ could be used.<smiles>COc1ccc(/C(=C/c2ccc(OC)cc2OC)C(=O)O)cc1</smiles>

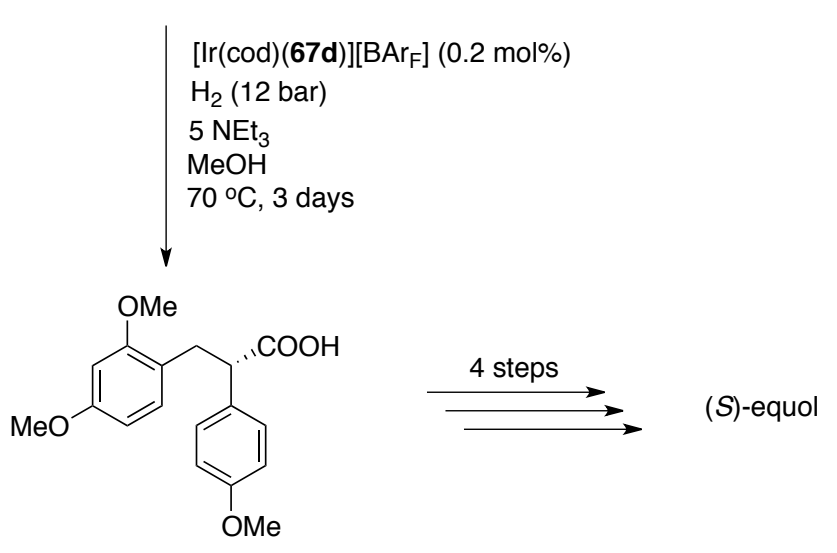

$97 \%$ yield, $98 \%$ ee

Scheme 21 The enantiodetermining step in the preparation of $(S)$-equol from S156 is catalyzed by $[\operatorname{lr}(\operatorname{cod})(67 d)]\left[B A r_{F}\right]$.

As mentioned in section 3.3, Zhou and co-workers also performed asymmetric hydrogenations of a variety $\alpha$-aryloxy and $\alpha$-alkyloxy crotonic and cinnamic acids using Ir-catalysts based on ligand 67 (Figure 13). ${ }^{145}$ The catalytic system tolerated the variation of the ether-group but more importantly, the $\beta$-substituent could be changed from $\mathrm{Ph}$ to $\mathrm{Me}$ to $\mathrm{H}$ while retaining good enantioselectivity. ${ }^{123}$

The successful asymmetric hydrogenations of crotonic- and cinnamicacid derivatives using iridium catalysts based on the spirocyclic oxazoline backbones prompted further expansion of the substrate scope. At $65{ }^{\circ} \mathrm{C}, \mathrm{E}-4-$ methyl-4-phenyl-3-butenoic acid $\mathbf{S 1 5 7}$ could be effectively reduced by $[\operatorname{lr}(\operatorname{cod})(67)]\left[\mathrm{BAr}_{\mathrm{F}}\right]$ in $60 \%$ ee provided that one equivalent of triethylamine or 
a similar amine base was present. ${ }^{148}$ Enantioselectivities above $90 \%$ ee could be obtained by changing the phosphine substituents to 3,5-dimethylphenyl. Furthermore, when the benzyl substituent on the oxazoline was changed to $\alpha$ methylnaphthyl (ligand 67e, Figure $13, R^{1}=3,5-\mathrm{Me}_{2}-\mathrm{Ph}$ and $\mathrm{R}^{2}=\mathrm{CH}_{2}-1$ naphthyl) ee's around $95 \%$ were obtained. With [Ir(cod)(67e)][BAr $\left.\mathrm{r}_{\mathrm{F}}\right]$, a series of 4,4-disubstituted 3-butenoic acids could be hydrogenated with good enantioselectivities (Scheme 22).

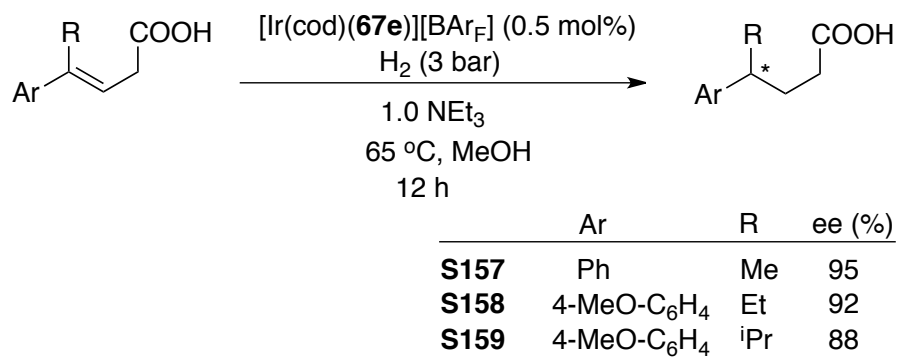

Scheme 22 Asymmetric hydrogenation of some $\beta, \beta$-disubstituted- $\alpha, \beta$ unsaturated acids S157-S159.

Another type of $\alpha, \beta$-unsaturated carboxylic acids, $\alpha$-substituted acrylic acids, were reduced slowly and in modest enantioselectivity using [Ir(cod)(67)][BAr $]$, under reaction conditions similar to those described above. Spirocyclic ligands where the oxazoline $\mathrm{N}$-donor had been replaced by a primary or secondary amine consistently gave enantioselectivities $>90 \%$ ee. ${ }^{149}$ Ligands $69 \mathrm{a}$ and $69 \mathrm{~b}$ both exhibited high selectivity but the former was significantly faster and thus used for further studies of both alkyl- (S161-163) and aryl-substituted (S160) derivatives (Scheme 23). Using $0.1 \mathrm{~mol} \%$ of $[\operatorname{lr}(\operatorname{cod})(69 \mathrm{a})]\left[\mathrm{BAr}_{\mathrm{F}}\right]$ under an atmosphere of hydrogen for $4 \mathrm{~h}$ produced quantitative yields and excellent enantioselectivities for a range of aryl- and alkyl-substituted substrates. 

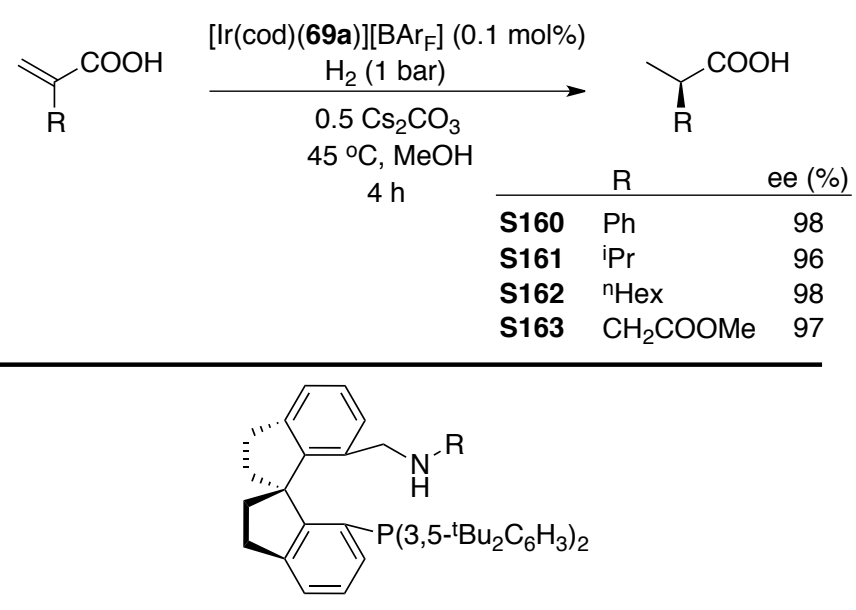

$69 \mathrm{a} \mathrm{R}=\mathrm{H}$

69b $R=M e$

Scheme 23 Asymmetric hydrogenation of some $\alpha$-substituted acrylic acids using phosphine-primary amine catalyst Ir-69a.

\section{$6.2 \alpha, \beta-$-Unsaturated Esters}

While (deprotonated) carboxylic acids are excellent coordinating functional groups, $\alpha, \beta$-unsaturated esters are less so. The $\alpha$ - and especially trans- $\beta$ methyl cinnamate esters such as $\mathbf{S 1 6 4}$ (Scheme 24) are typical test substrates for the asymmetric hydrogenation using $[\operatorname{Ir}(\operatorname{cod})(\mathrm{N}, \mathrm{P})]\left[\mathrm{BAr}_{\mathrm{F}}\right]$ complexes in $\mathrm{CH}_{2} \mathrm{Cl}_{2}$. The hydrogenation product has been obtained in $>95 \%$ ee using several ligands (Scheme 24). ${ }^{43,71 c, 77,90,94-95,98,103 a}$

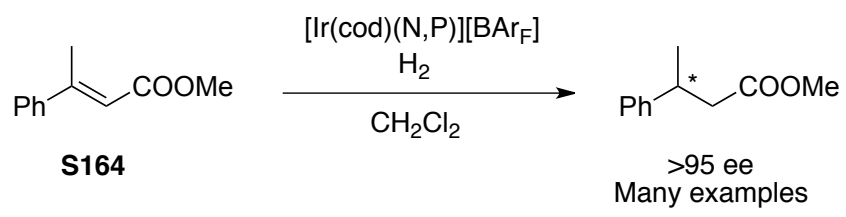

Scheme 24 trans- $\beta$-Methyl cinnamate ester S164 has been hydrogenated in excellent enantioselectivity by a large number of $\mathrm{N}, \mathrm{P}$-ligated Ir-complexes.

Besides S164, $\beta, \beta$-disubstituted acrylate esters haven't been extensively explored. However recently, chiral mimics of Crabtree's catalyst have proven useful for the asymmetric hydrogenation of these alkenes. Both the $E$ - and Z- isomer of the challenging methyl/phenethyl derivatives $\mathbf{S 1 6 5}$ 
and S166 (Table 9, entries 1 and 2) could be reduced in good enantioselectivity using the successful pyridine-phosphinite ligands $32 a$ and 32b (Figure 5). ${ }^{79 a}$

As described in section 3.3, the asymmetric hydrogenation of unsaturated esters that also contain vinylic ethers was succesful using ligand 25a (Figure 4). ${ }^{126 a}$

Ligand 13a (Figure 4) was used to obtain enantioselectivities over $90 \%$ for several $\beta, \beta$-substituted $\alpha, \beta$-unsaturated esters. ${ }^{57}$ Both the $\beta$-methyl (S167) and $\beta$-ethyl (S168) derivative could be highly selectively reduced (Table 9 , entries 3 and 4 ), but more significantly, the Z-alkene $\mathbf{S} 169$ could be reduced in $92 \%$ enantioselectivity (entry 5 ).

Recently, a comprehensive screening of $\alpha, \beta$-unsaturated esters in the Ir-catalyzed asymmetric hydrogenation was performed in order to thoroughly establish the substrate scope. ${ }^{150}$ Previously developed bicyclic ligands $\mathbf{1 7 b}$ (Figure 4) and 49b (Figure 6), which gave excellent enantioselectivity in the asymmetric hydrogenation of both $E$ - and $Z$ - $\beta$-methyl cinnamate esters were used. ${ }^{60 a, 95} \mathrm{~A}$ range of structurally different substrates (S170-S173) were reduced with excellent enantioselectivity (Table 9, entries 6-9). ${ }^{150}$

Table 9 Representative results from the asymmetric hydrogenation of $\beta, \beta$ disubstituted acrylate esters.

\begin{tabular}{|c|c|c|c|c|c|c|c|}
\hline & $R$ & & $\operatorname{Ir}(\operatorname{cod})(L)][B$ & & & & \\
\hline & & & $\begin{array}{c}\mathrm{H}_{2} \\
\text { rt, } \mathrm{CH}_{2} \mathrm{Cl}_{2}\end{array}$ & & & & \\
\hline htr & & $\mathrm{R}$ & $\mathrm{R}^{1}$ & $\mathrm{R}^{2}$ & $\mathbf{L}$ & ee $(\%)$ & Ref. \\
\hline 1 & S165 & $\mathrm{Me}$ & $\mathrm{CH}_{2} \mathrm{Bn}$ & Et & $32 a$ & 89 & $79 a$ \\
\hline 2 & S166 & $\mathrm{CH}_{2} \mathrm{Bn}$ & $\mathrm{Me}$ & Et & $32 b$ & 93 & $79 a$ \\
\hline 3 & S167 & $\mathrm{Me}$ & 4-MeO- $\mathrm{C}_{6} \mathrm{H}_{4}$ & Et & $13 a$ & 98 & 57 \\
\hline 4 & S168 & Et & 4-MeO- $\mathrm{C}_{6} \mathrm{H}_{4}$ & Et & $13 a$ & 98 & 57 \\
\hline 5 & S169 & 4- $\mathrm{MeO}-\mathrm{C}_{6} \mathrm{H}_{4}$ & $\mathrm{Me}$ & Et & $13 a$ & 92 & 57 \\
\hline 6 & S170 & $\mathrm{iPr}$ & $\mathrm{Ph}$ & Et & $17 b$ & $>99(S)$ & 150 \\
\hline 7 & S171 & $\mathrm{Ph}$ & $\mathrm{P} P r$ & Et & $49 b$ & $>99(R)$ & 150 \\
\hline 8 & S172 & $\mathrm{Me}$ & $\mathrm{CH}_{2} \mathrm{Ph}$ & $\mathrm{Et}$ & $17 b$ & $93(+)$ & 150 \\
\hline 9 & S173 & $\mathrm{CH}_{2} \mathrm{Ph}$ & $\mathrm{Me}$ & Et & $49 b$ & $85(-)$ & 150 \\
\hline
\end{tabular}


For all cases, when changing between the $E$ - and $Z$ - isomers, products with the opposite absolute configuration were obtained when using catalysts with the same configuration (Table $9, \mathbf{S} 170$ vs. $\mathbf{S} 171$ and $\mathbf{S 1 7 2}$ vs. S173).

$\beta, \beta$-Diaryl methyl acrylates ( $\beta$-aryl cinnamate esters) have been reduced using $\mathrm{N}, \mathrm{P}$-ligated iridium complexes, albeit less enantioselectively. With $1 \mathrm{~mol} \%[\operatorname{Ir}(\operatorname{cod})(46)]\left[\mathrm{BAr}_{\mathrm{F}}\right]$ under 100 bar $\mathrm{H}_{2}$, three sterically demanding alkenes (S174-S176) could be hydrogenated in moderate enantioselectivity (Scheme 25). ${ }^{61}$

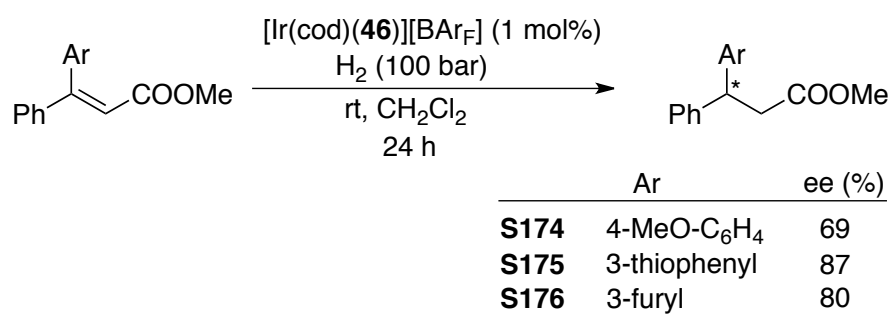

Scheme 25 Asymmetric hydrogenation of some $\beta$-aryl cinnamate esters using $[\operatorname{lr}(\operatorname{cod})(46)]\left[B A r_{F}\right]$.

The trans-a-methyl cinnamates have also been used as substrates for asymmetric hydrogenation with chiral analogues of Crabtree's catalyst but generally results in lower enantioselectivities than their $\beta$-substituted counterparts. ${ }^{60 a, 71 c, 95,103 a}$

During attempts to identify suitable ligands for the asymmetric hydrogenation of $\alpha, \beta$-substituted ethyl acrylates, bicyclic oxazoline 17c (Figure 4) was identified as an especially selective ligand. ${ }^{150}$ Using $0.5 \mathrm{~mol} \%$ $[\operatorname{lr}(\operatorname{cod})(17 \mathrm{c})]\left[\mathrm{BAr}_{\mathrm{F}}\right]$, both alkyl and aryl-substituted alkenes could be reduced in excellent enantioselectivity (Scheme 26). 


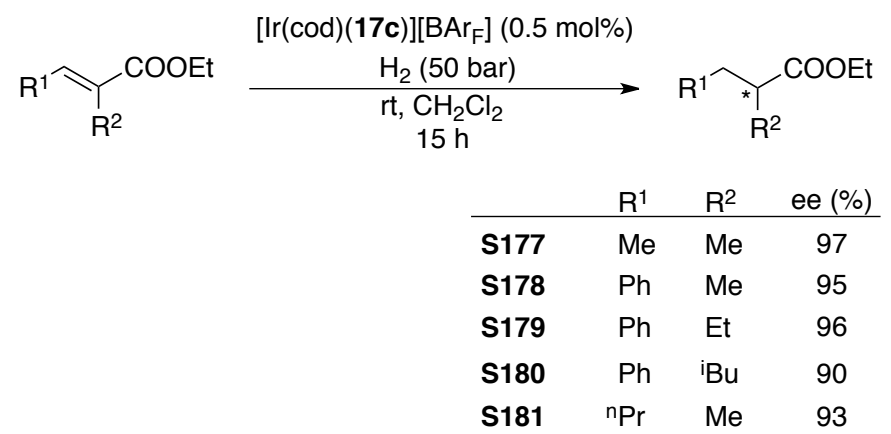

Scheme 26 Asymmetric hydrogenation of $\alpha, \beta$-substituted ethyl acrylates S177-S181.

In addition to varying the alkene substituents, a comparison of different tiglate and a-methyl cinnamate esters was also done. It was found that the alcohol part of the ester only had a minor influence on the enantioselectivity (Et, Bn, 'Pr and (+)-1-phenylethyl esters all gave similar enantioselectivities).

Newton, Ley and co-workers performed the diastereoselective hydrogenation of the $\alpha, \beta$-unsaturated ester $\mathbf{S 1 8 2}$ by feeding it together with 2 $\operatorname{mol} \%[\operatorname{lr}(\operatorname{cod})(e n t-19 a)]\left[B A r_{F}\right]$ (Figure 4) and $\mathrm{CH}_{2} \mathrm{Cl}_{2}$ into a flow-reactor. ${ }^{151}$ Hydrogen was added by a "tube-in-tube" diffusion system. By heating the flow to $50{ }^{\circ} \mathrm{C}$ for $80 \mathrm{~min}$, the product could be obtained in $75 \%$ diastereomeric excess (Scheme 27). Modifications of the setup allowed a decrease the catalyst loading however, although several catalysts were tested, the diastereomeric excess could not be significantly improved. 


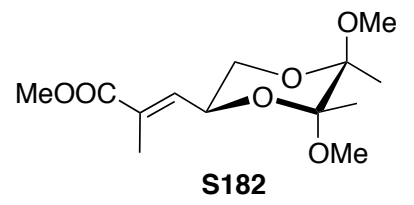

$\left[\operatorname{lr}(\mathrm{cod})(\right.$ ent-19a) $]\left[\mathrm{BAr}_{\mathrm{F}}\right](2 \mathrm{~mol} \%)$

$$
\mathrm{CH}_{2} \mathrm{Cl}_{2}
$$

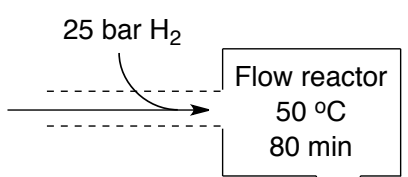

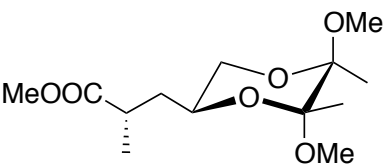

$93 \%$ conversion $75 \%$ de

Scheme 27 Diastereoselective hydrogenation of $\mathbf{S 1 8 2}$ performed in a flow reactor setup.

Ir-catalyzed asymmetric hydrogenation of five- and six-membered $\alpha, \beta$ unsaturated lactones with exocyclic double bonds has also been performed. ${ }^{152}[\operatorname{Ir}(\mathrm{cod})(70)]\left[\mathrm{BAr}_{\mathrm{F}}\right]$, under 20 bar $\mathrm{H}_{2}$ in toluene, reduced the unsaturated five-membered lactone $\mathbf{S} 183$ in $95 \%$ ee and the unsaturated sixmembered lactone $\mathbf{S} 184$ in $71 \%$ ee (Scheme 28 ).

Ir-17c (Figure 4), which formed an excellent catalyst for the enantioselective reduction of $\alpha, \beta$-substituted acyclic esters, also reduced the six-membered phenyl- and methyl-substituted alkenes \$184 and \$185, giving the saturated lactones in excellent ee (Scheme 28). ${ }^{150}$ 

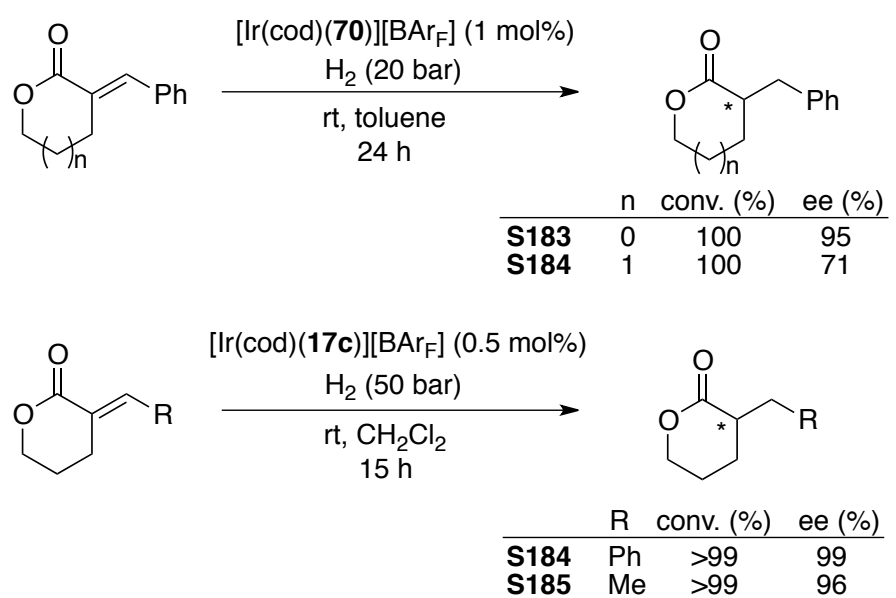<smiles>CC(C)[C@@H]1COC(c2ccccc2-c2ccccc2-c2ccccc2)=N1</smiles>

Scheme 28 Asymmetric hydrogenation of some $\alpha, \beta$-unsaturated lactones with exocyclic alkenes, S183-S185.

While the asymmetric hydrogenation of exocyclic alkenes in $\alpha, \beta$ unsaturated lactones yields products with an $\alpha-\mathrm{CH}_{2} \mathrm{R}$ substituent, the reduction of $\alpha, \beta$-unsaturated lactones with a $\beta$-substituted internal alkene gives more useful products. Unfortunately, the reduction of such alkenes has been shown to proceed only slowly. ${ }^{153}$ Five-membered methyl- and phenylsubstituted alkenes $\mathbf{S} 186$ and $\mathbf{S 1 8 7}$ were reduced in good enantioselectivity but only to $20 \%$ conversion after $24 \mathrm{~h}$ under 100 bar $\mathrm{H}_{2}$ using catalysts based on bicyclic ligands 17b (Figure 4) and 49b (Figure 6) (Scheme 29). For the six-membered variants, phosphine-imidazole ligand 41b (Figure 6) gave similar selectivity and conversion for the phenyl-derivative $\mathbf{S 1 8 8}$ while the methyl-substituted alkene $\mathbf{S 1 8 9}$ was completely reduced. ${ }^{153}$ 

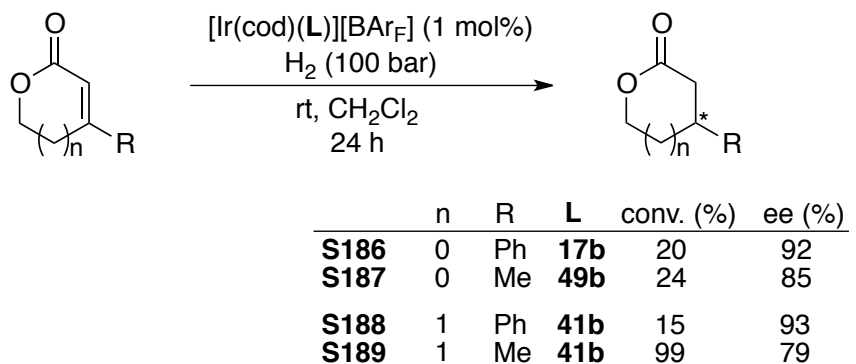

Scheme 29 Asymmetric hydrogenation of $\alpha, \beta$-unsaturated lactones with endocyclic alkenes, S186-S189.

\section{$6.3 \alpha, \beta-$-Unsaturated Amides}

A few examples of asymmetric hydrogenation of acrylic amides, catalyzed by chiral analogues of Crabtree's catalyst, have also appeared. Ferrocene-based PHOX-mimic 12b (Figure 4) was found to be the best ligand for the asymmetric hydrogenation of $\alpha, \beta$-disubstituted acrylamides (Scheme 30 ). ${ }^{154}$ While the $\alpha$-substituent was either methyl or methylene throughout, the $\beta$ substituent could be either aryl (S190-S192) or alkyl (S193-S195). Changing the amide $\mathrm{N}$-substituents moderately affected the enantioselectivity (this was also observed for the $\alpha, \beta$-disubstituted esters where the alcohol part only had a minor influence on the enantioselectivity). It was however shown, that for the trans- $\alpha$-methyl, $\beta$-phenyl derivatives such as $\mathbf{S 1 9 0}$, primary amides gave higher enantioselectivity than their secondary counterparts, and ${ }^{i} \mathrm{Bu}$ was the $\mathrm{N}$-substituent that gave the highest ee.

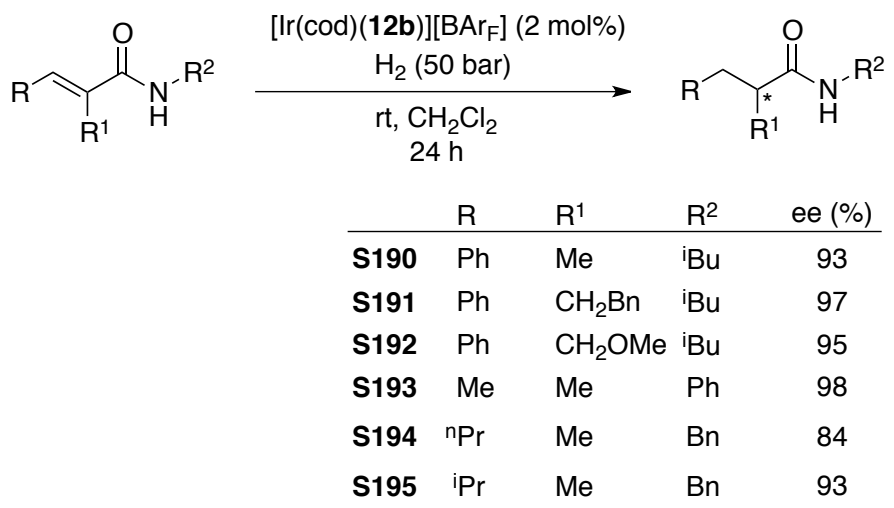


Scheme 30 Representative results from the asymmetric hydrogenation of $\alpha, \beta$-disubstituted acrylamides using $[\operatorname{lr}(\operatorname{cod})(\mathbf{1 2 b})]\left[B \mathrm{Br}_{\mathrm{F}}\right]$.

Recently, asymmetric hydrogenations of $\beta, \beta$-disubstituted acrylic Weinreb amides was presented. ${ }^{155}$ Using $[\operatorname{Ir}(\operatorname{cod})(68 \mathrm{~b})]\left[\mathrm{BAr}_{\mathrm{F}}\right]$ (ligand $\mathbf{6 8 b}$; see Table $8, \mathrm{R}^{1}=\mathrm{Ph}, \mathrm{R}^{2}=\mathrm{Bn}$ ) under 50 bar $\mathrm{H}_{2}$, high enantioselectivity could be obtained for several alkenes (Scheme 31). Although high enantioselectivities were maintained as long as the trans-substituent remained a bulky or aryl group $\left(\mathrm{R}=\mathrm{Ph}, \mathrm{Bn},{ }^{\mathrm{t}} \mathrm{Bu}\right.$ ), aliphatic trans-substituents such as in $\mathbf{S 2 0 0}$ gave significantly lower selectivity $\left(R={ }^{n} B u\right)$.<smiles>[2H]C=CC(=O)N(C)OC</smiles>

\begin{tabular}{|c|c|c|c|}
\hline \\
\hline \multicolumn{4}{|c|}{$\begin{array}{l}\mathrm{H}_{2}(50 \mathrm{bar}) \\
\mathrm{rt}, \mathrm{CH}_{2} \mathrm{Cl}_{2} \\
24 \mathrm{~h}\end{array}$} \\
\hline & $\mathrm{R}$ & $\mathrm{R}^{1}$ & ee $(\%)$ \\
\hline S196 & $\mathrm{Ph}$ & $\mathrm{Me}$ & 95 \\
\hline S197 & $\mathrm{Ph}$ & $\mathrm{iPr}$ & 82 \\
\hline S198 & 2- $\mathrm{MeC}_{6} \mathrm{H}_{4}$ & $\mathrm{Me}$ & 91 \\
\hline S199 & $\mathrm{Bn}$ & $\mathrm{Me}$ & 90 \\
\hline S200 & $\mathrm{n} B u$ & $\mathrm{Me}$ & 65 \\
\hline
\end{tabular}

Scheme 31 Asymmetric hydrogenation of $\beta, \beta$-disubstituted acrylamides.

\section{$6.4 \alpha, \beta-$-Unsaturated Ketones}

The asymmetric hydrogenation of $\alpha, \beta$-unsaturated ketones has been the subject of several studies. While the selective hydrogenation of the carbonyl function is best realized using the P,P-ligated Noyori-type catalytic systems, ${ }^{156}$ Takaya and co-workers showed that $\left[\operatorname{Ir}(\operatorname{cod})\left(\mathrm{BINAP}_{\mathrm{N}}\right)\left[\mathrm{BF}_{4}\right]\right.$ could be chemoselective towards either the carbonyl- or alkene-function of E-4-phenyl3-butene-2-one depending on the addition of auxiliary aminophosphine ligands. ${ }^{157}$ Alkene-selective asymmetric hydrogenation of enones has been achieved using various systems; P,P-ligated Ru- ${ }^{124,158} \mathrm{Rh}^{159}$ and $\mathrm{Pd}$ catalysts $^{160}$ have proven to be efficient. Organocatalytic transferhydrogenation $^{161}$ and auxiliary assisted heterogeneous systems ${ }^{162}$ have also 
shown to be advantageous. The majority of the above-mentioned catalytic systems are highly enantioselective for cyclic substrates but not as useful for the reduction of linear alkenes, and here, chiral mimics of Crabtree's catalyst have proved valuable.

Iridium complex $[\operatorname{Ir}(\operatorname{cod})(71)]\left[B \mathrm{r}_{\mathrm{F}}\right]$, based on sulphoximine-phosphine ligand 71, was found to give trace amounts of carbonyl reduction in the asymmetric hydrogenation of acyclic $\beta, \beta$-disubstituted enones. ${ }^{163}$ Thus, using [(71)][BAr $]$ under 60 bar $\mathrm{H}_{2}$ in toluene, the saturated ketone products could be obtained in good yield and enantioselectivity after 16-18 hours (Scheme 32). No change in selectivity was observed when the ketone substituent $\left(R^{2}\right)$ was replaced from a phenyl (S201) to a methyl (S202). Both the $E$ - and Zisomers of the phenyl/iso-propyl derivative (S204 and S205) gave excellent enantioselectivity but different absolute configurations of the product.

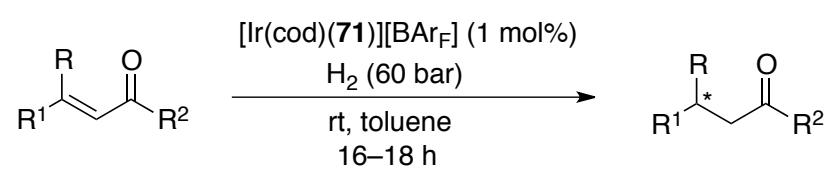<smiles>O=S(=O)(Nc1cccc2cccc(P)c12)c1ccccc1</smiles>

\begin{tabular}{llll|l} 
& $\mathrm{R}$ & $\mathrm{R}^{1}$ & $\mathrm{R}^{2}$ & ee (\%) \\
\hline $\mathbf{S 2 0 1}$ & $\mathrm{Me}$ & $\mathrm{Ph}$ & $\mathrm{Ph}$ & 81 \\
$\mathbf{S 2 0 2}$ & $\mathrm{Me}$ & $\mathrm{Ph}$ & $\mathrm{Me}$ & 79 \\
$\mathbf{S 2 0 3}$ & $\mathrm{Me}$ & $\mathrm{CH}_{2} \mathrm{Bn}$ & $\mathrm{Ph}$ & 81 \\
$\mathbf{S 2 0 4}$ & $\mathrm{Pr}$ & $\mathrm{Ph}$ & $\mathrm{Ph}$ & 97 \\
$\mathbf{S 2 0 5}$ & $\mathrm{Ph}$ & $\mathrm{iPr}$ & $\mathrm{Ph}$ & 92
\end{tabular}

Scheme 32 Representative results from the asymmetric hydrogenation of $\beta, \beta$-disubstituted $\alpha, \beta$-unsaturated ketones using $[\operatorname{Ir}(\operatorname{cod})(71)]\left[B A r_{F}\right]$.

$[\operatorname{lr}(\operatorname{cod})(71)]\left[B \mathrm{r}_{\mathrm{F}}\right]$ was also tested for the asymmetric hydrogenation of the $\alpha, \beta$-disubstituted enone E-3-methyl-4-phenyl-3-buten-2-one but the product was obtained in 55\% ee. ${ }^{164}$ Instead, the PHOX ligand 5 d, (Figure 3 ) proved to be highly selective for this reaction and gave the saturated ketone as the only product. Interestingly, when $\beta, \beta$-disubstituted enones were reduced by the same complex, significant amounts of the saturated alcohol were obtained. ${ }^{163}$ Using $[\operatorname{lr}(\operatorname{cod})(\mathbf{5 d})]\left[\mathrm{BAr}_{\mathrm{F}}\right]$, both aryl- and alkyl-substituted alkenes could be reduced in 3 hours and using only 2 bar $\mathrm{H}_{2}$ (Table 10 , 
entries 1-6). Good-to-excellent enantioselectivity was observed for all substrates tested including one 1,1-disubstituted alkene (\$210, entry 6) giving $86 \%$ ee.

While $[\operatorname{lr}(\operatorname{cod})(71)]\left[B \mathrm{Br}_{\mathrm{F}}\right]$ achieved slightly higher enantioselectivities with toluene as solvent, $[\operatorname{Ir}(\operatorname{cod})(5 d)]\left[B r_{F}\right]$ was used for the reduction of $\mathbf{S 2 0 7}$ and $\mathbf{S 2 0 6}$ with dichloromethane and close to identical results were observed (Table 10, entries 7 and 8). ${ }^{165}$

Recently, a catalytic system featuring phosphinite-oxazoline ligand $\mathbf{7 2}$, developed by Kazmaier and co-workers, was shown to give excellent enantioselecivities ( $>99 \%$ ee) in the hydrogenation of two $\alpha, \beta$-disubstituted enones (Table 10, entries 9 and 10). ${ }^{166}$

Table 10 Representative results from the asymmetric hydrogenation of $\alpha, \beta$ disubstituted enones. 


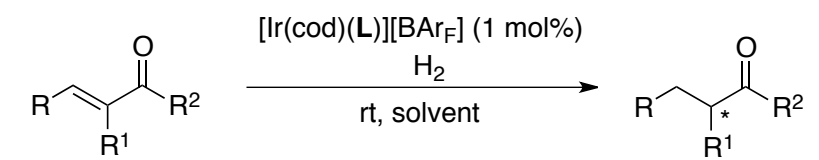

\begin{tabular}{r|llll|lll|l} 
Entry & $\mathrm{R}$ & $\mathrm{R}^{1}$ & $\mathrm{R}^{2}$ & Ligand & Solvent & ee (\%) & Ref. \\
\hline 1 & $\mathbf{S 2 0 6}$ & $\mathrm{Ph}$ & $\mathrm{Me}$ & $\mathrm{Ph}$ & $\mathbf{5 d}$ & toluene & $99(S)$ & 164 \\
2 & $\mathbf{S 2 0 7}$ & $\mathrm{Ph}$ & $\mathrm{Me}$ & $\mathrm{Me}$ & $\mathbf{5 d}$ & toluene & $98(S)$ & 164 \\
4 & $\mathbf{S 2 0 8}$ & $\mathrm{Ph}$ & $\mathrm{Ph}$ & $\mathrm{Ph}$ & $\mathbf{5 d}$ & toluene & $99(R)$ & 164 \\
5 & $\mathbf{S 2 0 9}$ & $\mathrm{Et}$ & $\mathrm{Me}$ & $\mathrm{Ph}$ & $\mathbf{5 d}$ & toluene & $87(S)$ & 164 \\
6 & $\mathbf{S 2 1 0}$ & $\mathrm{H}$ & $\mathrm{Bn}$ & $\mathrm{Ph}$ & $\mathbf{5 d}$ & toluene & $86(S)$ & 164 \\
7 & $\mathbf{S 2 0 7}$ & $\mathrm{Ph}$ & $\mathrm{Me}$ & $\mathrm{Me}$ & $\mathbf{5 d}$ & $\mathrm{CH}_{2} \mathrm{Cl}_{2}$ & 98 & 165 \\
8 & $\mathbf{S 2 0 6}$ & $\mathrm{Ph}$ & $\mathrm{Me}$ & $\mathrm{Ph}$ & $\mathbf{5 d}$ & $\mathrm{CH}_{2} \mathrm{Cl}_{2}$ & 97 & 165 \\
9 & $\mathbf{S 2 0 7}$ & $\mathrm{Ph}$ & $\mathrm{Me}$ & $\mathrm{Me}$ & $\mathbf{7 2}$ & $\mathrm{CH}_{2} \mathrm{Cl}_{2}$ & $>99$ & 166 \\
10 & $\mathbf{S 2 1 1}$ & $\mathrm{Ph}$ & $\mathrm{Et}$ & $\mathrm{Me}$ & $\mathbf{7 2}$ & $\mathrm{CH}_{2} \mathrm{Cl}_{2}$ & $>99$ & 166 \\
\hline
\end{tabular}

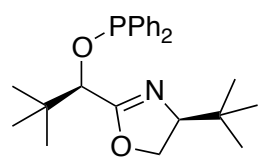

72

The exocyclic enones $\mathbf{S 2 1 2}$ and $\mathbf{S 2 1 3}$ are popular substrates for N,Pligated Ir-catalyzed hydrogenation systems and have been reduced effectively and in high enantioselectivity by several catalytic systems. ${ }^{152,164-166}$<smiles>O=C1CCCC/C1=C\c1ccccc1</smiles>

$\mathrm{S} 212$<smiles>O=C1/C(=C/c2ccccc2)CCc2ccccc21</smiles>

S213

Figure $17 \quad \alpha, \beta$-Disubstituted enones $\mathbf{S 2 1 2}$ and $\mathbf{S 2 1 3}$ are reduced in high enantioselectivity by several complexes of the type $[\operatorname{lr}(\operatorname{cod})(\mathrm{N}, \mathrm{P})]\left[\mathrm{BAr}_{\mathrm{F}}\right]$.

During the studies of linear alkenes, $[\operatorname{Ir}(\operatorname{cod})(8 d)]\left[B \operatorname{Br}_{F}\right]$ was also applied to the asymmetric hydrogenation of cyclic substrates and the catalytic system was shown to reduce the five-, six-, seven-, and eight-membered 
cyclic enones with exocyclic double bonds (S214-S217) in excellent enantioselectivity (Scheme 33). ${ }^{164}$

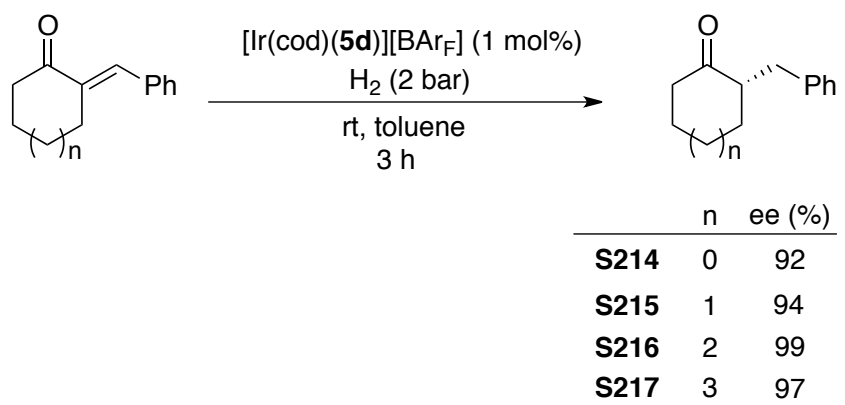

Scheme 33 Asymmetric hydrogenation of cyclic enones S214-S217 using $[\operatorname{lr}(\operatorname{cod})(5 d)]\left[B r_{r}\right]$.

Very high diastereo- and enantioselectivities were also observed for the reduction of enones S218 and S219 using $[\operatorname{Ir}(\operatorname{cod})(\mathbf{5 d})]\left[\mathrm{BAr}_{\mathrm{F}}\right]\left(\right.$ Scheme 34). ${ }^{165}$

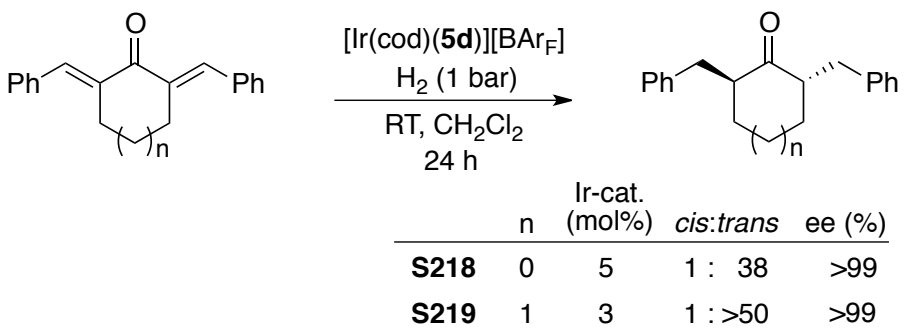

Scheme 34 Asymmetric hydrogenation of S218 and S219 using $[\operatorname{lr}(\operatorname{cod})(5 d)]\left[B A r_{F}\right]$.

The results obtained in the hydrogenation of S218 and S219, and especially the high distereoselectivities achieved, inspired the asymmetric hydrogenation of cyclic enones bearing 2-hydroxy groups S220-S222 (Scheme 35) ${ }^{167}$ In situ cyclization of the product ketones, possibly due to the acidity of the catalytic system, gave spiroketals which were isolated in good yields. Using ligand $68 \mathbf{b}$ (Table $8, R^{1}=P h, R^{2}=B n$ ), the five-membered cyclic ketone S220 was reduced in very low enantioselectivity while the sixmembered ketone S221 gave product spiroketals in excellent enantio- and 
diastereoselectivity. The seven-membered ketone $\mathbf{S 2 2 2}$ was also reduced in excellent ee but with a poor cis:trans ratio (Scheme 35).<smiles>O=C1/C(=C/c2ccccc2O)CCC/C1=C\c1ccccc1O</smiles>

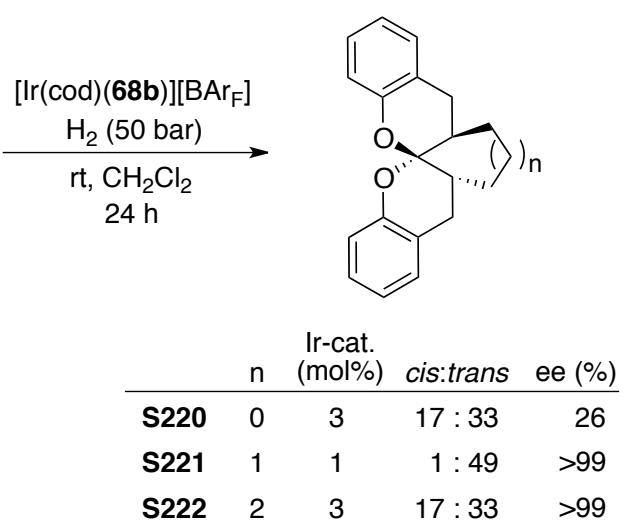

Scheme 35 Representative results from the asymmetric hydrogenation of enones with tandem spiroketalization.

As in the case of lactones, cyclic enones containing internal alkenes are reduced considerably slower and only one successful N,P-ligated iridium catalytic system has thus far been presented. $[\operatorname{lr}(\operatorname{cod})(\mathbf{4 1 b})]\left[B \mathrm{Br}_{\mathrm{F}}\right]$ (Figure 6), which also worked well in the reduction of the corresponding lactones (vide supra), was efficient in the asymmetric hydrogenation of three $\beta$-substituted cyclohex-2-enones. ${ }^{153}$ Both the methyl- (S223) and butyl-derivative (S224) could be completely reduced in good enantioselectivity in $\mathrm{CH}_{2} \mathrm{Cl}_{2}$ however the reaction time and hydrogen pressure had to be carefully controlled since a prolonged reaction time led to a reduction of the product ketone to the saturated alcohol (Scheme 36). While the carbonyl reduction did not begin until the alkene had been consumed for $\mathrm{R}=\mathrm{Me}$ and ${ }^{n} \mathrm{Bu}$, the phenyl derivative (S225) produced a mixture of saturated alcohols and ketone when performed in $\mathrm{CH}_{2} \mathrm{Cl}_{2}$. Although the degree of carbonyl reduction could be controlled by adjusting the $\mathrm{H}_{2}$ pressure, an alternative was to perform the reaction in 2,2,2-trifluoroethanol (TFE). Reduction of 3-phenyl-cyclohex-2enone in this solvent under 100 bar $\mathrm{H}_{2}$ gave the product (ketone) cleanly and in $94 \%$ ee (Scheme 36 ). 
<smiles>O=C1C=C(Br)CCC1</smiles>

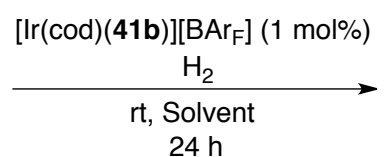

\begin{tabular}{ccccc} 
& $\mathrm{R}$ & solvent & $\mathrm{H}_{2}$ (bar) & ee (\%) \\
\hline S223 & $\mathrm{Me}$ & $\mathrm{CH}_{2} \mathrm{Cl}_{2}$ & 50 & 92 \\
S224 & $\mathrm{n}_{\mathrm{Bu}}$ & $\mathrm{CH}_{2} \mathrm{Cl}_{2}$ & 50 & 88 \\
S225 & $\mathrm{Ph}$ & TFE & 100 & 94
\end{tabular}<smiles>O=C1CCCC(P)C1</smiles>

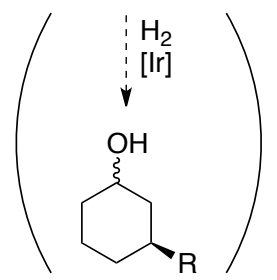

Scheme 36 The asymmetric hydrogenation of cyclic enones with $[\operatorname{lr}(\operatorname{cod})(\mathbf{4 1 b})]\left[\mathrm{BAr}_{\mathrm{F}}\right]$. The reaction conditions have to be controlled to avoid reduction of the product carbonyl.

The enantioselectivities in $\mathrm{CH}_{2} \mathrm{Cl}_{2}$ and TFE were comparable but slightly better in TFE for $\mathrm{R}=\mathrm{Ph}$ and $\mathrm{Me}$ and somewhat better in $\mathrm{CH}_{2} \mathrm{Cl}_{2}$ for $\mathrm{R}={ }^{\mathrm{n}} \mathrm{Bu}$. $\mathrm{N}, \mathrm{P}$-ligated iridium species can be a source of significant acidity, ${ }^{125}$ and it is possible that the alcoholic solvent acts as a buffer, preventing the carbonyl reduction either by removing formed protons or hydrogen bonding to the $\mathrm{C}=\mathrm{O}$ thus inhibiting bonding of Lewis acidic iridium species.

\section{Alkenes Bearing Other Heteroatoms}

Stereogenic centers bearing heteroatoms other than nitrogen or oxygen have also been prepared by asymmetric hydrogenation. With the exception of phosphorus as vinyl phosphonates, relatively few reports exist. The asymmetric hydrogenation of trisubstituted vinyl silanes has been performed exclusively using iridium N,P-catalysts, ${ }^{63}$ and the hydrogenation of thio-enolethers has only been reported using Rh-diphosphine catalytic system. ${ }^{168}$ Vinyl fluorides and boronates have been enantioselectivly reduced using different metal-ligand complexes and will be discussed.

\subsection{Phosphorus}

Vinyl phosphonates have frequently been used as substrates for asymmetric hydrogenation using rhodium-catalyzed systems. The majority of the reports focus on alkenes that, in addition to the phosphonate, also carry coordinating 
functional groups such as enamido- or enol ester-functionalities in the $\alpha$ or $\beta$ positions (Scheme 37). ${ }^{14,169}$ The products of these reactions are valuable as they are easily manipulated into $\alpha$ or $\beta$ amino- or hydroxy- phosphonic acids which, as amino acid isosters, have various effects in biological systems.

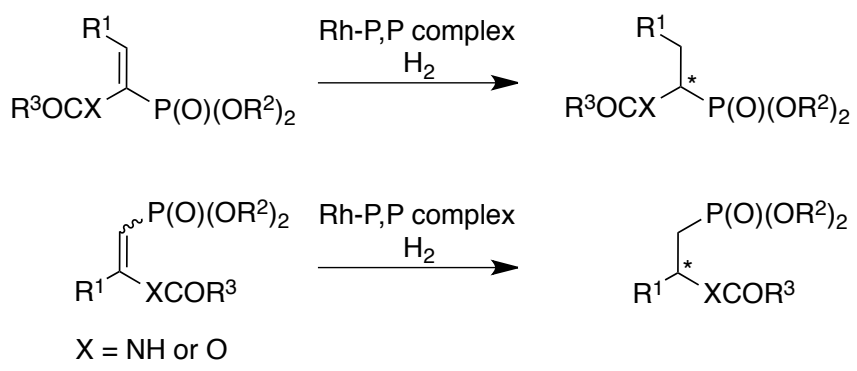

Scheme 37 Asymmetric hydrogenation of $\alpha$-enolbenzo- and $\alpha$-acetamidophosphonates are frequently performed with P,P-ligated rhodium catalysts.

Less functionalized vinyl phosphonates lack good coordinating groups like acetamides or enol esters. However, they still have the potential to coordinate through the $\mathrm{P}(\mathrm{O})(\mathrm{OR})_{2}$ function and is an interesting class of substrates for metal-catalyzed hydrogenation. 1-Aryl-ethenylphosphonates have been used as substrates for asymmetric hydrogenation using rutheniumdiphosphine catalysts. ${ }^{170}$ For rhodium just one example of ee's above $90 \%$ has been reported using a BoPhoz type ligand. ${ }^{171}$ With N,P-ligated Ircatalysts, 94, 92 and $93 \%$ ee for the phenyl- and two naphthyl-derivatives S226, S227 and S228 (Table 11, entries 1, 3 and 4) was obtained using $[\operatorname{lr}(\operatorname{cod})(\mathbf{5 a})]\left[\mathrm{BAr}_{\mathrm{F}}\right]\left(\right.$ PHOX-ligand 5a; Figure 3). ${ }^{172}$ Under similar conditions, the phenyl-substituted product from $\mathbf{S 2 2 6}$ could be obtained in $>99 \%$ ee using $[\operatorname{lr}(\operatorname{cod})(46)]\left[\mathrm{BAr}_{F}\right]$ (Figure 6). ${ }^{173}$ In addition to phosphonate esters, the corresponding diphenylphosphine oxides S229-S234 were evaluated in asymmetric hydrogenation reactions using $[\operatorname{lr}(\operatorname{cod})(46)]\left[B A r_{F}\right]$. Aromatic (S229-S231) and aliphatic (S232-S234) 1,1-disubstituted diphenylvinylphosphine oxides could be reduced, often in $>99 \%$ ee, using this catalytic system (Table 11, entries $5-10$ ). ${ }^{173}$ Hence, it seems that replacement of the $\mathrm{P}(\mathrm{O})(\mathrm{OEt})_{2}$-group with the bulkier $\mathrm{P}(\mathrm{O}) \mathrm{Ph}_{2}$ is advantageous for the hydrogenation with chiral mimics of Crabtree's catalyst. 
Table 11 Representative results from the asymmetric hydrogenation of 1 substituted ethenylphosphonates using $[\operatorname{Ir}(\operatorname{cod})(\mathrm{L})]\left[\mathrm{BAr}_{\mathrm{F}}\right]$.

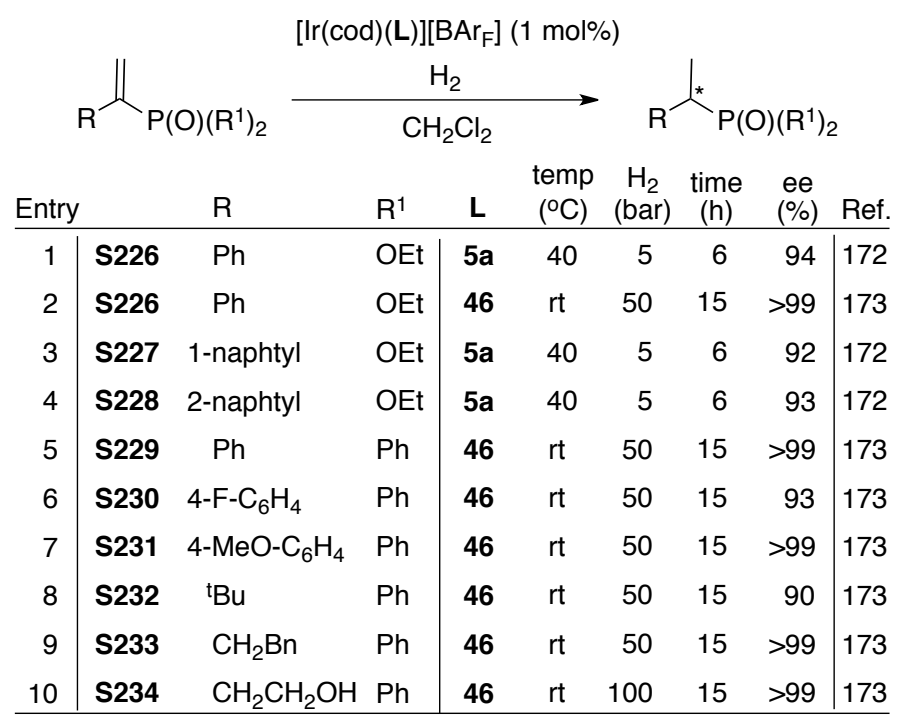

For the asymmetric hydrogenation of trisubstituted vinylphosphonates, a few catalytic systems utilizing rhodium-diphosphine and rhodiumphosphoramidite complexes have proved to be suitable. In 1999, $[\mathrm{Rh}(\operatorname{cod})(\mathrm{DIOP})]\left[\mathrm{BF}_{4}\right]$ was used to reduce $E-\beta$-methylphosphonato crotonate in $42 \%$ ee by stirring the reaction under an atmosphere of hydrogen for 78 hours without solvent. ${ }^{174}$ The investigators reasoned that the poor enantioselectivity was due to lack of good coordinating functional groups. However, an in-depth study of this reaction was not undertaken. In a study of several substituted (E)-carboxymethyl vinylphosphonates, a range of diphosphine ligands were tested together with $\left[\mathrm{Rh}(\operatorname{cod})_{2}\right]\left[\mathrm{BF}_{4}\right]$ in the asymmetric hydrogenation. ${ }^{175}$ Ligands from the Josiphos family were the most effective, reducing both alkyl and aryl substituted alkenes highly selectively. A high (5 mol\%) catalyst loading was needed to ensure full conversion of the alkenes in 24 hours. In another report, E-(2-aryl-1-propene)phosphonates were reduced in excellent enantioselectivity by a rhodium-phosphoramidite catalyst. $^{176}$ 
The $[\operatorname{Ir}(\operatorname{cod})(\mathrm{N}, \mathrm{P})]\left[\mathrm{BAr}_{\mathrm{F}}\right]$ catalytic system has also proved useful in this reaction; iridium complexes derived from ligand $\mathbf{4 6}$ (Figure 6), that reduced 1,1-disubstituted vinyl phosphonates, also gave high enantioselectivities in the reduction of two $(E)$-carboxyethyl vinylphosphonates S235 and S236 (Table 12, entries 1-2). ${ }^{173}$ Interestingly, the Z-isomer of the phenyl-substituted derivative (S237) was reduced faster than the $E$-isomer (S235), and in higher enantioselectivity but yielded the product with the same absolute configuration. This effect has sometimes been observed in the rhodiumcatalyzed asymmetric hydrogenation of functionalized vinylphosphonates, ${ }^{177}$ and can be attributed to substrate chelation. To our knowledge, this effect hasn't been observed previously in the Ir-catalyzed hydrogenation of alkenes. By contrast, in the hydrogenation of $\beta, \beta$-disubstituted- $\alpha, \beta$-unsaturated vinyl phosphonates with a rhodium-phosphoramidite catalyst, both the $E$ - and the $Z$-alkene gave excellent enantioselectivity, but the two isomers gave opposite enantiomers of the product. ${ }^{176}$ Together these results illustrate the intermediate nature of the weakly functionalized vinyl phosphonates and the fact that, in some cases chelation takes place while in other cases it does not.

The phosphite-oxazole ligand 44a (Figure 6) has also been used to obtain high enantioselectivity in the reduction of two trisubstituted vinylphosphonates with Z-configuration (Table 12, entries 4 and 5 ). ${ }^{92}$

Table 12 Asymmetric hydrogenation of some trisubstituted vinyl phosphonates.

\begin{tabular}{|c|c|c|c|c|c|c|c|c|c|}
\hline & . & $\stackrel{O}{P_{P}}-R^{3}$ & & $\operatorname{Ir}(\mathrm{cc}$ & L)] & & & $-R^{3}$ & \\
\hline & & & & $\begin{array}{r}\mathrm{H}_{2}(50 \\
\mathrm{rt}, \mathrm{C} \\
12\end{array}$ & $\begin{array}{l}100 \mathrm{~b} \\
{ }_{2} \mathrm{Cl}_{2} \\
24 \mathrm{~h}\end{array}$ & & & & \\
\hline Ent & & $Z / E$ & $\mathrm{R}^{1}$ & $\mathrm{R}^{2}$ & $\mathrm{R}^{3}$ & $\begin{array}{l}\text { Ir-cat. } \\
(\mathrm{mol} \%)\end{array}$ & L & $\begin{array}{c}\mathrm{ee} \\
(\%)\end{array}$ & Ref. \\
\hline 1 & S235 & $E$ & COOEt & $\mathrm{Ph}$ & OEt & 1 & 46 & 90 & 173 \\
\hline 2 & S236 & $E$ & COOEt & $\mathrm{Bn}$ & OEt & 1 & 46 & $>99$ & 173 \\
\hline 3 & S237 & $z$ & COOEt & $\mathrm{Ph}$ & OEt & 1 & 46 & $>99$ & 173 \\
\hline 4 & S238 & $Z$ & COOEt & $\mathrm{Ph}$ & $\mathrm{Ph}$ & 0.2 & $44 a$ & 92 & 92 \\
\hline 5 & S239 & $Z$ & $\mathrm{Me}$ & $\mathrm{Ph}$ & $\mathrm{Ph}$ & 0.2 & $44 a$ & 91 & 92 \\
\hline
\end{tabular}




\subsection{Boron}

Asymmetric hydrogenation of trisubstituted vinylboronates was first performed in 2004. ${ }^{178}$ In a screening using E-1,2-bis(Bpin)styrene S240 (Bpin = 4,4,5,5tetramethyl-1,3,2-dioxaborolane-2-yl) as substrate, rhodium was superior to iridium together with the P,P-ligands that were evaluated. Walphos type ligands were the most selective and the highest enantiomeric excess (93\%) was obtained when the reaction was performed in toluene using $2 \mathrm{~mol} \% \mathrm{Rh}$. Interestingly, a 2:1 ratio of ligand-to-metal gave the highest selectivity, while a 1:1 or lower, ligand-to-metal ratio gave reversed, and poor, enantioselectivity. 1,2-Bis(boronates) having aliphatic substituents could also be reduced in high enantioselectivity using a slightly modified ligand, but again, relatively high loadings of rhodium and the ligand were required.

Chiral mimics of Crabtree's catalyst have proven useful in this reaction and, in the first study, hydrogenation of E-1,2-bis(Bpin)styrenes was attempted using different ligands. ${ }^{65}$ When the reaction was performed under 1 bar of $\mathrm{H}_{2}$, using $0.5 \mathrm{~mol} \%[\operatorname{lr}(\operatorname{cod})(49 \mathrm{a})]\left[\mathrm{BAr}_{\mathrm{F}}\right]$ as pre-catalyst (49a; Figure 6), 1,2-di(Bpin)-1phenyl-ethane was obtained in $96 \%$ ee from S240 and the para-methoxy derivative in $88 \%$ ee from $\mathbf{S 2 4 2}$ (Table 13, entries 1 and 5). Using 17d (Figure 4) as the chiral ligand in the asymmetric hydrogenation of these alkenes gave close to racemic product mixtures and a higher hydrogen pressure resulted in significantly lower selectivity. ${ }^{65}$ For the $n$-butyl derivative (S243, entry 6 ), the highest enantioselectivity obtained was $48 \%$ when $[\operatorname{Ir}(\operatorname{cod})(18 \mathrm{~d})]\left[B A r_{F}\right]$ was used as pre-catalyst.

Recently, ligands 23b (Figure 4) and 32b (Figure 5), were applied in the iridium catalyzed asymmetric hydrogenation of 1,2-bis(boronates). While [Ir(cod)(23b)][BAr $r_{F}$ gave excellent results for two E-1,2-bis(Bpin)styrenes (Table 13, entries 2 and 4), ${ }^{7 b}[\operatorname{lr}(\operatorname{cod})(32 b)]\left[B r_{F}\right]$ could reduce the phenylderivative (S240, entry 3 ) as well as the bulky cyclohexyl (S245, entry 8$)$ and tert-butyl (S246, entry 9) derivatives highly selectively. ${ }^{179}$ The $n$-hexyl derivative $\mathbf{S} 244$ was reduced in $\mathbf{7 2} \%$ ee by this complex (entry 7 ). 
Table 13 Representative results from the asymmetric hydrogenation of vinyl1,2-bis(boronates) using complexes of the type $[\operatorname{lr}(\operatorname{cod})(\mathrm{N}, \mathrm{P})]\left[\mathrm{BAr}_{\mathrm{F}}\right]$.

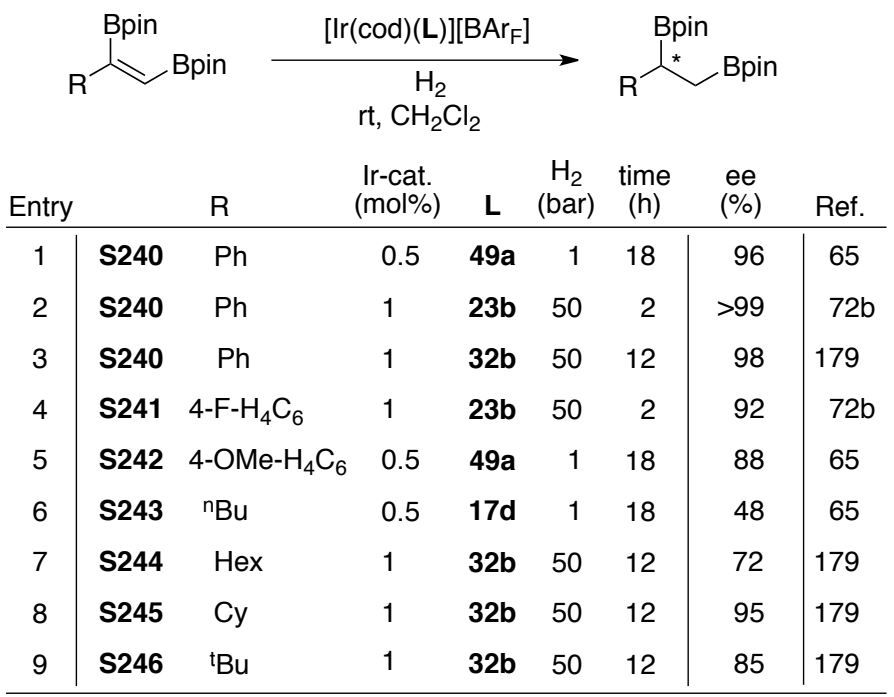


In addition to 1,2-bis(boronates), several trisubstituted alkenes containing only one boronic ester have been subjected to Ir-catalyzed asymmetric hydrogenation with good results. For instance, the sterically demanding cis-stilbene boronate $\mathbf{S 2 4 7}$ could be reduced using $0.5 \mathrm{~mol} \%$

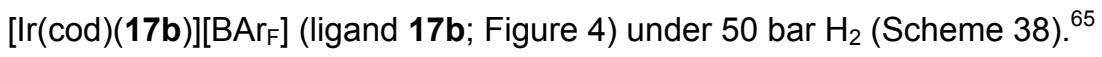

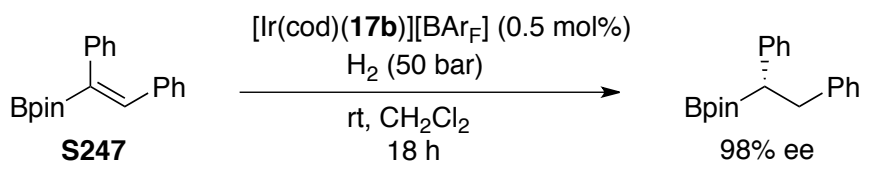

Scheme 38 Asymmetric reduction of $\mathbf{S 2 4 7}$ using $[\operatorname{Ir}(\operatorname{cod})(\mathbf{1 8 b})]\left[\mathrm{BAr}_{\mathrm{F}}\right]$.

Recently, a range of chiral boronic esters were prepared by asymmetric hydrogenation of trisubstituted vinyl boronates using the Ircomplex of ligand $\mathbf{3 2 b}$ (Figure 5), that was also used for bis(boronates). ${ }^{179}$ Under 50 bar $\mathrm{H}_{2}$ in $\mathrm{CH}_{2} \mathrm{Cl}_{2}$, alkenes with various aliphatic and aromatic groups (S248-S254) could be reduced in very high enantioselectivities (Scheme 39). In all cases the substituent on the prochiral carbon atom $\left(R^{1}\right)$ was a relatively bulky aliphatic group, indicating that this is a prerequisite for high enantiomeric excess.

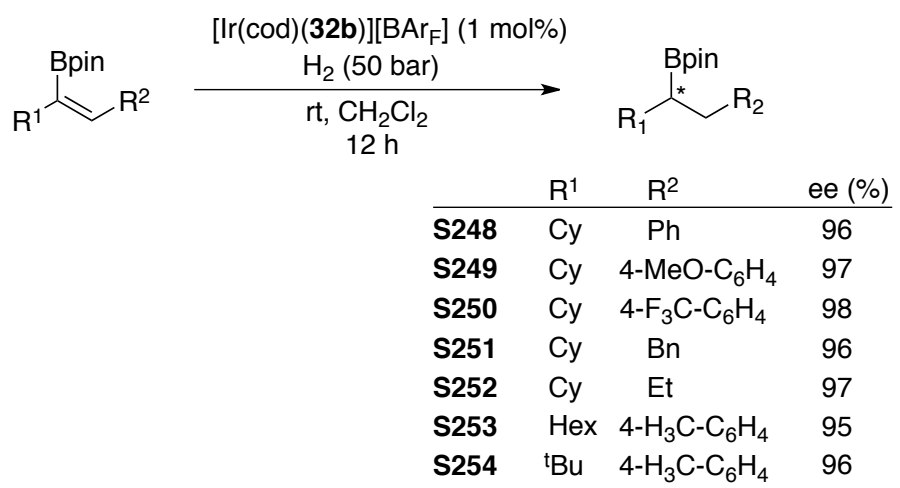

Scheme 39 Asymmetric hydrogenation of trisubstituted vinyl boronates using $[\operatorname{lr}(\operatorname{cod})(32 b)]\left[B A r_{F}\right]$.

1-Chloro-1-alkenyl boronates can also be reduced selectively using $\mathrm{N}, \mathrm{P}$-ligated Ir-complexes. ${ }^{180}[\operatorname{lr}(\operatorname{cod})(73)]\left[\mathrm{BAr}_{\mathrm{F}}\right]$ and $\mathrm{H}_{2}$ reduced several alkyl- 
(S255-S257) and aryl-substituted (S258-S260) derivatives with high enantioselectivity and without significant de-chlorination, although a high (4$14 \mathrm{~mol} \%$ ) catalyst loading was required (Scheme 40). Several P,P-ligated rhodium complexes, as well as one ruthenium complex, was also tested in this reaction. The ruthenium complex gave the dechlorination product almost exclusively, while the rhodium-catalysts were both slow and unselective compared to the chiral analogues of Crabtree's catalyst.

These results demonstrate the high catalytic activity and the uniquely high tolerance of chiral Crabtree mimics to functional groups, even directly on the double bond, in asymmetric hydrogenation.

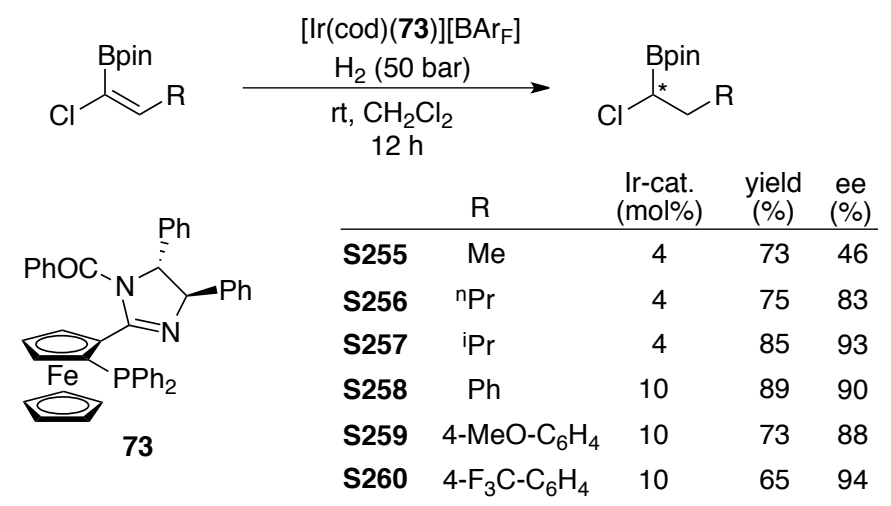

Scheme 40 Asymmetric hydrogenation of 1-chloro-1-alkenyl boronates.

The rhodium-Walphos system for the hydrogenation of 1,2bis(boronates) also proved useful for the reduction of 1,1-disubstituted vinyl boronates. Several 1-alkyl-1-(Bpin)-ethenes could be hydrogenated in high enantioselectivity but the reduction required high catalyst loadings and low reaction temperature. It was selective for long chain and cyclic aliphatics as well as for homoallylic ethers and esters. ${ }^{181}$ Prior to this work, hydrogenation of 1-phenylethenyl boronic esters was achieved using $3 \mathrm{~mol} \%$ $[\mathrm{Rh}(\mathrm{cod})(\mathrm{BINAP})]\left[\mathrm{BF}_{4}\right]$ as the catalyst precursor. ${ }^{182}$ The best selectivity $(80 \%$ ee) was obtained using simple 1,3,2,-dioxaborolane as the boronate function and stirring the reaction at $-20{ }^{\circ} \mathrm{C}$ for 7 days. With the pinacol ester as the boronate function and at room temperature, the reaction required only 24 hours to complete however the enantioselectivity was poor. 
Iridium catalysts have also proven very useful in the hydrogenation of this type of prochiral alkenes. The phenyl- and hexyl-substituted vinyl pinacolboronates S261 and S262 were hydrogenated using the iridium complex of ligand 17d (Figure 4) as catalyst. Good enantioselectivity was obtained for the phenyl derivative (Table 14, entry 1 ) but low selectivity was observed for the $n$-hexyl derivative (entry 3 ). ${ }^{65}$ As in the case of trisubstituted vinyl(bis)boronates, significantly lower catalyst loading was required when using chiral versions of Crabtree's catalyst as compared to the rhodium-P,Psystems.

Table 14 Asymmetric hydrogenation of 1,1-disubstituted vinyl boronates.

\begin{tabular}{|c|c|c|c|c|c|c|c|c|}
\hline & & {$[\operatorname{Ir}(\operatorname{cod})(\mathrm{L})$} & $\begin{array}{c}]\left[\mathrm{BAr}_{\mathrm{F}}\right] \\
\mathrm{H}_{2}\end{array}$ & $.5 \mathrm{~m}$ & & & & \\
\hline & Bpin & $\mathrm{R}$ & $\mathrm{CH}_{2} \mathrm{Cl}_{2}$ & & & Bpin' & $R$ & \\
\hline Entry & & $\mathrm{R}$ & $\mathbf{L}$ & $\begin{array}{r}\text { temp } \\
\left({ }^{\circ} \mathrm{C}\right)\end{array}$ & $\begin{array}{c}\mathrm{H}_{2} \\
\text { (bar) }\end{array}$ & $\begin{array}{l}\text { time } \\
\text { (h) }\end{array}$ & $\begin{array}{c}\text { ee } \\
(\%)\end{array}$ & Ref. \\
\hline 1 & S261 & $\mathrm{Ph}$ & $17 d$ & $\mathrm{rt}$ & 50 & 18 & 89 & 65 \\
\hline 2 & S261 & $\mathrm{Ph}$ & 74 & -20 & 2 & 4 & 4 & 179 \\
\hline 3 & S262 & nHex & $17 d$ & $\mathrm{rt}$ & 50 & 18 & 18 & 65 \\
\hline 4 & S262 & nHex & 74 & -20 & 2 & 4 & 96 & 179 \\
\hline 5 & S263 & Cy & 74 & -20 & 2 & 4 & 33 & 179 \\
\hline 6 & S264 & $\mathrm{CH}_{2} \mathrm{Bn}$ & 74 & -20 & 2 & 4 & 94 & 179 \\
\hline 7 & S265 & $\mathrm{Bn}$ & 74 & -20 & 2 & 4 & 94 & 179 \\
\hline 8 & S266 & $\mathrm{CH}_{2} \mathrm{OTBDMS}$ & 74 & -20 & 2 & 4 & 88 & 179 \\
\hline
\end{tabular}

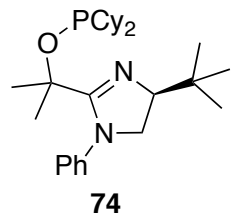

$[\operatorname{Ir}(\operatorname{cod})(74)]\left[B r_{F}\right]$ could be used as precatalyst to obtain excellent enantioselectivity in the asymmetric hydrogenation of several 1-substituted 1(Bpin)-ethenes after optimization of the catalytic system for the $n$-hexyl substituted alkene $\mathbf{S 2 6 2}$ (Table 14 , entries 4, 6, 7 and 8). ${ }^{179}$ At $-20{ }^{\circ} \mathrm{C}$ and under 2 bar of hydrogen, the reactions were complete after 4 hours using 0.5 
mol\% catalyst. Surprisingly, with $\mathrm{R}=\mathrm{Ph}$ (S261), an essentially racemic mixture of products was obtained. Also the cyclohexyl derivative S263 (entry 5) gave low enantioselectivity, indicating that this catalytic system is most efficient for alkenes in which the substituents are linked by a $\mathrm{CH}_{2}$-function.

\subsection{Fluorine}

The enantioselective reduction of vinyl fluorides, another challenging alkene type, has been briefly evaluated. A few examples involving fluorinated olefins carrying coordinating functional groups exist. Both the $E$ - and Z-isomer of the $\alpha, \beta$-unsaturated carboxylic acid S267 where $\mathrm{R}={ }^{\mathrm{n}} \mathrm{Pr}$ could be reduced in 88$90 \%$ ee by Ru-BINAP. ${ }^{183}$ The reaction proceeded smoothly at $50{ }^{\circ} \mathrm{C}$ in methanol, $p\left(\mathrm{H}_{2}\right)=5-50$ bar, for these two substrates but the scope of the reaction was not extended. For the Z-phenyl derivative enantioselectivity dropped significantly to $56 \%$.<smiles>[R]C=C(F)C(=O)O</smiles>

S267<smiles>OCC1=C(F)CN(Cc2ccccc2)CC1</smiles>

S268

Figure 18 Vinyl fluorides S267 and S268, carrying coordinating functional groups have been subjected to asymmetric hydrogenation using P,P-ligated ruthenium and rhodium complexes.

The tetrasubstituted vinyl fluoride $\mathbf{S 2 6 8}$, which is also an allylic alcohol, has been hydrogenated to its chiral product with cis-configuration in very high enantioselectivity. ${ }^{184}$ Several chiral diphosphine ligands were screened with the metal precursors $\left[\operatorname{Ir}(\mathrm{cod})_{2}\right]\left[\mathrm{BF}_{4}\right]$ and $\left[\mathrm{Rh}(\mathrm{nbd})_{2}\right]\left[\mathrm{BF}_{4}\right]$ in $\mathrm{CH}_{2} \mathrm{Cl}_{2}$ and $\mathrm{MeOH}$ but the major product was the defluorinated compound in most cases. An $\mathrm{N}, \mathrm{P}$-ligand (PHOX), was also tested as ligand to iridium in dichloromethane but here as well, defluorination was a problem. Some rhodium catalysts and a $P, P$-ligated ruthenium complex exhibited significantly less defluorination and were studied further. Optimization of the reaction conditions eventually yielded the product in $99 \%$ ee (with a lower percentage of defluorination) using a rhodium-Walphos system. ${ }^{184}$ 
Chiral mimics of Crabtree's catalyst have been used to prepare fluorine-bearing stereogenic centers by asymmetric hydrogenation of trisubstituted vinyl fluorides. ${ }^{64}$ While significant amounts of defluorinated products were obtained using phosphine-oxazole and phosphine-thiazole ligands (42 and 43, Figure 6), azaphosphine $\mathrm{P}$-donors $\left(\mathrm{N}-\mathrm{PAr}_{2}\right)$, in general, appeared to give less defluorination. Thus, a thiazole $\mathrm{N}$-donor ligand carrying an azadiarylphosphine, 46 (Figure 6), was prepared with the aim of obtaining low defluorination and high enantioselectivity. Indeed, when using $[\operatorname{lr}(\operatorname{cod})(46)]\left[B r_{F}\right]$ a low percentage of defluorination and excellent ee's for the two alkenes $\mathbf{S 2 6 9}$ and $\mathbf{S 2 7 1}$ were obtained (Table 15, entries 1a and 2a). ${ }^{64}$

In a subsequent study, imidazole-phosphine ligand 41a (Figure 6) was prepared as a more basic ligand than the corresponding oxazoles and thiazoles. ${ }^{87}$ Although there was a slight improvement in both selectivity and enantioselectivity, the effect was not very pronounced, suggesting that defluorination is affected by factors besides ligand acidity. [ $\operatorname{lr}(\operatorname{cod})(\mathbf{4 1 a})]\left[B \mathrm{Br}_{\mathrm{F}}\right]$ was tested in the asymmetric hydrogenation of a set of vinyl fluorides (S269S274) with varying results (Table 15). As expected, Z-alkenes (i.e. sterically trans alkenes) $\mathbf{S 2 6 9}$ and $\mathbf{S 2 7 1}$ were reduced faster and more selectively than the E-isomers $\mathbf{S 2 7 0}$ and $\mathbf{S 2 7 2}$. Less electron-poor alkenes $\mathbf{S 2 6 9 - S 2 7 2}(\mathrm{R}=$ $\mathrm{CH}_{2} \mathrm{OH}$ and $\mathrm{CH}_{2} \mathrm{OAc}$ ) were also reduced faster than the very electrondeficient $\alpha, \beta$-unsaturated esters $\mathbf{S 2 7 3}$ and $\mathbf{S 2 7 4} .^{87}$

Table 15 Asymmetric hydrogenation of trisubstituted vinyl fluorides. 


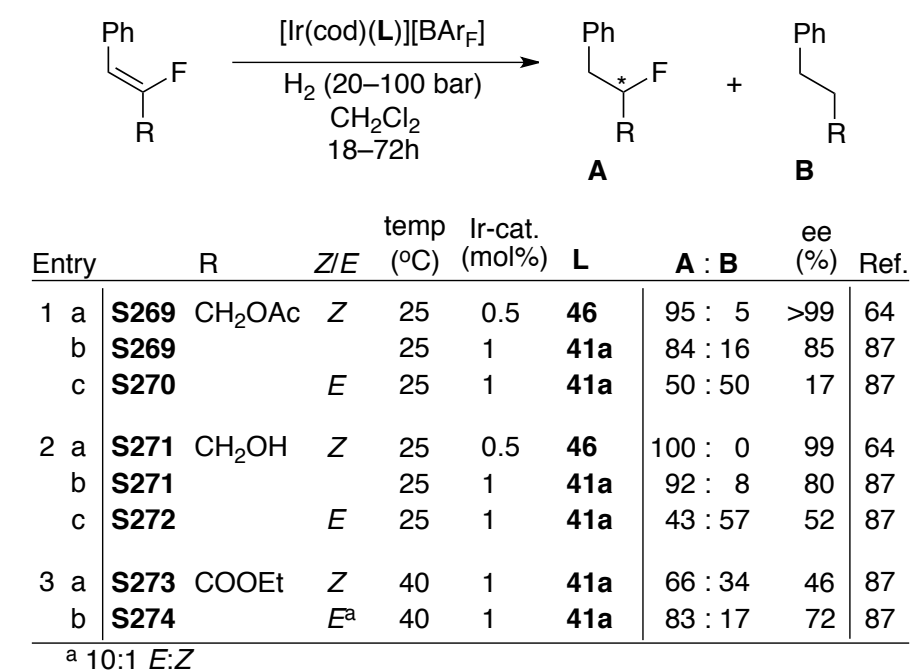

In addition to trisubstituted alkenes, a few tetrasubstituted vinyl fluorides could also be reduced using chiral mimics of Crabtree's catalyst. This is surprising, given that electron-poor alkenes are usually reduced more slowly using these catalytic systems. Using the bicyclic $\mathrm{N}$-linked oxazoline ligand 17b (Figure 4), three tetrasubstituted alkenes \$275-S277 could be reduced in ee's between 57 and 90\% (Scheme 41).

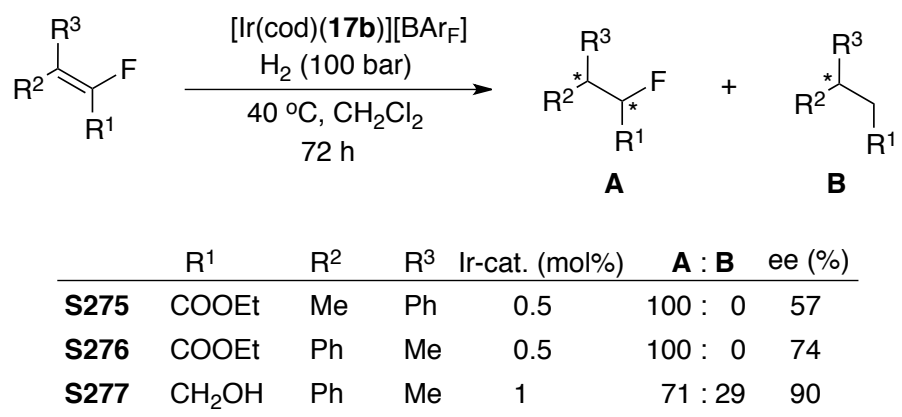

Scheme 41 Asymmetric hydrogenation of tetrasubstituted vinyl fluorides.

\subsection{Silicon}

The hydrogenation of vinyl silanes, another challenging alkene type, hasn't been the focus of extensive study even though organosilanes are important organic intermediates and a number of innovative new organosilicon drugs 
are in development. ${ }^{185}$ To the best of our knowledge there is only one example in which a Rh-catalyst was used in the diastereoisomeric hydrogenation of vinylsilanes that also contain a hydroxyl group. ${ }^{186}$

Chiral analogues of Crabtree's catalyst containing $\mathrm{N}$-phosphineoxazoline 17a (Figure 4) and phosphine-thiazoline 43a (Figure 6) hydrogenates (E)-trimethyl(2-phenylprop-1-en-1-yl)silane $\mathbf{S 2 7 8}$ in high enantioselectivities (96\% and $98 \%$ ee, respectively; Table 16, entries 1-2). ${ }^{63}$ The hydrogenation of substrates containing the TMS group directly attached to the prochiral carbon led, however, to low-to-moderate enantioselectivities (i.e. substrates S279-S281; Table 16, entries 5-8). The hydrogenation of alkylsubstituted substrate $\mathbf{S} 282$ also gave low enantioselectivity (Table 16, entry 9).

Recently, Ir-complexes with phosphite-containing ligands have proved to yield silicon-containing hydrogenation products effectively (ee's up to $98 \%$; Table 16, entries 3 and 4). ${ }^{72 b, 92}$ As previously mentioned the application of phosphite-containing ligands has also opened the possibility to hydrogenate terminal olefins containing a neighboring trimethylsilyl group (substrate S283; Table 16, entries 10-12). ${ }^{72 b, 73 b, 92}$ 
Table 16 Enantioselectivities achieved using chiral analogues of Crabtree's catalyst in the asymmetric hydrogenation of trimethylsilyl containing substrates S278-S283.

\begin{tabular}{|c|c|c|c|c|}
\hline Entry & Substrate & $\mathrm{L}$ & ee (\%) & Ref. \\
\hline 1 & & $17 a$ & 96 & 63 \\
\hline 2 & & $43 a$ & 98 & 63 \\
\hline 3 & & $23 a$ & 97 & $72 b$ \\
\hline 4 & & $45 a$ & 98 & 92 \\
\hline 5 & & $17 a$ & 26 & 63 \\
\hline 6 & & $43 a$ & 28 & 63 \\
\hline 7 & & $43 a$ & 58 & 63 \\
\hline 8 & & $43 a$ & 48 & 63 \\
\hline 9 & S282 & $43 a$ & 55 & 63 \\
\hline 10 & & $23 a$ & 96 & $72 \mathrm{~b}$ \\
\hline 11 & & $24 a$ & 96 & $73 b$ \\
\hline 12 & & $45 a$ & 93 & 92 \\
\hline
\end{tabular}

\section{Prediction of the Stereochemical Outcome}

While the number of available ligands for the $\left[\operatorname{Ir}(\operatorname{cod})\left(N, P^{*}\right)\right]\left[B A r_{F}\right]$ catalytic system has grown, most of the published ligands give high enantioselectivity only for a narrow type of alkene. ${ }^{2 c, 3 a}$ It appears as though the strict steric and geometric demands enforced by the ligands to obtain high enantioselectivity, also to a degree, prevent their generality. Thus, to reduce a specific alkene as part of a synthesis, one will likely have to screen a large array of different ligands to find the best one and, because of this, the incentive to provide easy, modular ligand syntheses is strong. 
The Andersson group has developed two series of ligands that perform well in the asymmetric hydrogenation of a large set of prochiral trisubstituted alkenes. ${ }^{3 c, d}$ The first is comprised of a variable ligand backbone that contains an oxazole, thiazole or imidazole $\mathrm{N}$-donor, and a phosphine or phosphinite $\mathrm{P}$ donor (Class 1, Figure 19, bottom). ${ }^{87,89-90}$ The second system, based on a 2aza-norbornane scaffold, consists of an oxazoline $\mathrm{N}$-donor and an azaphosphinite P-donor (Class 2, Figure 19, bottom). ${ }^{62 a, 65,129 a, 187}$ This system has been further modified to contain a thiazole $\mathrm{N}$-donor. ${ }^{95} \mathrm{~A}$ general structure of the successful N,P-ligands developed by several groups, with the individual elements highlighted, is shown in the upper part of Figure 19.

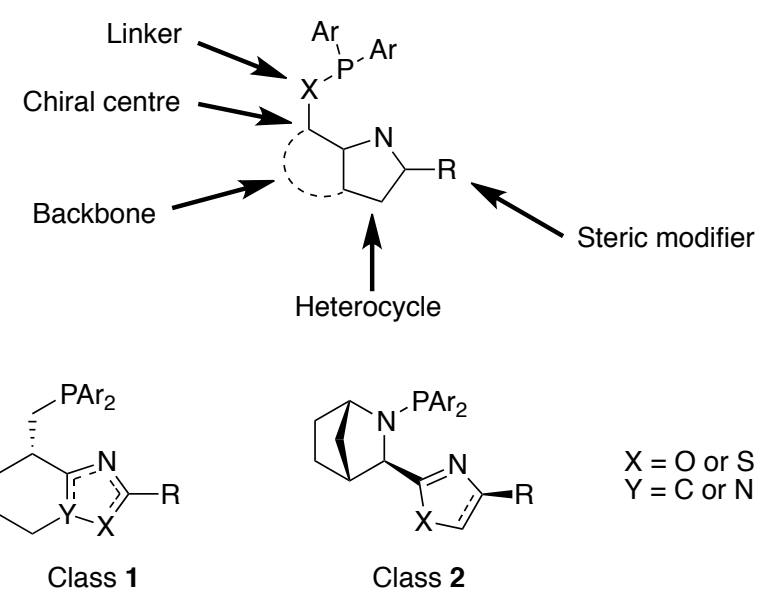

Figure 19 Top: General structure of many successful ligands for asymmetric hydrogenation, and Bottom: the two major ligand classes developed by Andersson and co-workers.

Computational $^{37,40}$ and to some extent also experimental ${ }^{31}$ studies strongly indicate that a complex iridium cation $\left[\operatorname{lr}(\mathrm{H})_{2} \mathrm{Z}\left(\mathrm{N}, \mathrm{P}^{*}\right)\right]^{+}$(Figure 20a, center; $\mathrm{N}, \mathrm{P}^{*}=$ chiral $\mathrm{N}, \mathrm{P}$-ligand, $\mathrm{Z}=$ solvent or $\mathrm{H}_{2}$ ) is formed upon activation of the $\left[\operatorname{lr}(\operatorname{cod})\left(N, P^{*}\right)\right]^{+}$precatalyst with hydrogen (see also section 1.4$)$. The primary steric environment experienced by the incoming alkene, which will coordinate trans to phosphorus, is derived from the group $\mathrm{R}$, which points out towards the alkene coordination site. Thus ligands from classes 1 and 2 produce differently shaped coordination pockets. This is illustrated in Figure 20a and 
emphasized in 20b, where the complex is viewed along the Ir-P bond i.e. as it would be presented to an approaching alkene. For Class 1 ligands, the phenyl group on the thiazole ring will point out of the page and down. For Class 2 on the other hand, the isopropyl group on the oxazoline moiety will point out of the page and up. The situation can be represented as in Figure 20c, with a simple quadrant model.

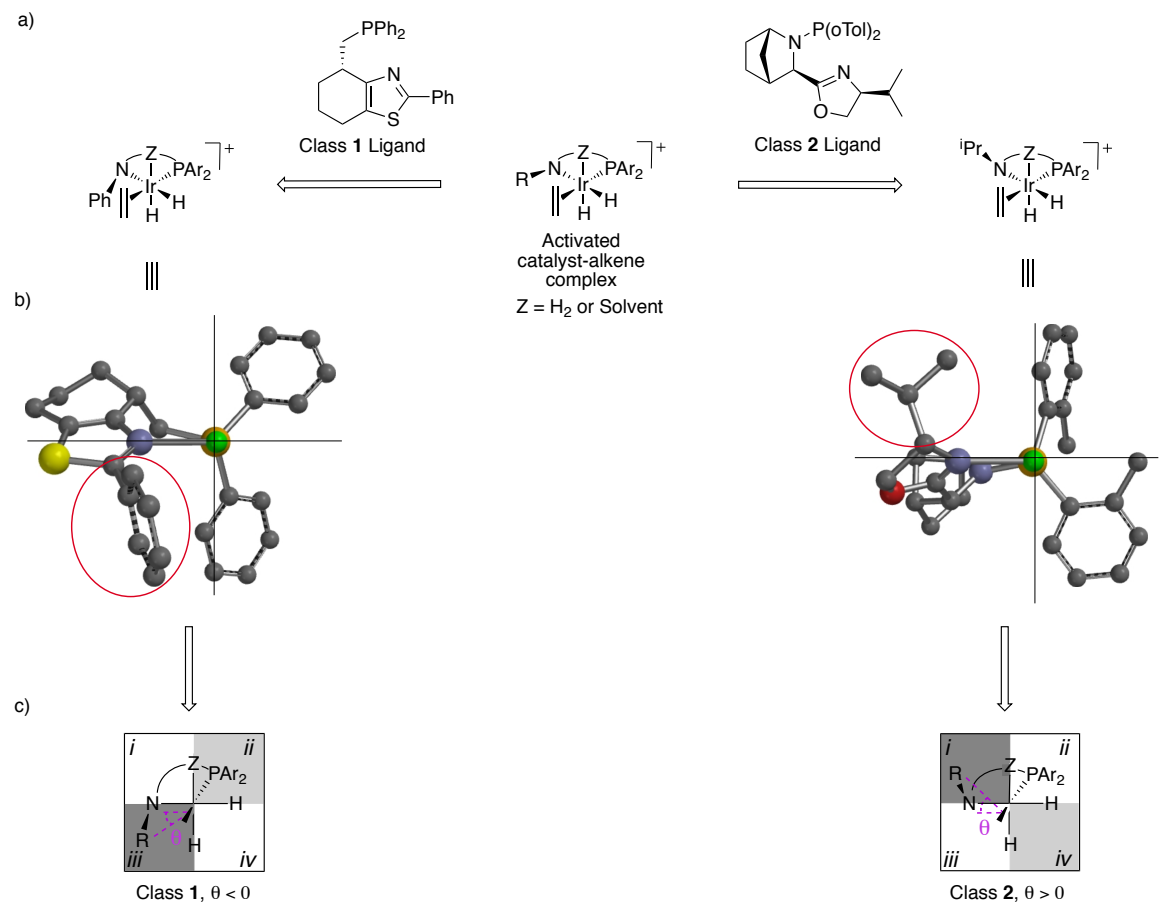

Figure 20 View of the steric environment experienced by an alkene approaching a $\left[\operatorname{lr}(\mathrm{H})_{2} \mathrm{Z}\left(\mathrm{N}, \mathrm{P}^{*}\right)\right]^{+}$complex. $\mathrm{Z}=$ Solvent or $\mathrm{H}_{2}$.

In Figure 20c, the situation is again viewed from the perspective of the incoming alkene. The dark-gray quadrants (iii for Class 1 and $i$ for Class 2) represent areas that are occupied by the $\mathrm{R}$ groups and the light-gray areas (ii for Class 1 and iv for Class 2) are somewhat encumbered by one of the aryl groups on the phosphorus. The other quadrants do not have any significant parts of the ligand pointing towards the incoming alkene and are thus considered to be open, relative to the other quadrants.

For any N,P-ligated complex of this kind, the position of the steric bulk can be determined by measuring the angle $(\theta)$ between the $N-I r-P$ plane and the 
center of the R-group, as shown in Figure 20c. ${ }^{41}$ The angle is negative for ligands in Class 1 and positive for those in Class 2, indicating that the quadrant accommodating the $\mathrm{R}$ group will be in the lower and upper corner respectively, for catalysts bearing these ligands. The quadrant system can be used to predict the absolute configuration of the products obtained in the asymmetric hydrogenation of trisubstituted alkenes by chiral N,P-ligated iridium catalysts. Since a trisubstituted alkene only has one hydrogen substituent, it will be oriented towards the most crowded quadrant of the chiral pocket in order to minimize steric interactions. This determines which face of the olefin coordinates to Ir and, as the $\mathrm{H}$ atoms are added to the coordinated face, catalysts bearing Class 1 and Class 2 ligands give products of opposite absolute configuration upon alkene reduction.

This selectivity model has proven to correctly determine the absolute configuration for a wide range of substrates, including non-functionalized triand disubstituted alkenes, $\alpha, \beta$-unsaturated esters and various cyclic alkenes. Figure 21 depicts the stereochemical outcome of the hydrogenations of a) cyclic alkenes $(X=N T$ s or $O, R=$ aryl or alkyl) and $b) \beta, \beta$-disubstituted $\alpha, \beta$ unsaturated esters and acids $\left(R=\right.$ aryl or alkyl, $R^{\prime}=H$ or alkyl). Isomeric cyclic 2,3-alkenes and 3,4-alkenes are reduced to alkanes of opposite absolute configuration because they coordinate on opposite olefin faces (Figure 21a). ${ }^{91,153}$ Similarly, $E$ and $Z$ isomeric pairs of $\beta, \beta$-disubstituted unsaturated esters or acids are hydrogenated to products of opposite absolute configuration (Figure 21b). ${ }^{150}$ 
a)
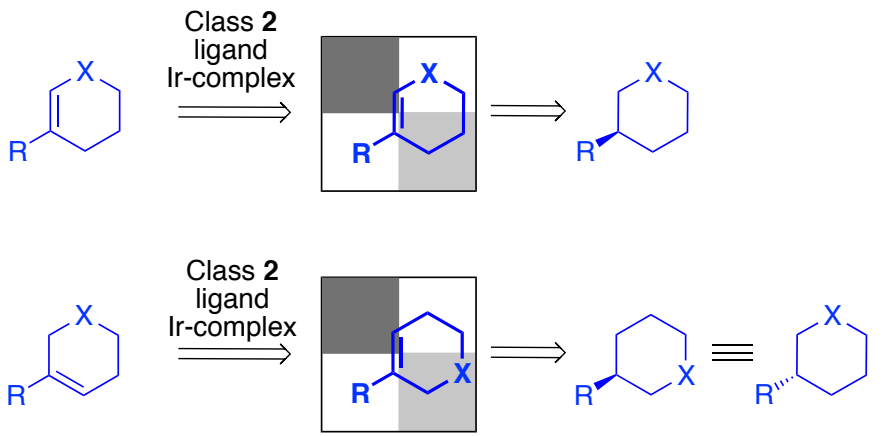

b)

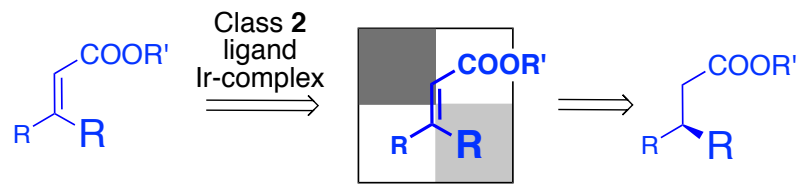

Figure 21 Prediction of the absolute configuration of the product alkanes from hydrogenation of isomeric alkenes using the quadrant-based selectivity model.

Interestingly, although the stereochemical outcome in the hydrogenation of $\beta, \beta$-disubstituted unsaturated esters can be predicted in this fashion, reductions of $\alpha, \beta$-disubstituted unsaturated esters gives products of the opposite absolute configuration to what is suggested by the model. ${ }^{150} \mathrm{~A}$ possible explanation for the failure of the model in this instance can be found in the strong polarization of the double bond in this type of substrates. The transfer of an iridium-bound hydride to a coordinated alkene is accompanied by a tilting of the alkene toward the $\mathrm{Ir}-\mathrm{H}$ bond. This is feasible for $\beta, \beta-$ disubstituted unsaturated esters, as depicted in Figure $22 \mathrm{a}$, because the same configuration that allows a hydride to be transferred to the olefin terminus bearing the partial positive charge is the one that tilts the olefin away from the bulk of the ligand $\mathrm{R}$ group. Conversly, inserting a $\alpha, \beta$-disubstituted 
unsaturated ester into the quadrant model results in the situation shown in Figure 22b; here, addition to the $\beta-C$ is hampered by steric interactions caused by the olefin tilting toward the ligand bulk whereas addition to the $\alpha-C$ is electronically disfavoured. Since the quadrant model relies on steric effects, the failure of the model for $\alpha, \beta$-disubstituted substrates indicates that electronic factors dominate.

a)

$\beta, \beta$-disubstituted
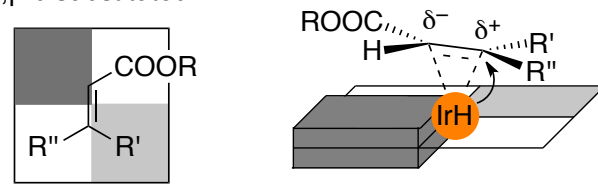

Sterically

and electronically

favoured

b)
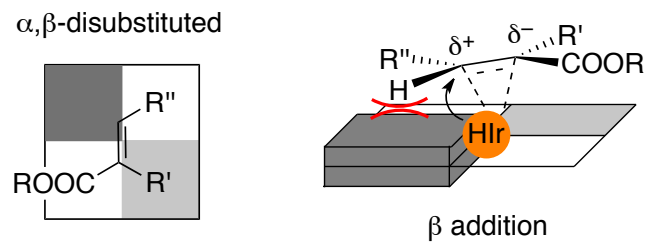

Sterically

disfavoured

Electronically

favoured

$\beta$ addition

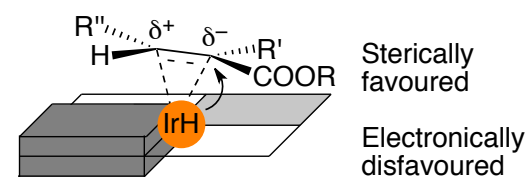

$\alpha$ addition

Figure 22 a) Hydride transfer to $\beta, \beta$-disubstituted $\alpha, \beta$-unsaturated esters is both sterically and electronically favoured. b) Hydride transfer to $\alpha, \beta$ disubstituted $\alpha, \beta$-unsaturated esters is either sterically or electronically disfavoured.

The angle $\theta$ can also be used to correctly predict the stereochemical outcome of alkene hydrogenation by many other chiral analogues of Crabtree's catalyst. ${ }^{41}$ For instance, an Ir center bearing the ligand ent-9a ${ }^{53}$ (Figure 4 ) has a calculated $\theta$ angle of $-34.2^{\circ}$, and thus hydrogenates $E-2-$ 
phenyl-2-butene to (S)-2-phenylbutane as the major product (96\% ee); whereas it reduces Z-2-phenyl-2-butene mainly to $(R)$-2-phenylbutane $(87 \%$ ee). Correspondingly, when an iridium catalyst bearing the PHOX ligand $\mathbf{5 a}^{69,188}$ (Figure 3, $\mathrm{R}^{1}=0-\mathrm{Tol}$ and $\mathrm{R}^{2}={ }^{\mathrm{t}} \mathrm{Bu}$ ) for which $\theta$ was calculated to be $+31.5^{\circ}$, is used, the product composition is inverted, with $E$-2-phenyl-2-butene producing mainly the $(R)$ product $(81 \%$ ee) and the $Z$ alkene giving mainly the $(S)$ product $(63 \%$ ee). The calculated $\theta$-angle, together with the quadrant model, can thus serve as a tool to readily predict the stereochemical outcome of hydrogenation reactions (Figure 23).

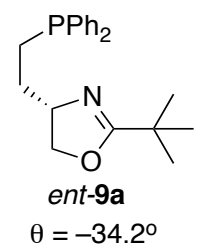<smiles>C/C=C(\C)c1ccccc1</smiles><smiles>C/C=C(/C)c1ccccc1</smiles>
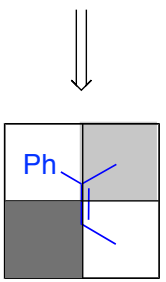<smiles>C=CC=C</smiles><smiles>CC[C@H](C)c1ccccc1</smiles>

(S)<smiles>C=C</smiles>
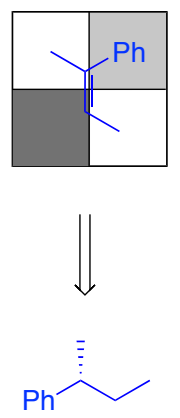

(R)<smiles>CC(C)(C)[C@@H]1COC(c2ccccc2P=O)=N1</smiles>

5 a

$\theta=31.5^{\circ}$<smiles>C/C=C(/C)c1ccccc1</smiles>

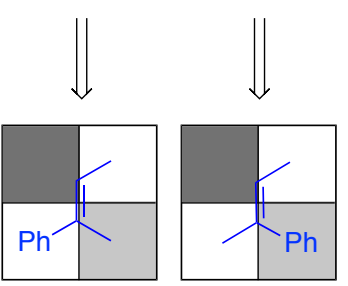

$\Downarrow$

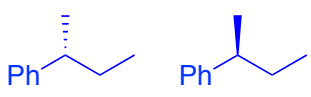

(R)

(S)

Figure 23 The angle $\theta$ (See Figure 20) correctly predicts the absolute configuration of the products of olefin hydrogenation by a wide range of N,Pligated iridium complexes. 


\section{Conclusion and Perspective}

Both the array of viable ligands for, and the substrate scope of, Ir-catalyzed asymmetric hydrogenation has expanded continuously over the past ten years. N,P-ligated iridium complexes are now not only the state-of-the-art method for the enantioselective reduction of tri-, tetra-, and 1,1-disubstituted non-functionalized alkenes, but also for several other substrates such as allylic alcohols, $\alpha, \beta$-unsaturated esters and carboxylic acids, vinyl boronates and vinyl phosphonates. Ir-catalyzed asymmetric hydrogenation have shown great potential in the alkene classes of vinyl fluorides, enol ethers and enamines however effective and general reduction methods are still lacking.

The use of Ir-catalyzed asymmetric hydrogenation in total synthesis and in industry is still limited by the fact that very few, if any, easily prepared ligands have proven effective for a wide range of alkene substrates. As the enantioselectivity obtained using a particular ligand is often strongly substratedependent, ligand development should continue to move towards modular ligands prepared by simple and inexpensive, yet flexible, synthetic routes. Furthermore, although low ( $<0.5 \mathrm{~mol} \%)$ catalyst loadings are frequently used for non-functionalized substrates, increased substrate functionalization typically lowers the turnover frequency (and thus, in practice, the catalyst loading) of Crabtree-type catalysts. Thus, effective methods for catalyst immobilization and/or re-use are highly desirable.

Although both supercritical $\mathrm{CO}_{2}$ and propylene carbonate have proven to be useful solvents for Ir-catalyzed asymmetric hydrogenation, no solvent system has yet produced reduction results to rival those obtained in the environmentally unfriendly dichloromethane.

Finally, although a considerable degree of knowledge about the reaction mechanism has been acquired, primarily through quantum chemical calculations, experimental data is still limited.

\section{Acknowledgment}

We are grateful to Dr. Thishana Singh and Dr. Tamara L Church for useful discussions. Energimyndigheten (The Swedish Energy Agency), Nordic Energy Research (N-INNER II), The Swedish Research Council (VR), The 
Knut and Alice Wallenberg Foundation and VR/SIDA supported this work. We would also like to thank the Spanish Government for providing grant CTQ201015835, the Catalan Government for grant 2009SGR116, and the ICREA Foundation for providing $\mathrm{M}$. Diéguez and $\mathrm{O}$. Pàmies with financial support through the ICREA Academia awards. 


\section{References}

(1) (a) Genêt, J.-P. In Modern reduction methods; Andersson, P. G., Munslow, I. J., Eds.; Wiley-VCH: Weinheim, 2008 (b) Chi, Y.; Tang, W.; Zhang, X. In Modern rhodium-catalyzed organic reactions; Evans, $\mathrm{P}$. A., Ed.; Wiley-VCH: Weinheim, 2005 (c) Kitamura, M.; Noyori, R. In Ruthenium in Organic Synthesis; Murahashi, S.-I., Ed.; Wiley-VCH: Weinheim, 2004.

(2) (a) Woodmansee, D. H.; Pfaltz, A. Chem. Commun. 2011, 47, 7912 (b) Pàmies, O.; Andersson, P. G.; Diéguez, M. Chem. Eur. J. 2010, 16, 14232 (c) Diesen, J. S.; Andersson, P. G. In Modern reduction methods; Andersson, P. G., Munslow, I. J., Eds.; Wiley-VCH: Weinheim, 2008 (d) Roseblade, S. J.; Pfaltz, A. Acc. Chem. Res. 2007, 40, 1402 (e) Cui, X.; Burgess, K. Chem. Rev. 2005, 105, 3272.

(3) (a) Woodmansee, D.; Pfaltz, A. In Iridium Catalysis; Andersson, P. G., Ed.; Springer: Berlin, 2011; Vol. 34 (b) Ager, D. In Science of Synthesis, Stereoselective Synthesis; de Vries, J. G., Molander, G. A., Evans, P. A., Eds.; Georg Thieme Verlag: Stuttgart, 2011; Vol. 1 (c) Church, T. L.; Andersson, P. G. Coord. Chem. Rev. 2008, 252, 513 (d) Källström, K.; Munslow, I.; Andersson, P. G. Chem. Eur. J. 2006, 12, 3194

(4) (a) Wang, D.-S.; Chen, Q.-A.; Lu, S.-M.; Zhou, Y.-G. Chem. Rev. 2011, 112, 2557 (b) Zhou, Y.-G. Acc. Chem. Res. 2007, 40, 1357 (c) Kuwano, R. Heterocycles 2008, 76, 909 (d) Glorius, F. Org. Biomol. Chem. 2005, 3, 4171.

(5) Dang, T. P.; Kagan, H. B. J. Chem. Soc. D 1971, 481.

(6) Knowles, W. S.; Sabacky, M. J.; Vineyard, B. D.; Weinkauff, D. J. J. Am. Chem. Soc. 1975, 97, 2567.

(7) Vineyard, B. D.; Knowles, W. S.; Sabacky, M. J.; Bachman, G. L.; Weinkauff, D. J. J. Am. Chem. Soc. 1977, 99, 5946.

(8) Knowles, W. S. J. Chem. Educ. 1986, 63, 222.

(9) Takaya, H.; Ohta, T.; Sayo, N.; Kumobayashi, H.; Akutagawa, S.; Inoue, S.; Kasahara, I.; Noyori, R. J. Am. Chem. Soc. 1987, 109, 1596. 
(10) Miyashita, A.; Yasuda, A.; Takaya, H.; Toriumi, K.; Ito, T.; Souchi, T.; Noyori, R. J. Am. Chem. Soc. 1980, 102, 7932.

(11) Ohta, T.; Takaya, H.; Kitamura, M.; Nagai, K.; Noyori, R. J. Org. Chem. 1987, 52, 3174.

(12) Burk, M. J.; Feaster, J. E.; Harlow, R. L. Organometallics 1990, 9 , 2653.

(13) Burk, M. J. J. Am. Chem. Soc. 1991, 113, 8518.

(14) Burk, M. J.; Stammers, T. A.; Straub, J. A. Org. Lett. 1999, 1, 387.

(15) Zhu, G.; Chen, Z.; Zhang, X. J. Org. Chem. 1999, 64, 6907.

(16) (a) Kitamura, M.; Tsukamoto, M.; Bessho, Y.; Yoshimura, M.; Kobs, U.; Widhalm, M.; Noyori, R. J. Am. Chem. Soc. 2002, 124, 6649 (b) Halpern, J. Science 1982, 217, 401 (c) Brown, J. M. Chem. Soc. Rev. 1993, 22, 25.

(17) (a) Ohta, T.; Ikegami, H.; Miyake, T.; Takaya, H. J. Organomet. Chem. 1995, 502, 169 (b) Inagaki, K.; Ohta, T.; Nozaki, K.; Takaya, H. J. Organomet. Chem. 1997, 531, 159 (c) Forman, G. S.; Ohkuma, T.; Hems, W. P.; Noyori, R. Tetrahedron Lett. 2000, 41, 9471.

(18) (a) Osborn, J. A.; Schrock, R. R. J. Am. Chem. Soc. 1971, 93, 3089 (b) Schrock, R. R.; Osborn, J. A. J. Am. Chem. Soc. 1976, 98, 2134.

(19) Shapley, J. R.; Schrock, R. R.; Osborn, J. A. J. Am. Chem. Soc. 1969, 91, 2816.

(20) (a) Crabtree, R. H.; Felkin, H.; Morris, G. E. J. Organomet. Chem. 1977, 141, 205 (b) Crabtree, R. H.; Gautier, A.; Giordano, G.; Khan, T. J. Organomet. Chem. 1977, 141, 113.

(21) Crabtree, R. H.; Felkin, H.; Fillebeen-Khan, T.; Morris, G. E. J. Organomet. Chem. 1979, 168, 183.

(22) (a) Meakin, P.; Jesson, J. P.; Tolman, C. A. J. Am. Chem. Soc. 1972, 94, 3240 (b) Crabtree, R. H.; Demou, P. C.; Eden, D.; Mihelcic, J. M.; Parnell, C. A.; Quirk, J. M.; Morris, G. E. J. Am. Chem. Soc. 1982, 104, 6994 (c) Halpern, J.; Okamoto, T.; Zakhariev, A. J. Mol. Catal. 1977, 2 , 65.

(23) (a) Chodosh, D. F.; Crabtree, R. H.; Felkin, H.; Morris, G. E. J. Organomet. Chem. 1978, 161, C67 (b) Smidt, S. P.; Pfaltz, A.; 
Martínez-Viviente, E.; Pregosin, P. S.; Albinati, A. Organometallics 2003, 22, 1000.

(24) Helmchen, G.; Pfaltz, A. Acc. Chem. Res. 2000, 33, 336.

(25) Schnider, P.; Koch, G.; Prétôt, R.; Wang, G.; Bohnen, F. M.; Krüger, C.; Pfaltz, A. Chem. Eur. J. 1997, 3, 887.

(26) Lightfoot, A.; Schnider, P.; Pfaltz, A. Angew. Chem. Int. Ed. 1998, 37, 2897.

(27) Blackmond, D. G.; Lightfoot, A.; Pfaltz, A.; Rosner, T.; Schnider, P.; Zimmermann, N. Chirality 2000, 12, 442.

(28) Smidt, S. P.; Zimmermann, N.; Studer, M.; Pfaltz, A. Chem. Eur. J. 2004, 10, 4685.

(29) Nishida, H.; Takada, N.; Yoshimura, M.; Sonoda, T.; Kobayashi, H. Bull. Chem. Soc. Jpn. 1984, 57, 2600.

(30) Crabtree, R. Acc. Chem. Res. 1979, 12, 331.

(31) Mazet, C.; Smidt, S. P.; Meuwly, M.; Pfaltz, A. J. Am. Chem. Soc. 2004, 126, 14176.

(32) Gridnev, I. D.; Imamoto, T. Acc. Chem. Res. 2004, 37, 633.

(33) Dietiker, R.; Chen, P. Angew. Chem. Int. Ed. 2004, 43, 5513.

(34) Vazquez-Serrano, L. D.; Owens, B. T.; Buriak, J. M. Inorg. Chim. Acta 2006, 359, 2786.

(35) Vazquez-Serrano, L. D.; Owens, B. T.; Buriak, J. M. Chem. Commun. 2002, 2518.

(36) Roseblade, S. J.; Pfaltz, A. C. R. Chim. 2007, 10, 178.

(37) Brandt, P.; Hedberg, C.; Andersson, P. G. Chem. Eur. J. 2003, 9, 339.

(38) Sun, Y.; Landau, R. N.; Wang, J.; LeBlond, C.; Blackmond, D. G. J. Am. Chem. Soc. 1996, 118, 1348.

(39) Perry, M. C.; Cui, X.; Powell, M. T.; Hou, D.-R.; Reibenspies, J. H.; Burgess, K. J. Am. Chem. Soc. 2003, 125, 113.

(40) Fan, Y.; Cui, X.; Burgess, K.; Hall, M. B. J. Am. Chem. Soc. 2004, 126, 16688.

(41) Church, T. L.; Rasmussen, T.; Andersson, P. G. Organometallics 2010 , 29, 6769.

(42) Hopmann, K. H.; Bayer, A. Organometallics 2011, 30, 2483. 
(43) Pfaltz, A.; Blankenstein, J.; Hilgraf, R.; Hörmann, E.; Mclntyre, S.; Menges, F.; Schönleber, M.; Smidt, S. P.; Wüstenberg, B.; Zimmermann, N. Adv. Synth. Catal. 2003, 345, 33.

(44) Schrems, M. G.; Pfaltz, A. Chem. Commun. 2009, 6210.

(45) Bell, S.; Wüstenberg, B.; Kaiser, S.; Menges, F.; Netscher, T.; Pfaltz, A. Science 2006, 311, 642.

(46) (a) Rovner, E. S.; Wein, A. J. Eur. Urol. 2002, 41, 6 (b) Wefer, J.; Truss, M. C.; Jonas, U. World J. Urol. 2001, 19, 312 (c) Hills, C. J.; Winter, S. A.; Balfour, J. A. Drugs 1998, 55, 813 (d) McRae, A. L.; Brady, K. T. Expert Opin. Pharmacother. 2001, 2, 883.

(47) Broene, R. D.; Buchwald, S. L. J. Am. Chem. Soc. 1993, 115, 12569.

(48) (a) Noyori, R. Science 1990, 248, 1194 (b) Takaya, H.; Otha, T.; Noyori, R. In Catalytic Asymmetric Synthesis; Ojima, I., Ed.; VCH: New York, 1993 (c) Ojima, I.; Clos, N.; Bastos, C. Tetrahedron 1989, 45, 6901 (d) Tanaka, M.; Ogata, I. J. Chem. Soc. Chem. Commun. 1975, $735 a$.

(49) Wang, X.; Guram, A.; Caille, S.; Hu, J.; Preston, J. P.; Ronk, M.; Walker, S. Org. Lett. 2011, 13, 1881.

(50) Zimmerman, N. Dissertation 2001, University of Basel.

(51) Franzke, A.; Pfaltz, A. Chem. Eur. J. 2011, 17, 4131.

(52) Bernardinelli, G. H.; Kündig, E. P.; Meier, P.; Pfaltz, A.; Radkowski, K.; Zimmermann, N.; Neuburger-Zehnder, M. Helv. Chim. Acta 2001, 84, 3233.

(53) Hou, D.-R.; Reibenspies, J.; Colacot, T. J.; Burgess, K. Chem. Eur. J. 2001, 7, 5391.

(54) Liu, D.; Tang, W.; Zhang, X. Org. Lett. 2004, 6, 513.

(55) Cozzi, P. G.; Menges, F.; Kaiser, S. Synlett 2003, 833.

(56) Li, X.; Li, Q.; Wu, X.; Gao, Y.; Xu, D.; Kong, L. Tetrahedron: opotse 25/10/2013 05:56 Asymmetry 2007, 18, 629.

(57) Lu, W.-J.; Chen, Y.-W.; Hou, X.-L. Adv. Synth. Catal. 2010, 352, 103.

(58) Cozzi, Pier G.; Zimmermann, N.; Hilgraf, R.; Schaffner, S.; Pfaltz, A. Adv. Synth. Catal. 2001, 343, 450.

(59) Xu, G.; Gilbertson, S. R. Tetrahedron Lett. 2003, 44, 953. 
(60) (a) Trifonova, A.; Diesen, J. S.; Andersson, P. G. Chem. Eur. J. 2006, 12, 2318 (b) Chakka, S. K.; Peters, B. K.; Andersson, P. G.; Maguire, G. E. M.; Kruger, H. G.; Govender, T. Tetrahedron: Asymmetry 2010, 21, 2295.

(61) Tolstoy, P.; Engman, M.; Paptchikhine, A.; Bergquist, J.; Church, T. L.; Leung, A. W. M.; Andersson, P. G. J. Am. Chem. Soc. 2009, 131, 8855 .

(62) (a) Cheruku, P.; Diesen, J.; Andersson, P. G. J. Am. Chem. Soc. 2008, 130, 5595 (b) Cheruku, P.; Gohil, S.; Andersson, P. G. Org. Lett. 2007, 9, 1659.

(63) Källström, K.; Munslow, I. J.; Hedberg, C.; Andersson, P. G. Adv. Synth. Catal. 2006, 348, 2575.

(64) Engman, M.; Diesen, J. S.; Paptchikhine, A.; Andersson, P. G. J. Am. Chem. Soc. 2007, 129, 4536.

(65) Paptchikhine, A.; Cheruku, P.; Engman, M.; Andersson, P. G. Chem. Commun. 2009, 5996.

(66) (a) Blankenstein, J.; Pfaltz, A. Angew. Chem. Int. Ed. 2001, 40, 4445 (b) Menges, F.; Pfaltz, A. Adv. Synth. Catal. 2002, 344, 40.

(67) Mclntyre, S.; Hörmann, E.; Menges, F.; Smidt, S. P.; Pfaltz, A. Adv. Synth. Catal. 2005, 347, 282.

(68) (a) Bayardon, J.; Holz, J.; Schäffner, B.; Andrushko, V.; Verevkin, S.; Preetz, A.; Börner, A. Angew. Chem. Int. Ed. 2007, 46, 5971 (b) Verevkin, S. P.; Emel'yanenko, V. N.; Bayardon, J.; Schäffner, B.; Baumann, W.; Börner, A. Ind. Eng. Chem. Res. 2011, 51, 126.

(69) Smidt, S. P.; Menges, F.; Pfaltz, A. Org. Lett. 2004, 6, 2023.

(70) (a) Feringa, B. L. Acc. Chem. Res. 2000, 33, 346 (b) van Leeuwen, P. W. N. M.; Kamer, P. C. J.; Claver, C.; Pàmies, O.; Diéguez, M. Chem. Rev. 2010, 111, 2077 (c) Diéguez, M.; Pàmies, O. Acc. Chem. Res. 2009, 43, 312.

(71) (a) Hilgraf, R.; Pfaltz, A. Synlett 1999, 1814 (b) Hilgraf, R.; Pfaltz, A. Adv. Synth. Catal. 2005, 347, 61 (c) Schönleber, M.; Hilgraf, R.; Pfaltz, A. Adv. Synth. Catal. 2008, 350, 2033.

(72) (a) Diéguez, M.; Mazuela, J.; Pàmies, O.; Verendel, J. J.; Andersson, P. G. J. Am. Chem. Soc. 2008, 130, 7208 (b) Mazuela, J.; Norrby, P.- 
O.; Andersson, P. G.; Pàmies, O.; Diéguez, M. J. Am. Chem. Soc. 2011, 133, 13634.

(73) (a) Diéguez, M.; Mazuela, J.; Pàmies, O.; Verendel, J. J.; Andersson, P. G. Chem. Commun. 2008, 3888 (b) Mazuela, J.; Verendel, J. J.; Coll, M.; Schäffner, B.; Börner, A.; Andersson, P. G.; Pàmies, O.; Diéguez, M. J. Am. Chem. Soc. 2009, 131, 12344.

(74) Nanchen, S.; Pfaltz, A. Chem. Eur. J. 2006, 12, 4550.

(75) Bunlaksananusorn, T.; Polborn, K.; Knochel, P. Angew. Chem. Int. Ed. 2003, 42, 3941.

(76) Liu, Q.-B.; Zhou, Y.-G. Tetrahedron Lett. 2007, 48, 2101.

(77) Drury, W. J.; Zimmermann, N.; Keenan, M.; Hayashi, M.; Kaiser, S.; Goddard, R.; Pfaltz, A. Angew. Chem. Int. Ed. 2004, 43, 70.

| (78) Zalubovskis, R.; Hörmann, E.; Pfaltz, A.,; Moberg ${ }_{*} C_{\vee}$ ARKIVOC 2008, $14,58$.

(79) (a) Kaiser, S.; Smidt, S. P.; Pfaltz, A. Angew. Chem. Int. Ed. 2006, 45, 5194 (b) Woodmansee, D. H.; Muller, M.-A.; Neuburger, M.; Pfaltz, A.

Chem. Sci. 2010, 1, 72 (c) Wang, A.; Fraga, R. P. A.; Hörmann, E.; Deleted: , M

Pfaltz, A. Chem. Asian. J. 2011, 6, 599 (d) Liu, Q.-B.; Yu, C.-B.; Zhou, Y.-G. Tetrahedron Lett. 2006, 47, 4733.

(80) Netscher, T. CHIMIA 1996, 50, 563.

(81) Verendel, J. J.; Andersson, P. G. Dalton Trans. 2007, 5603.

(82) Meng, X.; Li, X.; Xu, D. Tetrahedron: Asymmetry 2009, 20, 1402.

(83) Chelucci, G.; Marchetti, M.; Malkov, A. V.; Friscourt, F.; Swarbrick, M. E.; Kočovský, P. Tetrahedron 2011, 67, 5421.

(84) Li, X.; Kong, L.; Gao, Y.; Wang, X. Tetrahedron Lett. 2007, 48, 3915.

(85) Han, Z.; Wang, Z.; Zhang, X.; Ding, K. Tetrahedron: Asymmetry 2010, 21, 1529.

(86) Menges, F.; Neuburger, M.; Pfaltz, A. Org. Lett. 2002, 4, 4713.

(87) Kaukoranta, P.; Engman, M.; Hedberg, C.; Bergquist, J.; Andersson, P. G. Adv. Synth. Catal. 2008, 350, 1168.

(88) Paptchikhine, A.; Itto, K.; Andersson, P. G. Chem. Commun. 2011, 47, 3989.

(89) Källström, K.; Hedberg, C.; Brandt, P.; Bayer, A.; Andersson, P. G. J. Am. Chem. Soc. 2004, 126, 14308. 
(90) Hedberg, C.; Källström, K.; Brandt, P.; Hansen, L. K.; Andersson, P. G. J. Am. Chem. Soc. 2006, 128, 2995.

(91) Verendel, J. J.; Zhou, T.; Li, J.-Q.; Paptchikhine, A.; Lebedev, O.; Andersson, P. G. J. Am. Chem. Soc. 2010, 132, 8880.

(92) Mazuela, J.; Paptchikhine, A.; Pàmies, O.; Andersson, P. G.; Diéguez, M. Chem. Eur. J. 2010, 16, 4567.

(93) Källström, K.; Andersson, P. G. Tetrahedron Lett. 2006, 47, 7477.

(94) Cheruku, P.; Paptchikhine, A.; Ali, M.; Neudörfl, J.-M.; Andersson, P. G. Org. Biomol. Chem. 2008, 6, 366.

(95) Li, J.-Q.; Paptchikhine, A.; Govender, T.; Andersson, P. G. Tetrahedron: Asymmetry 2010, 21, 1328.

(96) Ilaldinov, I.; Fatkulina, D.; Bucharov, S.; Jackstell, R.; Spannenberg, A.; Beller, M.; Kadyrov, R. Tetrahedron: Asymmetry 2011, 22, 1936.

(97) Schenkel, L. B.; Ellman, J. A. J. Org. Chem. 2004, 69, 1800.

(98) Metallinos, C.; Van Belle, L. J. Organomet. Chem. 2011, 696, 141.

(99) Gschwend, B.; Pugin, B.; Bertogg, A.; Pfaltz, A. Chem. Eur. J. 2009, 15, 12993.

(100) Nanchen, S.; Pfaltz, A. Helv. Chim. Acta 2006, 89, 1559.

(101) Passays, J.; Ayad, T.; Ratovelomanana-Vidal, V.; Gaumont, A.-C.; Jubault, P.; Leclerc, E. Tetrahedron: Asymmetry 2011, 22, 562.

(102) (a) Coll, M.; Pàmies, O.; Diéguez, M. Chem. Commun. 2011, 47, 9215 (b) Coll, M. Dissertation 2011, Universitat Rovira i Virgili (c) Coll, M.; Pàmies, O.; Diéguez, M. Adv. Synth. Catal. 2013, 355, 143.

(103) (a) Rageot, D.; Woodmansee, D. H.; Pugin, B.; Pfaltz, A. Angew. Chem. Int. Ed. 2011, 50, 9598 (b) Rageot, D.; Pfaltz, A. Helv. Chim. Acta 2012, 95, 2176.

(104) Conticello, V. P.; Brard, L.; Giardello, M. A.; Tsuji, Y.; Sabat, M.; Stern, C. L.; Marks, T. J. J. Am. Chem. Soc. 1992, 114, 2761.

(105) Giardello, M. A.; Conticello, V. P.; Brard, L.; Gagne, M. R.; Marks, T. J. J. Am. Chem. Soc. 1994, 116, 10241.

(106) (a) Cui, X.; Burgess, K. J. Am. Chem. Soc. 2003, 125, 14212 (b) Cui, X.; Ogle, J. W.; Burgess, K. Chem. Commun. 2005, 672.

(107) Verendel, J. J.; Andersson, P. G. Unpublished Work.

(108) Co, T. T.; Kim, T.-J. Chem. Commun. 2006, 3537. 
(109) Troutman, M. V.; Appella, D. H.; Buchwald, S. L. J. Am. Chem. Soc. 1999, 121, 4916.

(110) Schrems, M. G.; Neumann, E.; Pfaltz, A. Angew. Chem. Int. Ed. 2007, 46, 8274 .

(111) (a) Tang, W.; Zhang, X. Chem. Rev. 2003, 103, 3029 (b) Burk, M. J. Acc. Chem. Res. 2000, 33, 363.

(112) (a) Zupančič, B.; Mohar, B.; Stephan, M. Org. Lett. 2010, 12, 3022 (b) Zhang, X.; Huang, K.; Hou, G.; Cao, B.; Zhang, X. Angew. Chem. Int. Ed. 2010, 49, 6421 (c) Reetz, M. T.; Goossen, L. J.; Meiswinkel, A.; Paetzold, J.; Jensen, J. F. Org. Lett. 2003, 5, 3099 (d) Qiu, L.; Wu, J.; Chan, S.; Au-Yeung, T. T.-L.; Ji, J.-X.; Guo, R.; Pai, C.-C.; Zhou, Z.; Li, X.; Fan, Q.-H.; Chan, A. S. C. PNAS 2004, 101, 5815.

(113) Weise, C. F.; Pischl, M. C.; Pfaltz, A.; Schneider, C. J. Org. Chem. 2011, 77, 1477.

(114) Morris, B. D.; Smyth, R. R.; Foster, S. P.; Hoffmann, M. P.; Roelofs, W. L.; Franke, S.; Francke, W. J. Nat. Prod. 2004, 68, 26.

(115) Minnaard, A. J.; Feringa, B. L.; Lefort, L.; de Vries, J. G. Acc. Chem. Res. 2007, 40, 1267.

(116) (a) Jiang, X.-b.; van den Berg, M.; Minnaard, A. J.; Feringa, B. L.; de Vries, J. G. Tetrahedron: Asymmetry 2004, 15, 2223 (b) Enthaler, S.; Erre, G.; Junge, K.; Michalik, D.; Spannenberg, A.; Marras, F.; Gladiali, S.; Beller, M. Tetrahedron: Asymmetry 2007, 18, 1288.

(117) Hayashi, T.; Kanehira, K.; Kumada, M. Tetrahedron Lett. 1981, 22, 4417.

(118) Berens, U., EP1582527A1, 2005, CAN143:347296.

(119) (a) Willson, T. M.; Brown, P. J.; Sternbach, D. D.; Henke, B. R. J. Med. Chem. 2000, 43, 527 (b) Liu, K. G.; Smith, J. S.; Ayscue, A. H.; Henke, B. R.; Lambert, M. H.; Leesnitzer, L. M.; Plunket, K. D.; Willson, T. M.; Sternbach, D. D. Bioorg. Med. Chem. Lett. 2001, 11, 2385 (c) Henke, B. R. J. Med. Chem. 2004, 47, 4118 (d) Aubert, J.; Clary, L.; Mauvais, P.; Rivier, M.; Thoreau, E.; Boiteau, J.-G., WO2005108352A1, 2005, CAN143:477743 (e) Shrestha, S.; Bhattarai, B. R.; Cho, H.; Choi, J.-K.; Cho, H. Bioorg. Med. Chem. Lett. 2007, 17, 2728. 
(120) (a) Coppola, G. M.; Schuster, H. F. In a-Hydroxy Acids in Enantioselective Syntheses; Wiley-VCH Verlag $\mathrm{GmbH} \&$ Co. KGaA, 2003 (b) Blaser, H.-U.; Schmidt, E. In Asymmetric Catalysis on Industrial Scale; Wiley-VCH Verlag GmbH \& Co. KGaA, 2004.

(121) Hanessian, S. Total Synthesis of Natural Products: The Chiron Approach; Pergamon Press: New York, 1983.

(122) (a) Maligres, P. E.; Krska, S. W.; Humphrey, G. R. Org. Lett. 2004, 6, 3147 (b) Cheng, X.; Xie, J.-H.; Li, S.; Zhou, Q.-L. Adv. Synth. Catal. 2006, 348, 1271 (c) Houpis, I. N.; Patterson, L. E.; Alt, C. A.; Rizzo, J. R.; Zhang, T. Y.; Haurez, M. Org. Lett. 2005, 7, 1947 (d) Chen, W.; McCormack, P. J.; Mohammed, K.; Mbafor, W.; Roberts, S. M.; Whittall, J. Angew. Chem. Int. Ed. 2007, 46, 4141.

(123) Li, S.; Zhu, S.-F.; Xie, J.-H.; Song, S.; Zhang, C.-M.; Zhou, Q.-L. J. Am. Chem. Soc. 2010, 132, 1172.

(124) Ohta, T.; Miyake, T.; Seido, N.; Kumobayashi, H.; Takaya, H. J. Org. Chem. 1995, 60, 357.

(125) Zhu, Y.; Fan, Y.; Burgess, K. J. Am. Chem. Soc. 2010, 132, 6249.

(126) (a) Zhu, Y.; Burgess, K. Adv. Synth. Catal. 2008, 350, 979 (b) Zhu, Y.; Burgess, K. RSC Adv. 2012, 2, 4728.

(127) (a) Kuwano, R.; Okuda, S.; Ito, Y. J. Org. Chem. 1998, 63, 3499 (b) Tanaka, M.; Watanabe, Y.; Mitsudo, T: Yasunori, Y.; Takegami, Y. Chem. Lett. 1974, 3, 137.

(128) (a) Xie, J.-H.; Zhu, S.-F.; Zhou, Q.-L. Chem. Rev. 2010, 111, 1713 (b) Church, T. L.; Andersson, P. G. In Chiral amine synthesis: Methods, Developments and Applications; Nugent, T. C., Ed.; Wiley-VCH: Weinheim, 2010.

(129) (a) Cheruku, P.; Church, T. L.; Trifonova, A.; Wartmann, T.; Andersson, P. G. Tetrahedron Lett. 2008, 49, 7290 (b) Baeza, A.; Pfaltz, A. Chem. Eur. J. 2009, 15, 2266.

(130) (a) Leleti, R. R.; Hu, B.; Prashad, M.; Repič, O. Tetrahedron Lett. 2007, 48, 8505 (b) Reddy, L. R.; Hu, B.; Prashad, M.; Prasad, K. Angew. Chem. Int. Ed. 2009, 48, 172 (c) Bonrath, W.; Eckhardt, J.-F.; Eggersdorfer, M. L.; Hinze, R.; Hoelderich, W. F., WO2008098774A1, 2008, CAN149:290163. 
(131) Takaya, H.; Ohta, T.; Inoue, S.; Tokunaga, M.; Kitamura, M.; R., N. Org. Synth. Coll. Vol. 1998, 9, 169.

(132) Wang, A.; Wüstenberg, B.; Pfaltz, A. Angew. Chem. Int. Ed. 2008, 47, 2298.

(133) (a) Zhou, J.; Burgess, K. Angew. Chem. Int. Ed. 2007, 46, 1129 (b) Zhou, J.; Zhu, Y.; Burgess, K. Org. Lett. 2007, 9, 1391.

(134) Hoveyda, A. H.; Evans, D. A.; Fu, G. C. Chem. Rev. 1993, 93, 1307.

(135) Interestingly, switching from alcohol to ester also reverses the catalyst selectivity.

(136) Zhu, Y.; Burgess, K. Acc. Chem. Res. 2012, 45, 1623.

(137) Zhu, Y.; Khumsubdee, S.; Schaefer, A.; Burgess, K. J. Org. Chem. 2011, 76, 7449 .

(138) Zhu, Y.; Burgess, K. J. Am. Chem. Soc. 2008, 130, 8894.

(139) Zhu, Y.; Loudet, A.; Burgess, K. Org. Lett. 2010, 12, 4392.

(140) Zhao, J.; Burgess, K. J. Am. Chem. Soc. 2009, 131, 13236.

(141) Zhao, J.; Burgess, K. Org. Lett. 2009, 11, 2053.

(142) Brown, J. M. Angew. Chem. Int. Ed. Engl. 1987, 26, 190.

(143) (a) Pai, C.-C.; Lin, C.-W.; Lin, C.-C.; Chen, C.-C.; Chan, A. S. C.; Wong, W. T. J. Am. Chem. Soc. 2000, 122, 11513 (b) Scrivanti, A.; Bovo, S.; Ciappa, A.; Matteoli, U. Tetrahedron Lett. 2006, 47, 9261 (c) Uemura, T.; Zhang, X.; Matsumura, K.; Sayo, N.; Kumobayashi, H.; Ohta, T.; Nozaki, K.; Takaya, H. J. Org. Chem. 1996, 61, 5510 (d) Cheng, X.; Zhang, Q.; Xie, J.-H.; Wang, L.-X.; Zhou, Q.-L. Angew. Chem. Int. Ed. 2005, 44, 1118.

(144) (a) Brown, J. M.; Parker, D. J. Org. Chem. 1982, 47, 2722 (b) Hoen, R.; Boogers, J. A. F.; Bernsmann, H.; Minnaard, A. J.; Meetsma, A.; Tiemersma-Wegman, T. D.; de Vries, A. H. M.; de Vries, J. G.; Feringa, B. L. Angew. Chem. Int. Ed. 2005, 44, 4209.

(145) Li, S.; Zhu, S.-F.; Zhang, C.-M.; Song, S.; Zhou, Q.-L. J. Am. Chem. Soc. 2008, 130, 8584.

(146) Zhang, Y.; Han, Z.; Li, F.; Ding, K.; Zhang, A. Chem. Commun. 2010, 46, 156.

(147) Yang, S.; Zhu, S.-F.; Zhang, C.-M.; Song, S.; Yu, Y.-B.; Li, S.; Zhou, Q.-L. Tetrahedron 2012, 68, 5172. 
(148) Song, S.; Zhu, S.-F.; Yang, S.; Li, S.; Zhou, Q.-L. Angew. Chem. Int. Ed. 2012, 51, 2708.

(149) Zhu, S.-F.; Yu, Y.-B.; Li, S.; Wang, L.-X.; Zhou, Q.-L. Angew. Chem. Int. Ed. 2012, 51, 8872.

(150) Li, J.-Q.; Quan, X.; Andersson, P. G. Chem. Eur. J. 2012, 18, 10609.

(151) Newton, S.; Ley, S. V.; Arcé, E. C.; Grainger, D. M. Adv. Synth. Catal. 2012, 354, 1805.

(152) Tian, F.; Yao, D.; Liu, Y.; Xie, F.; Zhang, W. Adv. Synth. Catal. 2010, 352, 1841.

(153) Verendel, J. J.; Li, J.-Q.; Quan, X.; Peters, B.; Zhou, T.; Gautun, O. R.; Govender, T.; Andersson, P. G. Chem. Eur. J. 2012, 18, 6507.

(154) Lu, W.-J.; Hou, X.-L. Adv. Synth. Catal. 2009, 351, 1224.

(155) (a) Nahm, S.; Weinreb, S. M. Tetrahedron Lett. 1981, 22, 3815 (b) Shang, J.; Han, Z.; Li, Y.; Wang, Z.; Ding, K. Chem. Commun. 2012 , $48,5172$.

(156) (a) Ohkuma, T.; Ooka, H.; Ikariya, T.; Noyori, R. J. Am. Chem. Soc. 1995, 117, 10417 (b) Ohkuma, T.; Koizumi, M.; Doucet, H.; Pham, T.; Kozawa, M.; Murata, K.; Katayama, E.; Yokozawa, T.; Ikariya, T.; Noyori, R. J. Am. Chem. Soc. 1998, 120, 13529 (c) Burk, M. J.; Hems, W.; Herzberg, D.; Malan, C.; Zanotti-Gerosa, A. Org. Lett. 2000, 2, 4173.

(157) Mashima, K.; Akutagawa, T.; Zhang, X.; Takaya, H.; Taketomi, T.; Kumobayashi, H.; Akutagawa, S. J. Organomet. Chem. 1992, 428, 213.

(158) Fehr, M. J.; Consiglio, G.; Scalone, M.; Schmid, R. J. Org. Chem. 1999, 64, 5768.

(159) Ohshima, T.; Tadaoka, H.; Hori, K.; Sayo, N.; Mashima, K. Chem. Eur. J. 2008, 14, 2060.

(160) Tsuchiya, Y.; Hamashima, Y.; Sodeoka, M. Org. Lett. 2006, 8, 4851.

(161) (a) Martin, N. J. A.; List, B. J. Am. Chem. Soc. 2006, 128, 13368 (b) Tuttle, J. B.; Ouellet, S. G.; MacMillan, D. W. C. J. Am. Chem. Soc. 2006, 128, 12662.

(162) (a) Thorey, C.; Bouquillon, S.; Helimi, A.; Hénin, F.; Muzart, J. Eur. J. Org. Chem. 2002, 2002, 2151 (b) Fogassy, G.; Tungler, A.; Lévai, A.; 
Tóth, G. J. Mol. Catal. A: Chem. 2002, 179, 101 (c) McIntosh, A. I.; Watson, D. J.; Burton, J. W.; Lambert, R. M. J. Am. Chem. Soc. 2006, $128,7329$.

(163) Lu, S.-M.; Bolm, C. Chem. Eur. J. 2008, 14, 7513.

(164) Lu, S.-M.; Bolm, C. Angew. Chem. Int. Ed. 2008, 47, 8920.

(165) Lu, W.-J.; Chen, Y.-W.; Hou, X.-L. Angew. Chem. Int. Ed. 2008, 47, 10133.

(166) Maurer, F.; Huch, V.; Ullrich, A.; Kazmaier, U. J. Org. Chem. 2012, 77, 5139.

(167) Wang, X.; Han, Z.; Wang, Z.; Ding, K. Angew. Chem. Int. Ed. 2012, 51, 936.

(168) (a) Meindertsma, A. F.; Pollard, M. M.; Feringa, B. L.; de Vries, J. G.; Minnaard, A. J. Tetrahedron: Asymmetry 2007, 18, 2849 (b) Zhang, W.; Zhang, X. J. Org. Chem. 2006, 72, 1020.

(169) (a) Chávez, M. Á.; Vargas, S.; Suárez, A.; Álvarez, E.; Pizzano, A. Adv. Synth. Catal. 2011, 353, 2775 (b) Qiu, M.; Hu, X.-P.; Huang, J.-D.; Wang, D.-Y.; Deng, J.; Yu, S.-B.; Duan, Z.-C.; Zheng, Z. Adv. Synth. Catal. 2008, 350, 2683 (c) Gridnev, I. D.; Yasutake, M.; Imamoto, T.; Beletskaya, I. P. PNAS 2004, 101, 5385 (d) Wang, D.-Y.; Hu, X.-P.; Huang, J.-D.; Deng, J.; Yu, S.-B.; Duan, Z.-C.; Xu, X.-F.; Zheng, Z. Angew. Chem. Int. Ed. 2007, 46, 7810 (e) Rubio, M.; Vargas, S.; Suárez, A.; Álvarez, E.; Pizzano, A. Chem. Eur. J. 2007, 13, 1821 (f) Rubio, M.; Suarez, A.; Alvarez, E.; Pizzano, A. Chem. Commun. 2005, 628 (g) Grassert, I.; Schmidt, U.; Ziegler, S.; Fischer, C.; Oehme, G. Tetrahedron: Asymmetry 1998, 9, 4193.

(170) (a) Beghetto, V.; Matteoli, U.; Scrivanti, A. Chem. Commun. 2000, 155

(b) Henry, J. C.; Lavergne, D.; Ratovelomanana-Vidal, V.; Genêt, J. P.; Beletskaya, I. P.; Dolgina, T. M. Tetrahedron Lett. 1998, 39, 3473 (c) Goulioukina, N. S.; Dolgina, T. y. M.; Beletskaya, I. P.; Henry, J.-C.; Lavergne, D.; Ratovelomanana-Vidal, V.; Genêt, J.-P. Tetrahedron: Asymmetry 2001, 12, 319.

(171) Wang, D.-Y.; Hu, X.-P.; Deng, J.; Yu, S.-B.; Duan, Z.-C.; Zheng, Z. J. Org. Chem. 2009, 74, 4408. 
(172) Goulioukina, N. S.; Dolgina, T. y. M.; Bondarenko, G. N.; Beletskaya, I. P.; Ilyin, M. M.; Davankov, V. A.; Pfaltz, A. Tetrahedron: Asymmetry 2003, 14, 1397.

(173) Cheruku, P.; Paptchikhine, A.; Church, T. L.; Andersson, P. G. J. Am. Chem. Soc. 2009, 131, 8285.

(174) Kadyrov, R.; Selke, R.; Giernoth, R.; Bargon, J. Synthesis 1999, 1056.

(175) Huang, Y.; Berthiol, F.; Stegink, B.; Pollard, M. M.; Minnaard, A. J. Adv. Synth. Catal. 2009, 351, 1423.

(176) Duan, Z.-C.; Hu, X.-P.; Wang, D.-Y.; Huang, J.-D.; Yu, S.-B.; Deng, J.; Zheng, Z. Adv. Synth. Catal. 2008, 350, 1979.

(177) (a) Kadyrov, R.; Holz, J.; Schäffner, B.; Zayas, O.; Almena, J.; Börner, A. Tetrahedron: Asymmetry 2008, 19, 1189 (b) Doherty, S.; Knight, J. G.; Bell, A. L.; El-Menabawey, S.; Vogels, C. M.; Decken, A.; Westcott, S. A. Tetrahedron: Asymmetry 2009, 20, 1437.

(178) Morgan, J. B.; Morken, J. P. J. Am. Chem. Soc. 2004, 126, 15338.

(179) Ganić, A.; Pfaltz, A. Chem. Eur. J. 2012, 18, 6724.

(180) Gazić Smilović, I.; Casas-Arcé, E.; Roseblade, S. J.; Nettekoven, U.; Zanotti-Gerosa, A.; Kovačevič, M.; Časar, Z. Angew. Chem. Int. Ed. 2012, 51, 1014.

(181) Moran, W. J.; Morken, J. P. Org. Lett. 2006, 8, 2413.

(182) Ueda, M.; Saitoh, A.; Miyaura, N. J. Organomet. Chem. 2002, 642, 145.

(183) Saburi, M.; Shao, L.; Sakurai, T.; Uchida, Y. Tetrahedron Lett. 1992, 33, 7877.

(184) Krska, S. W.; Mitten, J. V.; Dormer, P. G.; Mowrey, D.; Machrouhi, F.; Sun, Y.; Nelson, T. D. Tetrahedron 2009, 65, 8987.

(185) (a) Fleming, I.; Barbero, A.; Walter, D. Chem. Rev. 1997, 97, 2063 (b) Jones, G. R.; Landais, Y. Tetrahedron 1996, 52, 7599 (c) Bains, W.; Tacke, R. Curr. Opin. Drug Discovery Dev. 2003, 6, 526.

(186) Lautens, M.; Zhang, C.; Crudden, C. M. Angew. Chem. Int. Ed. Engl. 1992, 31, 232.

(187) Trifonova, A.; Diesen, J. S.; Chapman, C. J.; Andersson, P. G. Org. Lett. 2004, 6, 3825.

(188) Smidt, S. P.; Menges, F.; Pfaltz, A. Org. Lett. 2004, 6, 3653. 
